\title{
Distributed leadership for professional learning: Effective leadership practices in early childhood education
}

By Rachel Denee

\author{
A thesis submitted to Victoria University of \\ Wellington in partial fulfilment of the requirements \\ for the degree of Masters of Education. \\ Victoria University of Wellington, 2017
}

\begin{abstract}
In Aotearoa New Zealand, leadership within the early childhood education (ECE) sector is both positionally assigned and a required practice of all teachers. Within this context, distributed leadership - where all team members have the opportunity to lead - is increasingly seen as an effective leadership model (Thornton, 2010). The purported benefits of distributed leadership have significant overlap with professional learning: increased engagement, deeper learning, context-specific learning and improved pedagogical practices among teachers (Poekert, 2012). This study considers the relationship between distributed leadership and professional learning in ECE settings, and seeks to discover practices of effective positional leaders in facilitating both. A nationwide survey was carried out in Aotearoa New Zealand to capture a picture of current perceptions of ECE teachers and positional leaders about professional learning communities and, in particular, distributed leadership for professional learning. Subsequently, the leadership practices for distributed leadership and professional learning in three previously-identified high quality ECE services were investigated through individual and group interviews. The analysis of literature, survey and interview findings from this study led to a framework of effective leadership practice, consisting of six elements: inquiry and articulation of thinking; teachers enacting leadership; collaboration and dialogue; mentoring and coaching; fostering relational trust; and, creating vision and designing supportive structures.
\end{abstract}




\section{Acknowledgements:}

I wish to acknowledge, first and foremost, the support of my husband Gregory Gilbert. I truly couldn't have done this without you. Also, my darling children, Tui, Ida and Juniper, who have shared my time with my studies for their entire lives. One of my greatest hopes for you all is that you will love to learn throughout your lives, because it makes life rich and exciting.

Many thanks to my supervisor, Dr Kate Thornton, for bringing the perfect balance of encouragement and clarity, and for helping to keep everything moving in a straight line.

I am indebted to the excellent positional leaders and teachers who gave up their precious time to be interviewed, and managed to put complex and diverse ideas into words. Thanks to the hundreds of survey participants for giving your time.

Finally, to the community of family, friends and colleagues who have supported and encouraged me through this journey, I am buoyed by relationships most of all, so thank you. 


\section{Table of Contents}

DISTRIBUTED LEADERSHIP FOR PROFESSIONAL LEARNING: EFFECTIVE LEADERSHIP PRACTICES IN EARLY CHILDHOOD EDUCATION..... 0

LIST OF TABLES: . .4

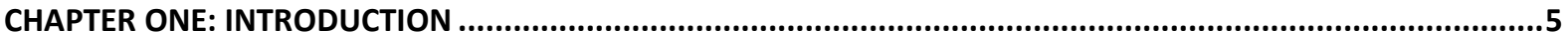

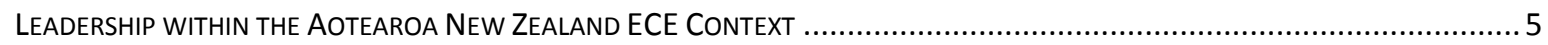

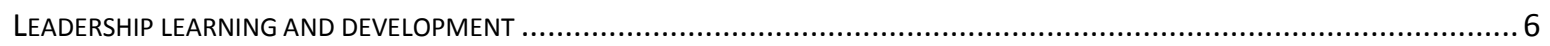

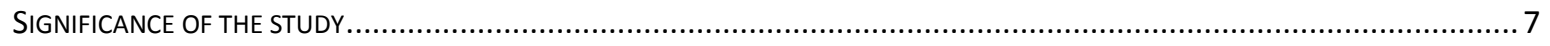

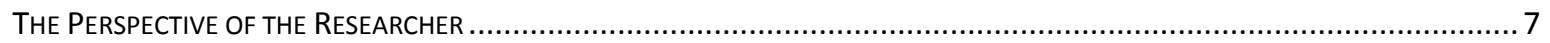

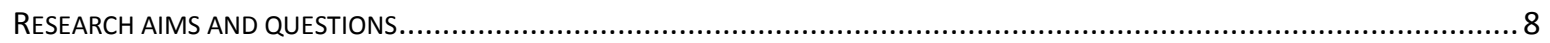

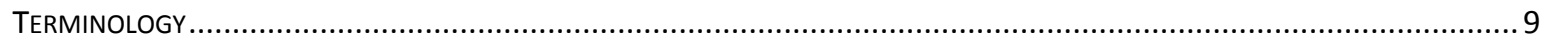

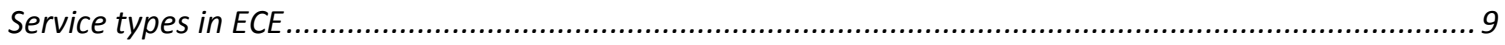

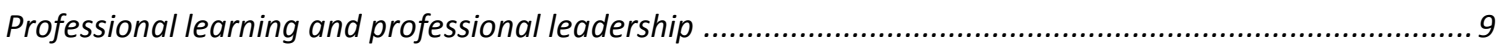

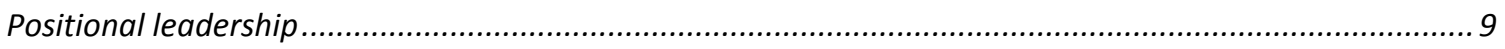

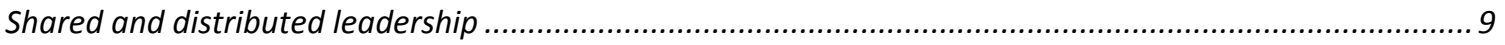

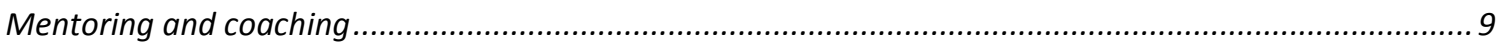

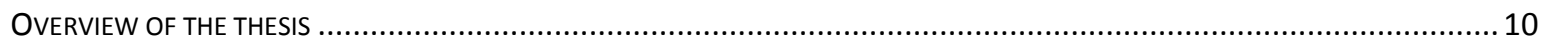

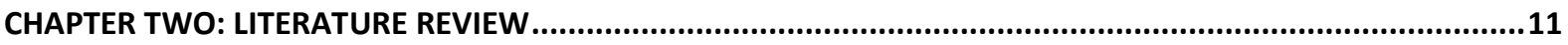

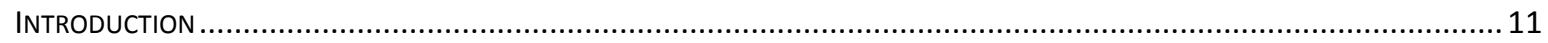

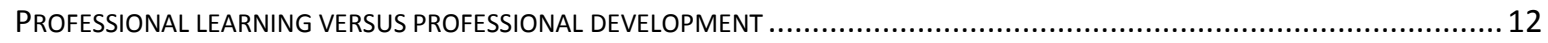

DEFINING PROFESSIONAL LEARNING COMMUNITIES WITHIN THE ECE SECTOR .......................................................... 13

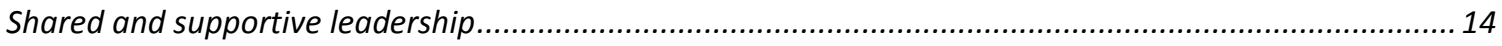

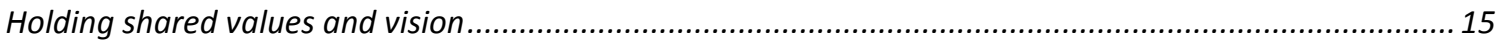

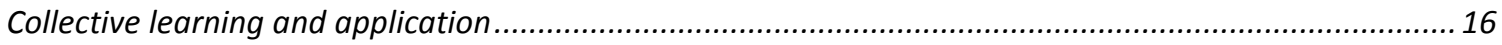

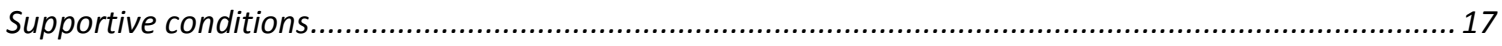

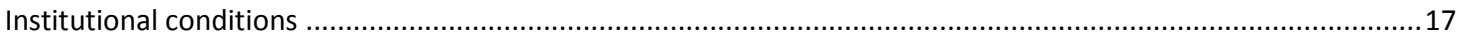

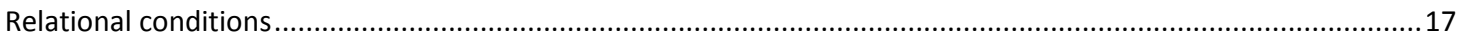

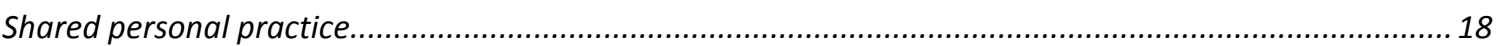

Summation of Professional Learning Communities ........................................................................ 18

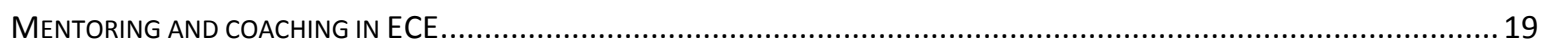

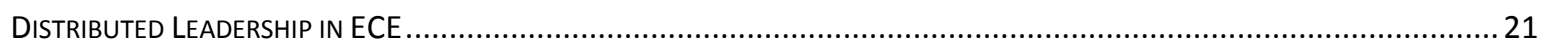

The positional leader's role in distributed leadership ............................................................................. 21

The relationship between distributed leadership and professional learning ............................................2 23

The positional leader within distributed leadership and professional learning .........................................23

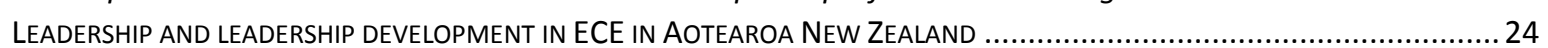

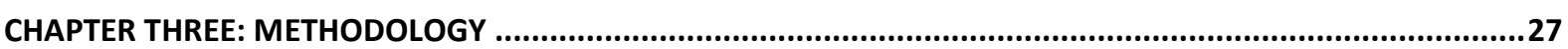

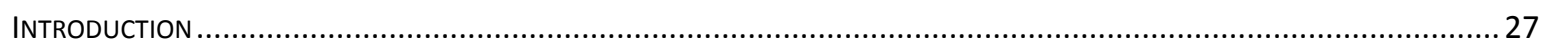

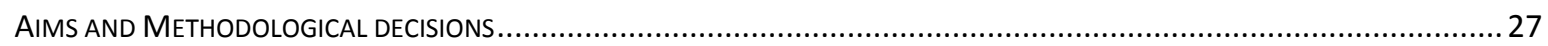

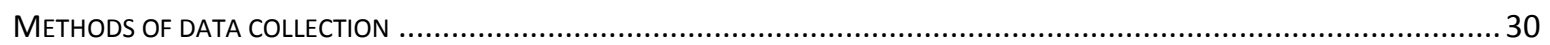

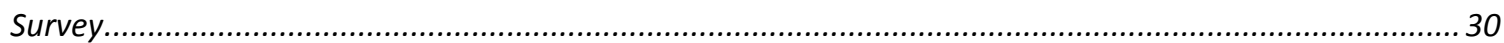

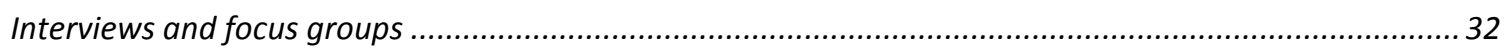

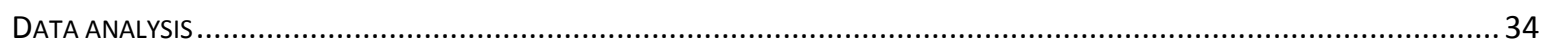

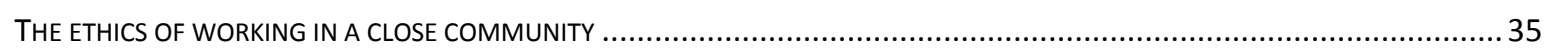

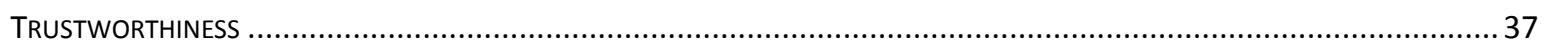

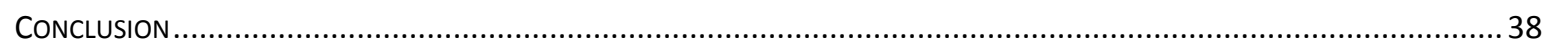

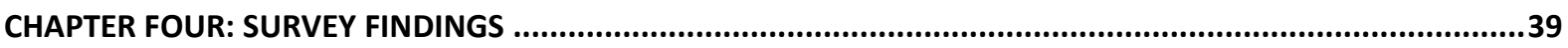

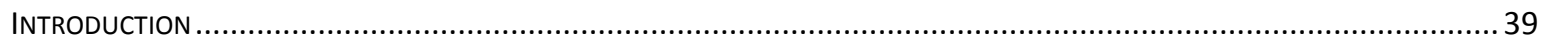

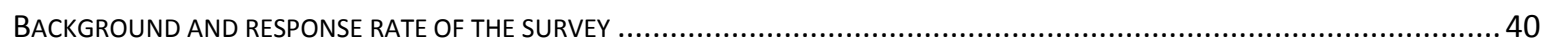

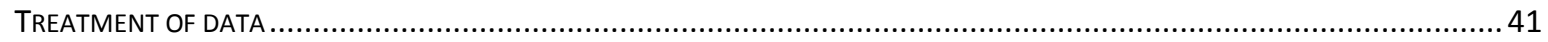




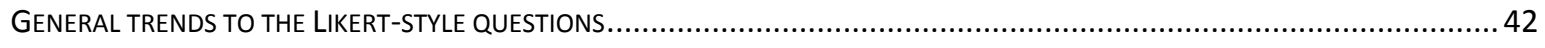

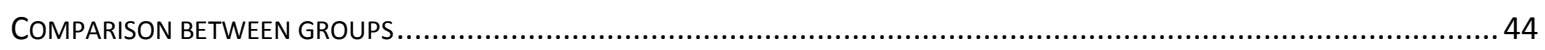

Differences between teachers and positional leaders ..................................................................4 44

Differences between kindergartens and early education and care centres ............................................47

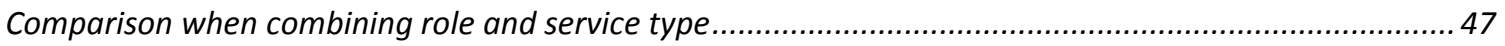

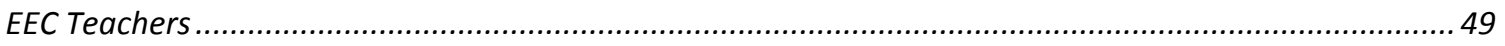

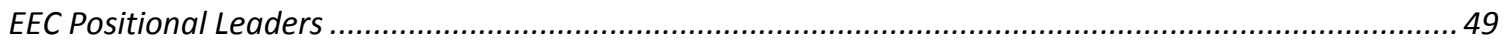

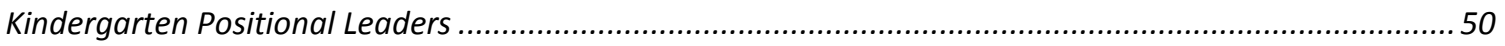

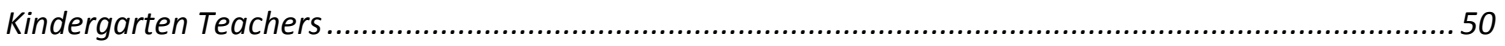

QUALITATIVE COMMENTS FROM THE SURVEY: BARRIERS AND GOOD PRACTICES ................................................. 51

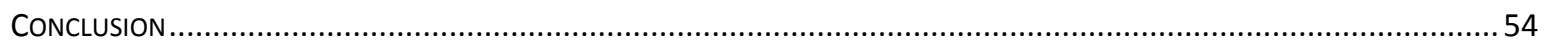

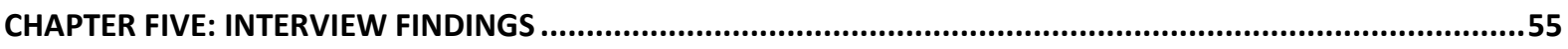

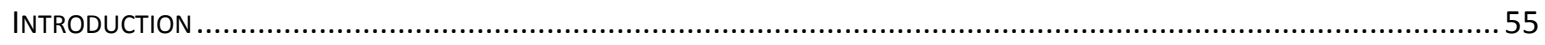

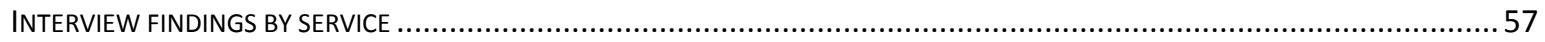

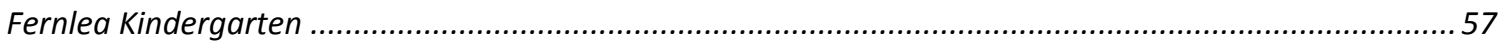

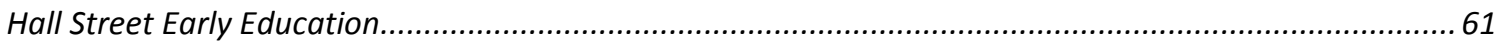

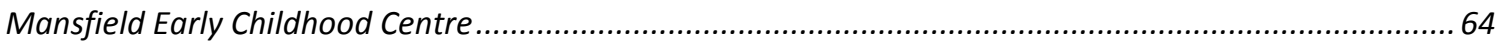

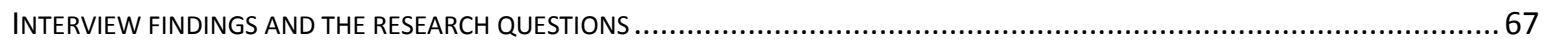

QUESTION 1: HOW DOES DISTRIBUTED LEADERSHIP CONTRIBUTE TO TEACHERS' PROFESSIONAL LEARNING? ..........................68

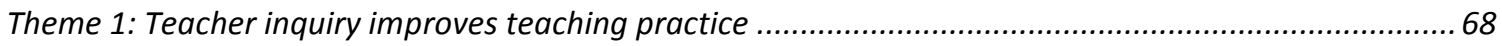

Theme 2: Articulation of thinking results in learning for both the presenter and the audience .................69

Theme 3: Diversity of leadership, knowledge, and experience provides rich learning ............................. 70

Theme 4: Engaging in leadership motivates teachers ....................................................................... 71

Theme 5: Empowerment of teacher leaders encourages professional learning ...................................... 72

Theme 6: Professional dialogue amongst teacher leaders is constructive ............................................. 72

Theme 7: Collaborative learning results in transfer of learning ......................................................... 73

QUESTION 2: WHAT IS THE POSITIONAL LEADER'S ROLE IN FACILITATING DISTRIBUTED LEADERSHIP FOR PROFESSIONAL LEARNING?

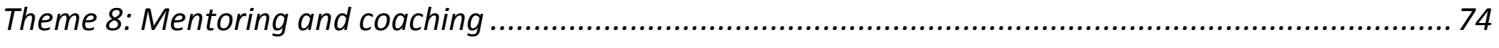

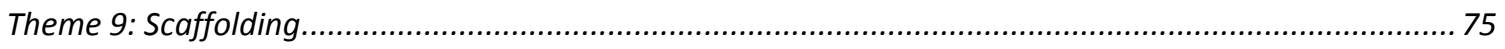

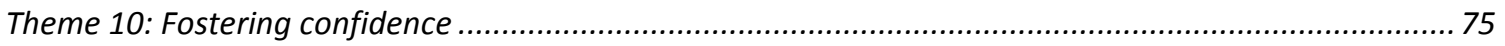

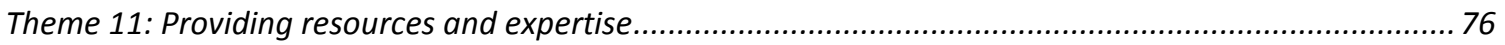

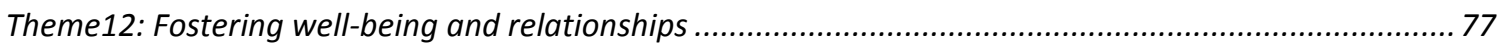

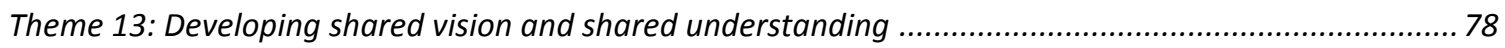

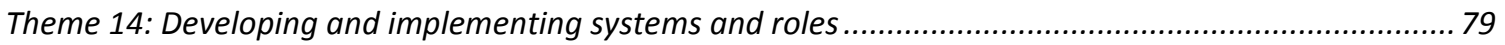

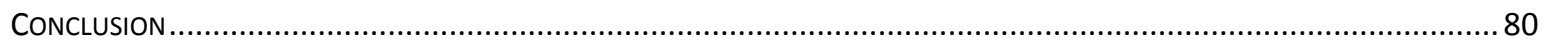

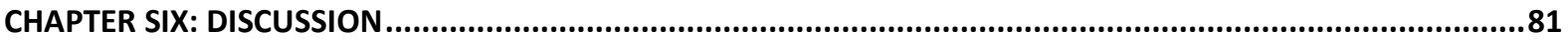

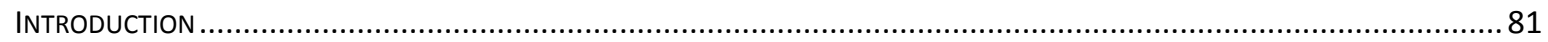

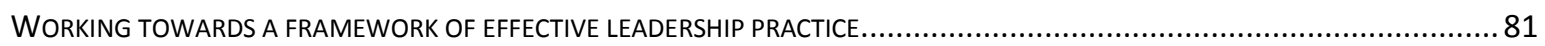

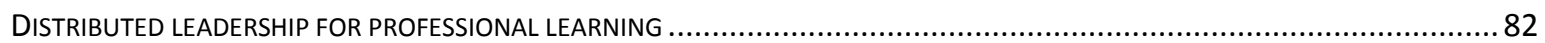

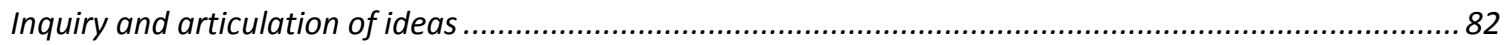

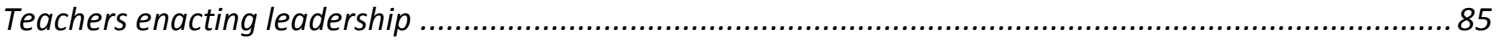

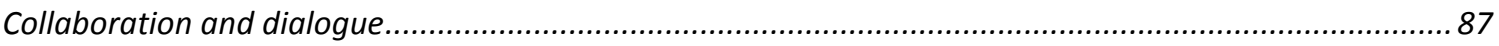

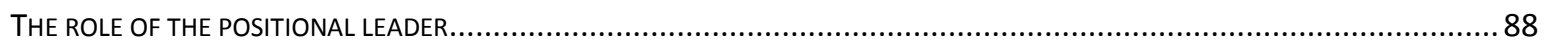

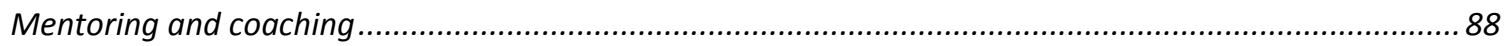

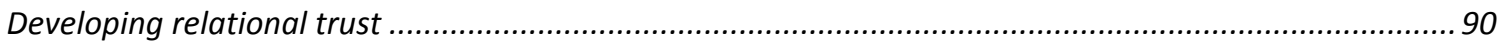

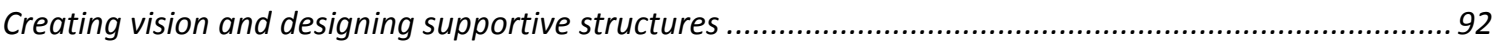

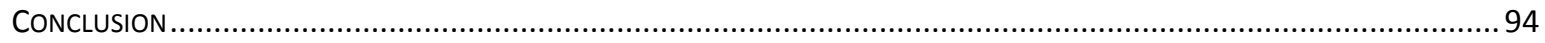

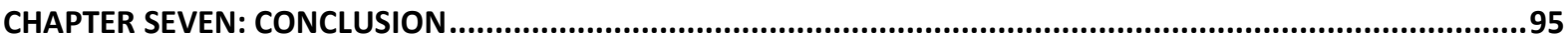

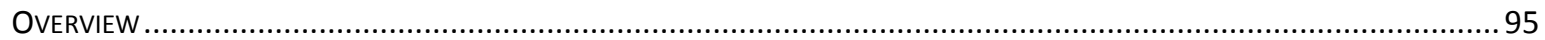




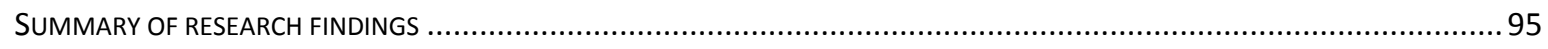

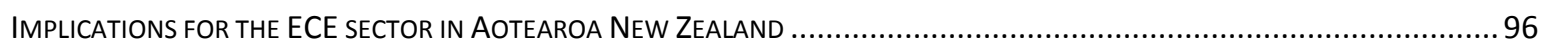

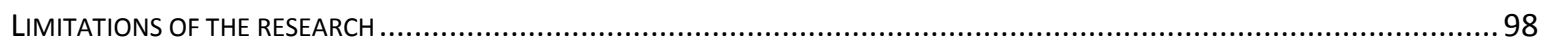

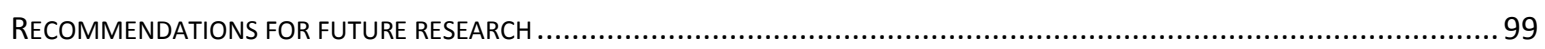

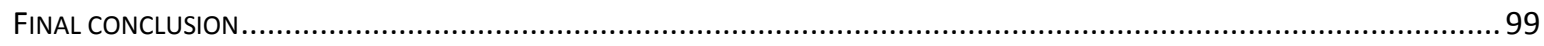

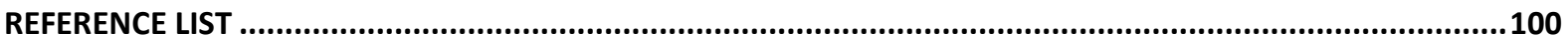

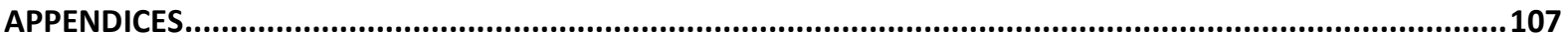

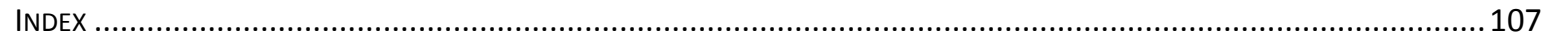

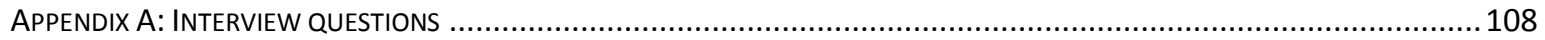

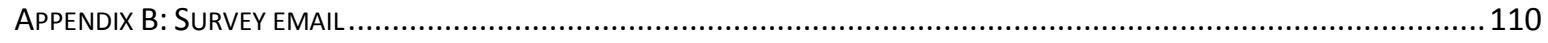

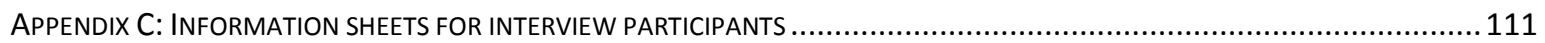

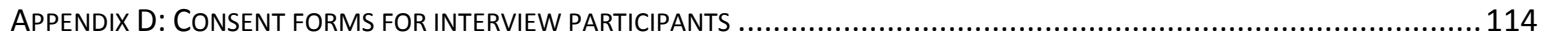

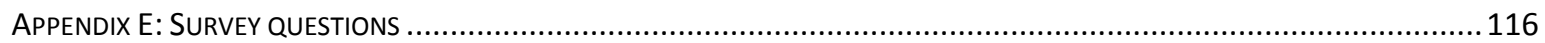

List of tables:

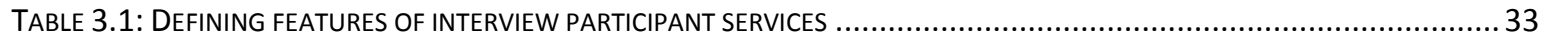

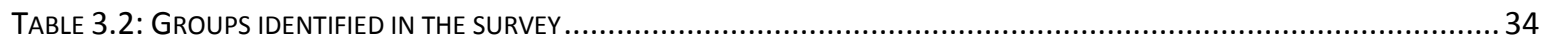

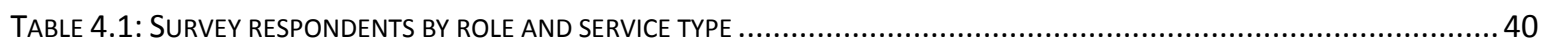

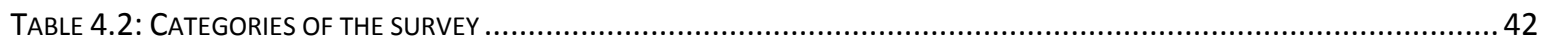

TABLE 4.3: PROPORTION OF SURVEY ANSWERS RATED POSITIVELY AND NEGATIVELY BY CATEGORY .................................. 43

TABLE 4.4: SURVEY QUESTIONS RESPONDED TO MOST NEGATIVELY AND POSITIVELY ................................................4

TABLE 4.5: FREQUESNCY OF DIFFERENCE OF MEANS BETWEEN TEACHERS AND POSITIONAL LEADERS ..................................44

TABLE 4.6: AREAS OF GREATEST DISAGREEMENT BETWEEN TEACHERS AND POSITIONAL LEADERS, REWEIGHTED DATA BY SERVICE

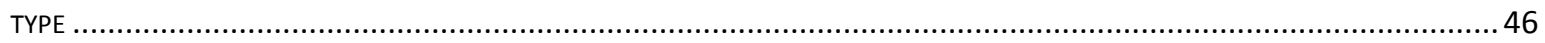

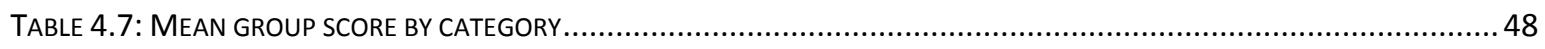

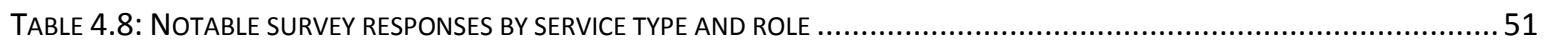

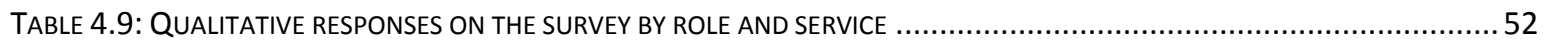

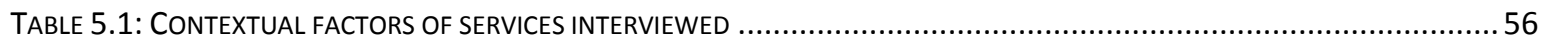

TABLE 5.2: CODES USED TO REFERENCE INTERVIEW PARTICIPANTS' QUOTES..........................................................5 56

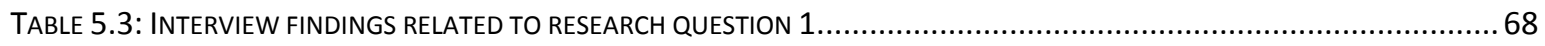

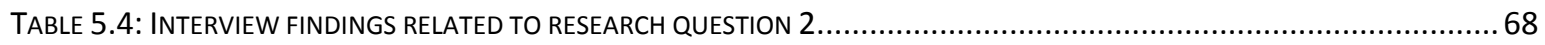

\section{List of figures:}

FIGURE 6.1: DISTRIBUTED LEADERSHIP FOR PROFESSIONAL LEARNING FRAMEWORK 


\section{Chapter one: Introduction}

\section{Leadership within the Aotearoa New Zealand ECE Context}

Aotearoa New Zealand has a single, national, early childhood curriculum, Te Whāriki (Ministry of Education, 1996), and a single regulatory agency, the Education Review Office (ERO), that monitors all service types. All trained teachers in the sector register through the Education Council of Aotearoa New Zealand for professional accreditation and on that application they are tasked with demonstrating leadership. In addition, the Ministry of Education posits that leadership includes "growing thoughtful leadership" within one's team (Ministry of Education, 2014). In sum, every trained early childhood teacher in Aotearoa New Zealand is tasked with leadership responsibilities in relation to common pedagogical imperatives.

Within this context, services generally have hierarchically defined roles (termed positional leaders) that are meant to foster leadership. These positional leaders usually have oversight of teacher pedagogical development (through goal setting, for example) but many positional leaders also teach, and in this regard they differ from positional leaders in the compulsory school sector; in early education and care and kindergarten settings, teaching is always in teams. Thus, despite differences in responsibility for positional leaders and teachers-asleaders, there is often a levelling of hierarchy in that everyone does the same job, together, in the same spaces.

The sector, then, can be seen as promoting a devolution of leadership practices, although some tasks - including the 'growing' of leadership - are not evenly distributed throughout the team. Positional leaders are expected to negotiate a tricky and contextually unique form of leadership that both directs development and grows leadership in others. A lack of standardised leadership development in the sector (to be discussed in the following section) does not help individuals in positional leadership to determine when or how to manage this negotiation.

The practices required for ECE positional leaders mirror, in many regards, the leadership described in professional learning community literature, where, to use a musical metaphor, 
positional leaders are members of the choir but also conductors (Huffman \& Hipp, 2003). In this configuration, positional leaders practice "distributed leadership" to encourage autonomy, deeper learning, engagement and the effective use of individual expertise (Clarkin-Phillips, 2011; Stoll, 2011). The similarities are all the more pertinent as professional learning is posited as a sustainable and effective way of improving pedagogical outcomes in educational settings (Colmer, 2008). In addition, the shared teaching spaces and smaller teaching communities of many ECE providers promise to facilitate some of the requirements of professional learning communities, such as having shared personal practice and collective learning and application (Thornton \& Wansborough, 2012).

The commonalities and potential of professional learning communities for pedagogical advancement and leadership practices in Aotearoa New Zealand is promising, yet there remain questions over how positional leadership should be enacted within this context. Particularly, what does it mean to distribute leadership in this context and how can this be done effectively?

\section{Leadership learning and development}

The need for leadership development in the early childhood sector in Aotearoa New Zealand has long been recognised within academic and governmental circles (Ministry of Education, 2002; Thornton et al, 2009). However, despite repeated calls for regular training of leaders within the sector, many in positional leadership positions have received no formal leadership training (Cooper, 2014; Thornton, 2010; Weisz-Koves, 2011). Nevertheless, positional leaders face 'leadership dilemmas' (Reynolds \& Cardno, 2008) and strengths and weaknesses in this area directly impact outcomes for children (Education Review Office, 2016).

The leadership issues that arise out of this context are further complicated by movements in the wider education sector to adopt shared or distributed leadership models for better educational outcomes (Heikka \& Waniganayake, 2011). On one hand these models promise to democratise leadership to all teachers, but on the other hand, how this leadership works and is established - particularly in ECE - is not very clearly defined (Clarkin-Phillips, 2011; Timperley, 2005). The professional learning that is often envisioned as accompanying these 
styles of leadership similarly promises better engagement, deeper learning and improved outcomes for children (Spillane, Halverson \& Diamond, 2004).

This study seeks to better understand the intersection between distributed leadership and professional learning within the early childhood education (ECE) sector. It uses survey and interview methods; the first of these was conducted nation-wide while the second was more proximate to Wellington for logistical reasons.

\section{Significance of the study}

The lack of formal and consistent leadership development in Aotearoa New Zealand ECE, alongside the tendency for the sector to have young positional leaders (Thornton, 2010), has led to a lack of support for positional leaders in the sector. This study aims to provide guidance for positional leaders and those that support them. While this guidance is specific to leadership, it may relate to aspects of regulatory review and the improvement of pedagogical practices of services (Education Review Office, 2016)

The study also seeks to enrich the literature on leadership practices in ECE by better understanding the value of distributed leadership in high-functioning services and developing a framework for effective leadership to foster distributed leadership. It sits within a recent interest in distributed leadership and professional learning communities in ECE, particularly in the work of Colmer et al $(2014 ; 2015)$ and Thornton and Cherrington (2014) that builds upon the work of Thornton and Wansborough (2012), Thornton (2010) and Clarkin-Phillips (2007; 2011).

\section{The Perspective of the Researcher}

I have been a positional leader in ECE since 2006, in community-based, private and kindergarten services. In my various roles I have had the privilege of working with sector leaders, such Dr Anne Meade, who have contributed to pedagogical advancement and leadership in the sector. I also participated in Dr Kate Thornton's doctoral research project that developed leadership skills through mentoring and working in a professional community. 
I obtained my first assistant leader role while still completing my Bachelor of Teaching degree and became the sole leader of the same centre immediately after completing my degree. For me, the issue of pedagogical improvement within a team has always been tied to leadership of that team. It has also been clear from the outset of my teaching and leadership career that ECE has distinct challenges in that most of the teachers I have worked with are conflict avoidant and many are resistant to traditional models of leadership. This provides challenges in an environment where everyone works very closely together - in shared spaces and with the same children.

\section{Research aims and questions}

With this project I aim to gain a deeper understanding of the practices of positional leaders that facilitate distributed leadership and professional learning. I believe that the project will help address gaps within educational leadership literature in Aotearoa New Zealand and in some international contexts. Through the research I aim to answer the following questions:

- How does distributed leadership contribute to teachers' professional learning in early childhood education settings?

- What is the positional leader's role in facilitating distributed leadership for professional learning?

The first research question, 'How does distributed leadership contribute to teachers' professional learning in early childhood education settings?,' aims to explore the positive connection, proposed by the literature, between these two areas of practice. The second question, 'What is the positional leader's role in facilitating distributed leadership for professional learning?,' examines the practices of the positional leader in particular, which may be emulated to improve distributed leadership for the purpose of professional learning in early childhood teams. 


\section{Terminology}

A number of terms within early education and within the literature on professional learning are briefly outlined in this section. Those that are specific to bodies of academic literature are also addressed in more depth in the literature review.

\section{Service types in ECE}

ECE has a variety of service providers with different ownership and management structures. For the sake of simplicity, I refer to services that are part of kindergarten associations as 'kindergartens' and full-day services with multiple trained teachers teaching groups of children as 'early education and care' (EEC). In addition, I make reference to a teacher-led service in which the only language spoken is Māori, as a 'Māori immersion centre.'

\section{Professional learning and professional leadership}

The terms 'professional learning' and 'professional leadership' are used in line with literature on professional learning and professional learning communities. These relate to pedagogical learning that is embedded within the practices of the service and the leadership that facilitates this learning respectively. Within Aotearoa New Zealand and more broadly, the term 'pedagogical leadership' is sometimes used to make clearer distinction between leadership for pedagogy and leadership for management, however I retain the word 'professional' as it is used within the literature that I refer to throughout the project.

\section{Positional leadership}

The term 'positional leadership' refers to hierarchically defined positions of leadership within ECE services. These positions are commonly head teacher or manager, or in larger umbrella organisations could also include senior teachers, regional coordinators, and so on.

\section{Shared and distributed leadership}

Leadership that is devolved from the positional leader to others in the teaching team is termed 'shared' or 'distributed' leadership. Developing a more precise understanding of these terms within ECE is part of this project; their definitions and how they should be understood within the sector are taken up in the literature review and discussion.

\section{Mentoring and coaching}

Throughout this project I join the terms 'mentoring' and 'coaching' to acknowledge the crossover between the definition and uses of these terms in their respective bodies of literature. In ECE, 'mentoring' is commonly used (see, for example, Murphy \& Thornton, 
2015), and is described as encompassing coaching along with other leadership practices (Thornton, 2015). However, the terms are often joined in the literature as either 'coaching and mentoring' or 'mentoring and coaching' to acknowledge the convergence of research, practices, and definitions between the two terms, and the difficulty of trying to make clear distinctions between them (Brockbank \& McGill, 2006; Clutterbuck, 2008). For the purpose of this study, I have chosen to use the joined term, to encompass the wealth of leadership strategies available in the combined literature which may enable positional leaders to better facilitate teachers' professional learning and leadership development.

\section{Overview of the thesis}

This thesis consists of five sections, this introduction and a conclusion. The sections begin with a review of the literature of professional learning, distributed leadership and their current application in the Aotearoa New Zealand ECE sector. I discuss my methodology and choice of a mixed-methods approach in the section that follows. I report my findings in two chapters, 4 and 5, first to unpack the results of the sector-wide survey that I conducted and then to summarise the data from focus groups and interviews that were conducted with services that were identified as high-functioning. In Chapter 6, I discuss the findings under two categories: the impact of distributed leadership for professional learning and the role of the positional leader in fostering distributed leadership. I use these groupings to develop a framework for effective leadership practice. Finally, I conclude the thesis with the implications of the research, acknowledgement of its limitations and identification of areas for future research. 


\section{Chapter Two: Literature review}

\section{Introduction}

This project examines the intersection of leadership, professional learning and the ECE sector of Aotearoa New Zealand. More specifically, it focuses how distributed leadership operates within the sector and specific workplaces to achieve positive professional learning outcomes. Even with this more narrowed focus, the bodies of literature behind the key terms of the project are immense.

To examine the literature in sufficient depth, this review first focuses on the characteristics and rationale for the use of professional learning - rather than professional development within education. It then positions professional learning more specifically within Aotearoa New Zealand ECE, using aspects of professional learning communities to consider leadership for professional learning. Mentoring and coaching is then considered as an approach to leadership of professional learning in ECE. Next, the review succinctly contextualises distributed leadership within leadership literature before categorising and analysing its synergies and challenges within professional learning. Once again, the discussion is positioned within the Aotearoa New Zealand ECE sector at the close of this section. Finally, the chapter highlights areas of leadership and leadership development that need further attention to help ECE services better enact distributed leadership for effective professional learning within Aotearoa New Zealand.

Two key findings emerge from the literature. First, despite the increasing body of literature on distributed leadership and the recognition within that literature that positional leaders play a pivotal role in fostering distributed leadership and professional learning, there is very little practical advice on actions they need to take within this role. This can lead to confusion over practices that are or are not aligned with the principles of each of the terms. Second, despite calls from academics and governing agencies for leadership training in ECE, there continues to be a distinct lack of recognised leadership development pathways for ECE leaders in Aotearoa New Zealand. From these findings I note the gap, within the academic 
literature as well as the literature from the sector, between the abstractions within the theories and practical understandings of how they should be implemented.

\section{Professional learning versus professional development}

'Professional learning' is a term that appears to arise out of dissatisfaction over traditional forms of professional development while retaining some of the same meaning. For proponents of professional learning, traditional professional development has a number of weaknesses. It is characterised as a system where individuals leave their professional environments to learn about something in a one-off workshop from an expert (Vescio, Ross \& Adams, 2008). Irrespective of the knowledge of the expert, deep learning is thwarted by the decontextualisation of learning from the professional environment (Webster-Wright, 2009). In addition, learning is assumed to occur in individuals (those that attend a professional development workshop) rather than in the social processes that generate and deepen meaning. In sum, they lack contextual meaning, learning transfer and sustainable change (Watson \& Williams, 2011).

While professional learning strives to achieve the same goals, namely improved professional practice, it embeds learning within the professional context of the learners and requires learners to engage in professional dialogue, to inquire, research and teach each other. Professional dialogue between teachers is more than simply exchanging information; such dialogue allows the co-construction of new meaning and knowledge (Rinaldi, 2003). The embedding of learning pays heed to theory that learners get more out of learning that occurs within the context that it is applied as it makes use of tacit knowledge (WebsterWright, 2009). The processes of inquiry, research and peer teaching draws on theories of active learning while also recognising that learning occurs in the social creation of meaning about the world we live in (Mitchell \& Cubey, 2003).

It is not surprising that professional learning is a well-received concept in education, and ECE in Aotearoa New Zealand particularly. The contextual, active and socio-cultural aspects of learning are emphasised in pedagogical literature over the model of didactic learning that many believe underpin traditional professional development. For example, Te Whāriki, Aotearoa New Zealand's ECE curriculum, explicitly draws on socio-cultural learning theories 
(Ministry of Education, 1996). In addition, the embedding of learning allows groups to focus on issues that relate directly to the community; this may result in stronger engagement and longer lasting learning (Hord, 1997; Webster-Wright, 2009).

In the Aotearoa New Zealand ECE context, teachers and leaders tend to work in relatively small groups (compared to, say, primary or secondary teachers). They also, often, teach the same groups of children. In this case, where a core group of teachers works together over time, professional learning occurs in a tightly bound community. It is with this context - of the professional learning community - that more specific features can be identified. Here, learning not only occurs in a specific context but also strives to achieve similar professional goals: the continued development of professional identities and practices. These correspond to specific attributes of teaching, reflection and leadership (see, for example, Cranston, 2009; Nelson, Slavit, Perkins \& Hathorn, 2008).

\section{Defining professional learning communities within the ECE sector}

'Professional Learning Community' is an enticing concept for teachers; it flips the identities of 'teachers' to 'learners' while empowering teachers to take control of their professional development; it suggests a culture of learning and critical inquiry; and it posits teaching as a practice that requires continued reflection (Morrissey, 2000). At the same time, the term is open to multiple interpretations, not least because teachers can see themselves as already forming a community that engages in varied levels of reflection and that learning is intrinsic to the teaching practice (Thornton \& Wansborough, 2012). In order to differentiate between regular practice within schools and professional learning communities that are "continuous", "intentional" and have the explicit aim of improving the effectiveness of teaching to benefit student learning (Hord \& Sommers, 2008), the term requires clearer definition. I take a holistic approach in looking at structures alongside teacher and positional leader practices; as it examines praxis (the meeting of theoretical constructs and practice) within the structural context that it occurs (Torres \& Mercado, 2004).

Hord's (1997) seminal work on professional learning communities, Professional Learning Communities: Communities of continuous inquiry and improvement, puts forward five characteristics of the community specific to educational settings. These characteristics 
underpin widely cited texts by Hipp and Huffman $(2003 ; 2010)$ in which the five characteristics are further broken down in order to construct a measurement tool, the Professional Learning Community Assessment (PLCA and the PLCA - Revised or 'PLCA-R'), to assess professional learning communities. This survey has been used extensively and tested for reliability and validity (American Institute for Research, 2017) and, importantly for this literature review, used within the Aotearoa New Zealand ECE sector (Thornton \& Wansborough, 2012). I use these five characteristics to structure my definition of leadership of professional learning communities here for these reasons.

The five characteristics are: shared and supportive leadership, shared values and vision, collective learning and application, shared personal practice, and supportive conditions. Before breaking these down further it is important to note that researchers within the field have identified additional characteristics of professional learning communities. For example, in a literature review by Thornton and Wansborough (2012) the authors identify 'results orientation', 'reflective practice/dialogue' and 'trusting relationships' as features within the broader literature. However, while these characteristics are not explicit in Hord's typology, they are nevertheless implicit, and become more explicit in the PLCA. For example, in the revised PLCA, 'supportive conditions' is broken into supportive structures and supportive relationships, clearly incorporating 'trusting relationships'. Similarly, 'reflective practice/dialogue' is captured in questions on the PLCA under the heading of 'collective learning and application'. In other words, using five characteristics offers a shorthand to examine the range of features within professional learning communities.

\section{Shared and supportive leadership}

The requirements of leadership and positional leaders within the professional learning community feature throughout the literature (see, for example, Eraut, 2002; Morrissey, 2000; Stoll et al., 2006; Thornton \& Wansborough, 2012). Just as traditional professional development is represented as outdated in its pedagogical underpinnings, traditional styles of leadership - paternal, directive and solitary - are criticised for their inability to develop expertise and responsibility for learning (Timperley, 2005). In contrast, where a positional 
leader genuinely shares leadership, teachers respond with increased motivation, engagement and innovation (Clarkin-Phillips, 2007).

The idea of shared and supportive leadership however, is deceptively more complex than it seems at first glance. On one hand the term denotes a form of democratic leadership - i.e. leadership that comes from the community's constituents rather than being centrally located - but on the other hand education researchers have continuously pointed out that positional leaders also act as experts (Robinson, Hohepa \& Lloyd, 2009). For example, Huffman and Hipp (2003) argue that the positional leader has to be both an equal participant in the learning community as well as someone who provides coaching and mentoring, oversight and orchestration of the community. While others may argue that some of these functions can also be shared, it is nevertheless clear that positional leaders have complex responsibilities that require tacit and implicit knowledge about leadership as well as professional knowledge.

In all of this, it is clear that the positional leader and their enactment of leadership are crucial to the development of the functioning of the professional learning community, not least through the support and enablement of democratic leadership (Cherrington \& Thornton, 2013; Marsh, 2015; Poekert, 2012; Thornton \& Wansborough, 2012; Torrance, 2014). As Spillane et al. (2011, p. 160) note, our understanding about the "knowledge and expertise" required for this to occur remains an underdeveloped area of research though recent literature is beginning to address it more directly - I will take this up in the section on distributed leadership below.

\section{Holding shared values and vision}

Where traditional PD can treat participants as atomised teachers rather than parts of interdependent teams, the term professional learning communities implies commonalities between members. For Atkin (1996) having shared values and vision is integral for making the community purposeful and focused: shared vision acts as a beacon to lead people forward on the same path. Lambert (2003, p. 50) uses as similar analogy, describing shared vision as, "the touchstone for all other actions - the yardstick for questions and the reference point for conversations." In a learning community where everyone sees themselves as leaders, there is a risk that each member could go off in different directions; 
shared values and vision help to maintain cohesion and utilise the strength of collaboration. Where professional learning communities face potential interpersonal and pedagogical challenges, shared vision allows for coherent evaluation and accountability (Atkin, 1996).

Atkin's use of shared vision is necessarily vague; this can be seen reflected in ECE in Aotearoa New Zealand where Te Whāriki is meant to act as a shared vision but results in a variety of practices (sometimes within the same team) that cannot always be seen as complementary (Blaiklock, 2010). While there is widespread acceptance that shared vision and values are integral to professional learning communities (Stoll et al., 2006) their construction needs further investigation.

\section{Collective learning and application}

Professional learning communities "collectively seek new knowledge and ways of applying that knowledge to their work" (Morrissey, 2000, p. 6). The application aspect of this premise draws on experiential learning theory (Webster-Wright, 2009) whereas the collective aspect relates to social constructivist theory (Palincsar, 1998). For WebsterWright, both the social and applied aspects of professional learning communities are more engaging, promoting deeper learning. Hord (1997) uses the term 'collective creativity' to describe the beneficial process of collective learning and application. Here, the concept is translated explicitly from Senge's "learning organisation" where groups "continually expand their capacity to create the results they truly desire, where new and expansive patterns of thinking are nurtured, where collective aspiration is set free, and where people are continually learning how to learn together" (Senge, 1990, p. 3, in Hord, 1997, p. 18, emphasis added).

Senge's aspirational language promises a transformative community and organisation. Without undercutting the potential of an organisation that learns and applies that learning collectively, there are nevertheless underdeveloped aspects of this vision. First, collective application seems underdeveloped in the literature compared to collective learning. This can be read in two ways: where group application is a result of learning, or as a sort of utopian horizon where everyone is imagined to be working in the desired way. In either case, the ECE context allows us to examine the necessary link between collective learning and application in that the sector is dominated by small teams that work in the same spaces 
with children. More than other educational contexts, the relationship between learning and application should be observable. Second, the question of different approaches to collective learning (diverse learning and teaching styles) does not seem to be acknowledged.

As with the other features of professional learning communities, then, collective learning and practice can be seen as a necessary part of the effective community, but some of its functioning requires further elaboration.

\section{Supportive conditions}

Hord identifies a number of supportive conditions needed to foster professional learning. Later research more explicitly breaks down these conditions into two distinct categories, the first relating to infrastructural conditions and the second relating to relational conditions. Neither of these should be underestimated in their importance, so they are addressed separately here.

\section{Institutional conditions}

Professional learning communities require adequate time and common spaces to function as communities, as well as time to further research into specific areas of development (Stoll, 2011; Thornton \& Cherrington, 2014). Thornton and Wansborough's (2012) adaptation of PLCA-R posed three questions to gauge the sufficiency of institutional conditions in ECE. These related to adequate financial support, adequate time and adequate communication structures within the organisation. All of these should be considered baseline requirements if learning communities are to be sustainable.

\section{Relational conditions}

Although initially combined with institutional conditions in Hord's typology, a growing body of literature suggests that collective practice, honest reflection and evaluation and shared vision cannot be attained without a strong relational foundation within a community (Cooper, 2014; Stoll, 2011; Thornton \& Wansborough, 2012). An interpersonal aspect of this is relational trust, as members of the community will not engage openly and honestly in the process if they feel threatened (Stamopoulos, 2012; Spillane et al, 2004). Other aspects that Hord identifies, such as a culture of collaboration and inquiry need to be established by the community together. Finally, Hord identifies the need of the community to be open to change - an aspect of relational conditions that one could argue is individual as much as collective. 
As with institutional conditions, relational conditions should be seen as a prerequisite to the establishment and functioning of the learning community. However, institutional conditions are often outside of the control of the community members or even their employers in ECE (Hord, 1997); funding is determined primarily through government and this impacts significantly on the time that can be allocated to professional learning. Relational conditions are different in that they are intrinsic to the community itself. As such, personal, interpersonal and organisational-cultural conditions should be seen as developmental practices. These practices have significant impact on other aspects of the learning community and are also influenced by those aspects, not least shared and supportive leadership.

\section{Shared personal practice}

Hord's fifth characteristic of professional learning communities is wide-ranging and, in many ways, more explicit than most of the others. Shared personal practice has practical components, such as "peers helping peers" through peer review of teaching (Hord, 1997, p. 23). These practices are envisioned as supportive and supportively-critical rather than evaluative. They also have "fundamental requirements" such as "mutual respect" and "trustworthiness" (Hord, 1997, p.23).

Once again, Hord is painting something of a utopian horizon for working professional learning communities, so that it is probably not productive to point out all of the difficulties in practically enabling this vision. However, some contradictions need to be addressed. For example, any review process, peer-to-peer or positional leader-to-peer, is necessary evaluative if it is to have any critical component. In an evaluative process, it is important to acknowledge and prepare for the potential of conflict and insecurity as well as differences in personality types and skills as teachers. So while a degree of shared personal practice is necessary for professional learning communities to function effectively, the difficulty of setting up processes and relationship to enable it cannot be glossed over; they are very difficult to achieve (Cranston, 2009; Morrissey, 2000; Thornton \& Wansborough, 2012).

\section{Summation of Professional Learning Communities}

Hord's five characteristics of a professional learning community are all deemed necessary to achieve the results that the communities promise. Although there are some practical 
suggestions for how the aspects can be achieved, they are more appropriately used as measures to gauge the extent to which a community is operating in a productive way to better their practices. It is also clear that there is substantial overlap between the characteristics; aspects of leadership surface in all of the other characteristics, there are close ties between relational conditions and shared personal practices and so on. While this can be seen as the interdependence of the characteristics, it is also due to the conflation of conditions that need to be in place for learning communities to exist and the ongoing practices that support and reinforce them.

In other words, the communities require substantial leadership work to create a working context in which the community can exist. Part of this will be ongoing (for example, the evaluation of peers requires relational trust but will also strengthen relational trust if done properly) but part also seems to be required beforehand. For example, the distributed leadership model that is proposed is unlikely to develop out of traditional leadership models, supportive-critical conversations will be difficult unless there is a shared vision and goals, and openness to change seems predicated upon trust and shared vision.

The need for preconditions as well as the development of teacher autonomy through shared and distributed leadership points once again to the role of the positional leader in establishing effective conditions for the learning community (Cooper, 2014; Marsh, 2015). This is not only because the positional leader holds more institutional authority but also because traditional models of leadership need to be broken down for all involved and the positional leader is central to the practice and development of skills required to rebuilding leadership expectations (Huffman \& Hipp, 2003; Marsh, 2015).

\section{Mentoring and coaching in ECE}

Mentoring and coaching is highlighted in leadership literature as a key component of educational leadership, and a powerful tool for capacity building and development of teachers (Aubrey, Godfrey \& Harris, 2013; Clutterbuck, 2008; Day, 2001; Rodd, 2013; Thornton, 2015). Mentoring and coaching literature presents sets of practices, including facilitating goal-setting, questioning and listening, and advice and guidance (Brockbank \& McGill, 2006; Rowley, 2006; Thornton, 2014), which are reflected in literature on ECE 
leadership (Clarkin-Phillips, 2009; Rodd, 2013; Thornton et al, 2009). Thornton (2015, p. 1) describes mentoring as "an effective leadership approach that enhances professional learning and practice." Positioning mentoring and coaching as a leadership approach suggests that ECE positional leaders would benefit from having this skillset available in their repertoire.

Mentoring and coaching encompasses a broad range of practices that align with leadership practices in the leadership of professional learning communities, as introduced above. The mentoring and coaching literature in education emphasises facilitating professional development, and this means that these practices are highly relevant to professional learning community leadership, to pedagogical leadership, and to ECE leadership. The value of an external influence is highlighted in the literature (Cherrington \& Thornton, 2013; Stoll, 2011; Thornton, 2015); however, in ECE it is more often the positional leader who will enact mentoring and coaching within the team (Rodd, 2013), for example in facilitating teacher registration and appraisal processes. This may be beneficial for positional leaders, as mentoring has been shown to benefit the learning of the mentor as well as the mentee (Harrington, 2015; Thornton, 2014). Mentoring and coaching, as described by Dembkowski, Aldridge, Hunter and Whitmore (2006), includes questioning, analysis, reflection and action; these elements are reminiscent of ECE self-review guidelines (Ministry of Education, 2006), and of action learning and teacher inquiry (Timperley, Wilson, Barrar \& Fung, 2007), and therefore speak to the relevance of mentoring and coaching to ECE professional learning and development.

Mentoring and coaching is an important tool for developing the many aspects of professional learning communities (Colmer, 2008; Huffman \& Hipp, 2003; Thornton, 2015). Thornton (2015, p. 10) is clear that, "effective ECE leaders mentor and coach their colleagues and encourage them to become involved in leadership" and that much-needed professional development for leaders in ECE should include the development of skills for coaching and mentoring. 


\section{Distributed Leadership in ECE}

Leadership is a key component of early childhood teaching; evidence of leadership within teaching practices is required for an individual to attain and maintain teacher certification (Education Council New Zealand, 2015) and distributed leadership underpins the pedagogical leadership measure within the Education Review Office framework (Education Review Office, 2016, p. 31). As such, the term 'leadership' within the sector denotes a range of practices that are not dependent on the position of the individual teacher within a team: head teachers, manager-teachers and newly appointed teachers all have a responsibility to enact leadership (Education Council New Zealand, 2015). It is not surprising, then, that Aotearoa New Zealand's Ministry of Education (MoE) promotes a vision of shared leadership within ECE (Ministry of Education, 2011). The ministry justifies this democratic "shift of control from the [positional] leader to the group" (Ministry of Education, 2011) through reference to contemporary academics in the field. The shift is easily rationalised and mirrors the discussion of learning communities above; distributed leadership models are considered beneficial in a number of ways, including in staff retention and engagement, learner outcomes, and developing effective professional learning within educational teams (Leithwood, Mascall \& Strauss, 2009). As such, shared or distributed leadership models are becoming an expectation for ECE workplaces, with a change in emphasis from leadership as tied to hierarchical position within a teaching organisation to leadership as a set of behaviours that teachers should develop and practice. Although a range of terminology is used to describe this new leadership (Dieronitou, 2014, p. 38), distributed leadership can be delineated from other approaches by a shift in view of leadership away from people and onto practice (Harris, 2013). According to Harris, when leadership is seen as a practice rather than being bound by position, it becomes available to everyone. It is important to note that this approach does not amount to delegation of responsibilities (Harris, 2013).

Distributed leadership literature is concerned with the distribution of meaningful and authentic opportunities for leadership, where participants hold some power and enact selfmanagement (Clarkin-Phillips, 2009; Hatcher, 2005; Spillane et al, 2004).

\section{The positional leader's role in distributed leadership}

The role of the positional leader within the professional learning community can effectively be broken into two components. These are explicit pedagogical and professional knowledge 
and knowledge of leadership. The latter of these is a key area that requires elaboration in order to establish professional learning communities. Researchers in the school and ECE sectors have begun to recognise the crucial place of the positional leader in developing distributed leadership (e.g. Colmer et al, 2015; Marsh, 2015; Murphy, Smylie, Mayrowetz, \& Seashore Lewis, 2009; Sheppard, Hurley \& Dibbon, 2010). These authors suggest that, although distributed leadership allows different members of the community to enact leadership, the role of the positional leader is not minimised in this approach. For example, Fullan (2005) posits eight elements of "sustainable learning" that reinforce the need for distributed leadership, and these also recognise the positional leader as central to development of distributed leadership within the educational organisation. As a whole, the literature highlights the critical importance of positional leaders in effectively facilitating distributed leadership environments. Colmer et al $(2015$, p. 104) argue that in the ECE context, "Distribution does not replace positional leadership structures, and site leaders play an important role in coordinating leadership and developing leadership capability within the group." That idea is reinforced by Murphy et al $(2009$, p. 181$)$, as positional leaders "occupy the critical space in the teacher leadership equation," and are central to the work redesign necessary to "bring distributed leadership to life in schools."

The role of positional leaders in enacting distributed leadership is complex and challenging (Marsh, 2015). According to Murphy et al. (2009) positional leaders require strength of identity as leaders in order to begin distributing leadership, particularly in transforming the definition of the positional leadership role in the face of entrenched hierarchical models and traditional views of leadership in educational organisations. Weisz-Koves (2011) similarly calls for a redefinition of traditional leadership roles (in ECE) to allow successful distributed leadership to develop.

So what constitutes these newly defined positional leadership practices in the development of distributed leadership in educational settings? Several aspects of the positional leader's role are recurrent in distributed leadership literature: maintaining vision and learning focus (Marsh, 2015; Sheppard et al, 2010); offering teachers opportunities for leadership (Colmer et al, 2015; Murphy et al, 2009; Weisz-Koves, 2011); developing relational trust (Marsh, 2015; Murphy et al, 2009; Sheppard et al, 2010); and managing supportive structures (Colmer et al, 2015; Murphy et al, 2009). However, within these different aspects, the 
research also highlights the need for further research and attention to the role of the positional leader in distributing leadership, in particular in the ECE context. A gap appears in the area of practical guidance for positional leaders, as is apparent in other sections of this literature review.

\section{The relationship between distributed leadership and professional learning}

There are many similarities in current thinking about distributed leadership and professional learning in education. The ideas outlined above regarding the positional leader's role in distributed leadership are similarly highlighted in literature about leadership of professional learning communities (Cherrington \& Thornton, 2013; Edwards, 2012; Mitchell, Riley \& Loughran, 2010; Thornton \& Wansborough, 2012). Commonalities include collaboration, relational trust, shared vision, supportive structures, and opportunities for leadership. This cross-over of terms and concepts makes clear the relationship between the two, and this relationship can be interpreted in different ways. Some researchers describe distributed leadership as an element of professional learning (e.g. Timperley et al, 2008), particularly in professional learning community literature (e.g. Hipp \& Huffman, 2009). Others describe professional learning as an effect or element of distributed leadership, in research focused on leadership practice (e.g. Timperly, 2005). Poekert (2012) acknowledges the cyclical influence between the two arenas of practice, where professional learning builds leadership capability in teachers, distributed leadership leads to professional learning for teachers, and so on. Regardless of the perspective, the positive connection between the two is evident and has potential power for capacity-building in teachers in terms of both leadership and learning.

\section{The positional leader within distributed leadership and professional learning}

Colmer et al $(2014 ;$ 2015) have researched leadership of professional learning in ECE, and propose distributed leadership as the ideal environment for effective professional learning for teachers. They explain the importance identified in research of both positional and distributed leadership in ECE, and choose to use the terms 'positional leaders' and 'informal leaders' to distinguish between these important roles in their writing. The ECE positional leader is shown as an important guiding influence, with the power and responsibility to bring out leadership in everyone for the purpose of professional learning and improved practice. They argue that, "distributed leadership assists in creating professional learning 
environments where educators can debate, disagree and provide critical feedback to each other" (Colmer et al, 2014, p. 105). Edwards (2012) agrees that distributed leadership provides a rich environment for improved professional learning, and also emphasises the role of the positional leader in distributing leadership in professional learning communities. Edwards points out that the role of the positional leader is challenging and complex when required to lead a group of leaders, and where the direction and focus of the learning is fluid and changeable depending on the group's co-construction. To this end, the positional leader's skills in building relational trust are important, as social trust allows the professional learning community to develop smoothly and effectively (Edwards, 2012, p. 28; Marsh, 2015; Stoll, 2011; Thornton \& Cherrington, 2014).

\section{Leadership and leadership development in ECE in Aotearoa New}

\section{Zealand}

Leadership development in ECE in Aotearoa New Zealand is regularly referred to in the literature as disturbingly lacking (e.g. Clarkin-Phillips, 2009; Cooper, 2014; Thornton et al, 2009; Thornton, 2010; Weisz-Koves, 2011). The Ministry of Education developed a strategic plan for ECE in 2002, Pathways to the Future: Nga Huarahi Arataki; within this plan was a goal to implement leadership development programmes for ECE leaders in order to strengthen leadership in ECE services. This particular goal has not been realised in the 15 years since the strategic plan was released.

New Zealand Teachers Council (NZTC) ${ }^{1}$ commissioned a report in 2009 on understandings and issues of leadership and leadership development in the ECE context in Aotearoa New Zealand: Conceptualising leadership in early childhood education in Aotearoa New Zealand (Thornton, Wansborough, Clarkin-Phillips, Aitkin, \& Tamati, 2009). The report outlines current and possible conceptions of leadership in the sector, highlights issues and dilemmas, and makes recommendations for future leadership development in the sector. The issues which are outlined are some of those highlighted in this literature review contributing to the rationale for this research study: lack of emphasis on and clarity about leadership in ECE,

\footnotetext{
${ }^{1}$ NZTC was replaced by Education Council New Zealand in 2015.
} 
lack of development and support for leaders (particularly for newly qualified leaders), and a lack of resourcing by the government for leadership development despite repeated calls for leadership development in the sector even from within the Ministry of Education (Thornton et al, 2009, p. $5-11)$.

Following that report, Thornton (2010) analysed School leadership and student outcomes: identifying what works and why, Best Evidence Synthesis iteration (Robinson, Hohepa \& Lloyd, 2009), drawing out recommendations for leadership practice which could be translated from school-sector research into the ECE context. The relevant key ideas include pedagogical leadership and goal setting, engaging with teachers in theorising and problemsolving, and the importance of development of relational trust. Thornton highlighted the discussion of research on distributed leadership with a demonstrated positive effect on student learning outcomes, as opposed to distributing leadership simply for the benefit of teachers $(2009$, p. $36-37)$.

Two recent examples of conceptions of leadership in ECE in Aotearoa New Zealand appear to demonstrate a lack of development in this area since 2009: the Ministry of Education and Aotearoa New Zealand Government's Education website has a section specifically for leadership in ECE with a follow-on section about enacting leadership to benefit " 5 out of 5" children (Ministry of Education, 2016); Te Tari Puna Ora o Aotearoa, the NZ Childcare Association, released an extensive report, Developing pedagogical Leadership in Early Childhood Education (Ord, Smorti, Carroll-Lind, Robinson, Arvay-Armstrong Read, BrownCooper, Meredith, Rickard \& Jalal, 2013). Both of these attempts to develop leadership within the sector make implicit or explicit mention of distributed leadership or professional learning communities but direct focus onto areas that commonly need development and "tools" designed to help leaders "enact pedagogical leadership" (Ord et al, 2013, p. 5). In sum, the ECE sector in Aotearoa New Zealand has been discussing and debating leadership and leadership development for many years, most clearly since Pathways to the Future: Nga Huarahi Arataki, the strategic plan for ECE (Ministry of Education, 2002), specified a goal for policy on leadership development for the sector. As described above, research in the Aotearoa New Zealand ECE context has highlighted the importance of focusing leadership development on distributed and pedagogical leadership. However, it seems that little progress has been made in terms of provision, availability and requirement 
of such leadership development. This study aims to contribute to the literature to provide positional leaders in ECE some guidance on effective leadership practices that contribute to pedagogical improvement. 


\section{Chapter three: Methodology}

\section{Introduction}

In any research project, the design and methods used are integral to the legitimacy of the findings (Cohen, Manion \& Morison, 2011, p. 115). In addition, the methodology underpinning the design has to be consistent and align with the subject matter (Ling \& Ling, 2017 , p. 2). In this project I have chosen to use a qualitative approach combined with descriptive statistics (Fraenkel, Wallen \& Hyun, 1993), in order to get a wide-angled snapshot of the ECE sector using a survey before focusing quite narrowly on effective practices within selected workplaces through focus groups and individual interviews. My epistemological approach throughout the research is interpretative as it acknowledges the need to understand not only the language people use to describe their practices and experiences, but also the need to understand how terminology and practices are given meaning within particular social contexts (Cohen et al., 2011).

This chapter is broken into four sections. It begins by summarising three key points from the literature review that contribute to the methodological decisions made in the project. Second, it discusses the methods chosen to generate data as well as my rationale for doing so. In the next section of the chapter, I describe the analytical techniques for each of the methods of data collection. Finally, in the fourth section I address ethical concerns that stem from the methodology given that the ECE community remains fairly close-knit.

\section{Aims and Methodological decisions}

Despite the many claims that distributed leadership results in improved professional learning outcomes (Clarkin-Philips, 2009; Poekert, 2012) and widespread acceptance of the benefits of distributed leadership in New Zealand (Clarkin-Philips, 2009; Timperly, 2005), there is very little empirical data on how positional leaders can distribute leadership effectively so as to improve professional learning, particularly in the New Zealand context. 
This research projects seeks to address this gap in literature by answering the following research questions:

- How does distributed leadership contribute to teachers' professional learning in early childhood education settings?

- What is the positional leader's role in facilitating distributed leadership for professional learning?

Each of these questions seeks to understand concrete practices within the sector from positional leader and teacher perspectives. To achieve this understanding it confronts a number of potential problems that were identified in the literature review. First, there is little information on how distributed leadership is practised across New Zealand. This is troubling because some of the terminology is used inconsistently across the sector, as established previously in the literature review. Second, leadership and professional learning are highly dependent on the context in which they occur. Methodologically, then, context has to be taken into account to understand practices and researchers should avoid the temptation to discover a "universal" best-practice - a consideration that requires an interpretivist methodology (Cohen et al., 2011, p.5). Third, literature on distributed leadership tends to lack concrete discussion of the role of positional leaders in fostering leadership. This results in a dearth of understanding of how leadership can be distributed within a hierarchical context, such as in the majority of ECE providers in New Zealand. Epistemologically, the academic literature related to professional learning and distributed leadership adheres to the interpretive methodology. In simple terms, the term 'interpretive' means here that the studied phenomena (in this case distributed leadership and professional learning) derive their meaning from their social uses and the practices related to them (Scotland, 2012, p. 12). This is not surprising given that leadership and professional learning are social phenomena, or occur in social settings. This project follows the same epistemological assumptions as the broader literature in that there is no 'real' distributed leadership or professional learning outside of the meaning and practices assigned to it in any given context. However, in order for the researcher to gain an informed understanding of the topic, research into the various conceptions of the terms necessarily accompanies the investigation into how participants use them and the way 
participants' ideas are made sense of (Ling, 2017, p.33). As such, it seeks to identify the ways in which the terms are practiced and given meaning, theoretically, in the sector generally and in effective workplaces more specifically.

The need to gain an understanding of the sector as a whole led to the decision to use a survey - a method that allows wide distribution without the time and financial costs of hosting more qualitative forms of research (Cohen et al., 2011, p. 82, 109²). However, surveys can also tend towards positivist principles in that they can present pre-determined categories and understandings of particular phenomena (Cohen et al, 2011, p. 6). To balance this tendency, the survey used to collect data contained qualitative sections; this is detailed in the next section.

More traditional qualitative methods, focus groups and interviews, were used to investigate the practices of a select number of high-quality ECE services. This is because these methods allow for deeper understanding of individual and group experiences (Scotland, 2012, p. 12). In addition, they allow participants to set the terms of the discussion to some degree (Newby, 2014, p. 356). So although the general topics of distributed leadership and professional learning are pre-set by the researcher, participants can define and explain the practices relating to these terms differently to how the researcher has thought of them.

As a whole, the methods of data collection constitute a mixed-methods approach that allows for a broad understanding of the sector, some comparison within the sector and detailed exploration of select workplaces. The workplaces themselves act as case studies in that they are meant to provide insight into how leadership is distributed and professional practice enacted in a variety of contexts. Although some commonalities may be found, the research does not seek to discover or construct a single 'best-practice' for the sector.

\footnotetext{
${ }^{2}$ Cohen et al. (2011, p. 109) note the cost of non-electronic surveys and they also raise concerns over access to internet connections. Considerations for online surveys do not seem as pressing now as when their text was published as internet is widely available and survey platforms fairly recognisable to participants.
} 


\section{Methods of data collection}

\section{Survey}

Thornton and Wansborough (2012) have conducted the only broad survey, to date, to examine professional learning within the New Zealand ECE sector. Using the same survey instrument would allow the researcher to validate or challenge earlier findings and also to map changes over time. The Thornton and Wansborough survey gathered minimal data about the participants themselves, focusing instead on six categories of questions related to professional learning. The survey tool generated primarily quantitative data through a Likert-type questionnaire, though groups of questions allowed the users to add qualitative comments.

The Thornton and Wansborough survey was adapted from the survey entitled Professional Learning Communities Assessment - Revised (PLCA-R) by Hipp and Huffman (2010; American Institutes for Research, 2017); and the iteration of the survey used in this research was further adapted to align with the research questions of this project. Specifically, the current survey includes a section of questions specific to leadership distribution and removes a section on relational trust (termed "Supportive conditions-Relationships" in the original PLCA-R (American Institutes for Research, 2017)), as this was deemed extraneous to the current project. In addition, participant data was changed from the original to reflect the ECE sector, asking participants to identify which type of service they work in, how long they have been registered as a teacher, and whether or not they work in management. The original PLCA-R allowed flexibility to adapt this type of participant-specific data to suit the group being investigated ${ }^{3}$ (American Institutes for Research, 2017). The survey used in this project also used a five and seven point Likert-type scale rather than the four point scale initially used in the PLCA. This was an accidental outcome of the researcher being unfamiliar with the electronic platform, but as the data was used to look at trends across the sector rather than compare exact values across iterations of the tool, it did not have a significant impact on the findings.

\footnotetext{
${ }^{3}$ Initial research using the tool was conducted in primary schools; the flexibility of the tool was meant to allow for application in different educational contexts.
} 
In order to get a broad representation of the ECE sector, the researcher investigated potential methods of survey distribution. An online survey was determined most appropriate as it was cost efficient and required little administration for participants (other than navigating the survey site). Given that the survey was explicitly for registered teachers, sourcing email lists through the Education Council (the registering body for teachers in Aotearoa New Zealand) was deemed most likely to allow for the broadest reach possible in effect, the potential to reach the entire research population. However, the potential ethical downsides of sourcing and using individual email addresses (for example, the invasion of individuals' privacy and the EC's potential reservations about supplying email lists) outweighed the potential gains. Instead, an email list of ECE services was sourced from the Ministry of Education (MoE) website. Ethical implications and decisions about this list are dealt with later in this chapter.

The MoE email list provides a comprehensive list of services alongside service types so that those suitable for the research (those with positional leaders and teaching teams) could be selected. This type of list also has the potential to negate issues related to convenience sampling (advertising the survey through specific professional networks or groups, for example) in that it does not discriminate based on philosophical approaches, the social networks of teachers and leaders, or regional proximity. At the same time, where individual email addresses would allow reach throughout the population of teachers and positional leaders in ECE, the MoE email lists had a single email address for services and sometimes for entire networks (e.g. some kindergarten associations). To account for this, the researcher sought to find centre or kindergarten specific email addresses where possible by contacting umbrella organisations.

A further sampling consideration that arose from the list is the distribution of the email about the survey to broader teams of teachers. As the findings section illustrates, the response rate of positional leaders was very high in proportion to teachers. As such, one can hypothesise that the email with links to the survey was more often received and responded to by the person who oversees organisational email. One can also question whether positional leaders who passed on email would be more likely to distribute leadership. This is merely conjecture, but is worth methodological consideration. 
In sum, the survey had the opportunity to reach a broad base and because every ECE service that employs the target population was invited to participate, the sampling method was voluntary. However, as the target population was the individuals within the organisations rather than the organisations themselves, communication channels within the organisations may have resulted in fewer teachers participating proportionally than positional leaders.

\section{Interviews and focus groups}

Interviews and focus groups allow researchers to gain a deeper understanding of participants' experiences (Mertens, 2014, p. 382). In semi-structured methods in particular, the researcher guides the general topic of discussion but the participants are given opportunities to determine the language and themes important to their particular situation (Newby, 2014, p. 356). In this research, a semi-structured approach was adopted so that participants were able to identify the elements in their workplace that promoted distributed leadership and professional learning. In addition, they were given the opportunity to discuss the effect of the centre's professional learning on their practices.

The researcher designed the interview and focus group questions with this broader methodological consideration in mind. Guiding questions were submitted as part of the ethics proposal for the project (see Appendix A) but within the interviews the researcher used techniques from coaching and mentoring literature to enable participants to take direction of the discussion. In brief, the method intentionally uses silence (pauses in the conversation) to allow the participant(s) time to reflect and dig more deeply into the topic.

Interviews were used with positional leaders within each of the services. This was to allow a more focused consideration of their leadership approaches and practices. Except in one service, focus groups were conducted with the teaching team but not the positional leader(s). This was designed to promote a free flow of ideas in a group that was not hierarchically structured. In other words, the design meant to gain data without undue influence from the positional leader. The one service that requested to have its positional leaders present did so on the grounds that the positional leaders learn from feedback and would thus benefit from the discussion. This interview situation is addressed further in the ethical considerations at the end of this chapter. 
Unlike the survey, the interviews and focus groups sought to gain a deeper understanding of services that were identified as performing well in their leadership and professional learning. This identification is necessarily subjective ${ }^{4}$ so I relied on expert opinion in the field to find appropriate services. I sought recommendations from the head of an early childhood tertiary institution, a prominent early childhood academic and researcher, and the Senior Teacher team within a kindergarten association.

In the final decision of what specific services to approach, I attempted to include each of major service types as well as a diversity of clientele (see Table 3.1). This meant approaching a kindergarten, a community-based centre, a private centre and a Māori immersion centre. In addition, I varied the clientele they serviced by selecting one urban, one suburban and one small town (semi-rural) service as well as a service located in a regional city.

Table 3.1: Defining features of interview participant services

\begin{tabular}{|l|l|}
\hline Service type & Defining features \\
\hline Private centre & Suburban \\
\hline Community centre & Urban \\
\hline Kindergarten & Semi-Rural \\
\hline Māori immersion centre & Regional city \\
\hline
\end{tabular}

Interviews and focus groups required considerable administrative efforts as the researcher was engaged in full time employment while researching and each of the services had their regular time commitments alongside unforeseeable difficulties in participating in the research (such as illness of key personnel and issues within the services that demanded priority). Unfortunately, the interview and focus group planned with the Māori immersion

\footnotetext{
${ }^{4}$ I initially considered using ERO reports to determine appropriate centres because ERO assesses all ECE services in New Zealand and always uses the same criteria. However, feedback on ERO reports tends to be standardised with very little evaluative language that could be used to distinguish high performing services.
} 
centre was postponed and eventually cancelled altogether. The timing of this did not allow for a suitable replacement.

\section{Data analysis}

The quantitative data from the survey allowed the researcher to distinguish perceptions of practices across the ECE sector as well as between groups of participants (see Table 3.2). Typically, quantitative data between groups can be analysed to determine if differences are significant (i.e. if they are likely not due to chance) (Cohen et al, 2011, p. 641). There is debate about the legitimacy of assessing Likert-type data in this way, due to the fact that numerical values are assigned to Likert values in order to determine significance. However, because the Likert scales do not correspond to real numeric intervals (i.e. participants may not see the difference between 'strongly agree' and 'agree' the same as the difference between 'agree' and 'neither agree nor disagree') (Cohen et al, 2011, p. 387), statistical analysis may be inaccurate. In addition, as the section above indicates, the sampling for the research was not random: some groups may have been more inclined or able to complete the survey than others. As such, significance cannot be decided with any confidence (Cohen et al, 2011, p.155). Rather than use the data to make inferences about the sector as a whole, they are used in a primarily descriptive manner.

Table 3.2: Groups identified in the survey

\begin{tabular}{|l|l|l|}
\hline \multirow{2}{*}{ Type of service } & \multicolumn{2}{|c|}{ Role within the service } \\
\hline & Kindergarten Teacher & Kindergarten Positional leader \\
\cline { 2 - 3 } & Centre Teacher & Centre Positional Leader \\
\hline
\end{tabular}

The survey allowed participants to comment at the end of each section of quantitative questions. These data allow the participants to clarify or expand on their feelings about the section, a particular question, or the survey as a whole. These data were coded inductively, meaning that the researcher grouped the data through common themes, but that these themes were derived from the comments rather than from pre-determined categories (Cohen et al., 2011, p.5). An inductive coding approach is appropriate for this part of the 
data because participants were given the opportunity to define, expand on or explain their understanding of the survey topics within their practices.

The interviews and focus groups generated extensive data that were transcribed and then coded, also inductively. Because of the amount of data, I re-read each transcript multiple times before the themes emerged. In total, three interviews (each approximately 45 minutes long) were conducted - one with each of the positional leaders at the services. In addition, three focus groups were recorded and transcribed (each approximately one hour long).

The most difficult aspect of this coding was distinguishing differences and similarities between the interviews and focus groups; often themes were similar because participants used common language to describe their practices, but their processes and practices that they described as supporting these themes varied. There were also, unsurprisingly, similarities between the positional leaders and their teaching teams, though again the focus of discussions varied due to the positional leaders focussing specifically on their practices and processes whereas the teachers tended to speak more generally about the team and service practices. In the end, fourteen themes were identified. These were then regrouped into two main sets (in response to the two research questions) and six subsets to make their relation to one another clearer and to make the discussion section more coherent. Newby (2014, p. 473) describes this iterative process as a repetition of coding and tagging, which gradually "refines, re-orders and reduces in scale the data we began with."

\section{The ethics of working in a close community}

This section details the steps taken to ensure anonymity where possible in the research as well as the decisions that reduce the potential for harm. In addition, it addresses the ethical issue of the positional leaders of one service wanting to observe the focus group with their teaching staff.

Although there are thousands of ECE teachers across New Zealand and hundreds of individual services, the ECE community is relatively tight-knit in that specific academics and leaders in the sector are widely known and relationships occur across different service types 
and regions within the sector. This may be because the professionalization of ECE is still relatively young in New Zealand and because trained teachers are sought in all service types in the sector. In terms of research, it raises ethical questions about anonymity of participants.

Anonymity is often an ethical requirement of research because it reduces the chance of participants or the communities they work in experiencing harm as a result of their participation (Cohen et al, 2011, p.85). For example, a teacher participant who details poor leadership practices must be protected from retribution by their positional leader, and anonymity allows for this protection. However, in tight-knit communities, features of a service or practice described by participants may be identifiable to others. In this case, additional means of assuring anonymity, or mitigating potential harm, may be required.

This research project was designed to benefit to the ECE community and reduce any potential for harm. It did this in the design of data collection as well as in the reporting:

1. The survey was accessed by participants through an internet link and did not solicit any information that could lead to personal identification. The only individual-specific data collected was the IP address of the participant as this is a standard feature of 'Qualtrics' reporting and presumably allows the researcher to determine if the same participant has submitted more than one survey response. In this project, the IP address was not used in the analysis as multiple teachers could access the survey from the same workplace.

2. The services selected for the interview portion of data collection had a number of identifying features (such as the number of teachers employed there, the client groups they serviced, their urban/suburban/rural location, and so on). In addition, some of the teaching practices described may be identifiable to others in the sector. To address this concern, the researcher:

- Focused on high-achieving services so that identification would not result in harm to the services, their employees or the communities they service.

- Sought to maintain anonymity where possible by changing the name of the services and participants when reporting the findings. 
Standard ethical research procedures were used in the establishment of this research project. Survey participants were invited via an email which outlined the project and explained that consent to participate was given by engaging in the anonymous online survey (see Appendix B). Interview participants were approached via email and phone calls, and asked if they would be willing to consider participating by reading the information sheets and consent forms (see Appendix C and Appendix D). After the interviews, participants were sent a copy of their transcripts to confirm accuracy before data analysis; three participants made small changes to grammar and spelling. Finally, interview participants were sent a summary of the research.

The topic of this project - professional learning - and the sector's aspirations to embrace professional learning through the distribution of leadership (Ord et al, 2013, p. 12) also pose challenges to traditional conceptions of risk of harm. This became clear when at one of the services the positional leaders wanted to be part of the teachers' focus group. The potential power dynamic between positional leaders and employees, and the chance for harm associated with it, could be deemed ethically compromising. However, the approach taken by this team in its development of relational trust, professional learning, goal setting and feedback, are all based on open communication and learning from this communication. Exclusion from the interview would have contradicted the types of practices that the service was effective for using. In addition, it would have presumed power dynamics which the service has tried to reduce if not get rid of altogether. The ethical decision to allow the positional leaders to observe the focus group was not taken lightly, nor was it a decision that would be appropriate for all research in this area.

\section{Trustworthiness}

This small-scale study is presented as an insight into leadership and professional learning practice in the ECE sector in Aotearoa New Zealand. The researcher uses a qualitative approach to explore possible explanations and solutions to a particular issue in educational leadership practice. Therefore, the study is not intended to represent the sector as a whole, and the results are not designed to be reproducible. 
The survey was completed by a generous number of participants, 614 , which is considered a trustworthy sample size according to Johnson and Christensen (2008). The survey is analysed using descriptive statistics, not quantitative analysis, because of the issues with Likert scales and self-reporting as described earlier in this chapter.

Interview and focus group participants were chosen on recommendation from sector leaders, as detailed above. Participants provided informed consent, and opportunities were given for participants to check the data for accuracy. Interview and focus group data were coded inductively multiple times to distil a relatively trustworthy interpretation of the key ideas in the data.

\section{Conclusion}

This research project sought to provide the ECE sector with a greater understanding of its use of professional learning and distributed leadership. It also sought to serve the community by highlighting ways in which successful services from a variety of contexts practice effective leadership and professional learning. The research is designed with these aims in mind and is underpinned by a methodological approach that understands knowledge as being generated within specific social contexts. With this in mind, the nonnumeric data have been coded based on the words and ideas that participants used rather than pre-conceived ideas about good practice in the area.

The qualitative approach used in the study aims to capture a wide angled view of the sector as a whole but also to dig deeply into effective practices. In all of the design, data gathering and reporting, the researcher sought to benefit the community and minimise any potential harm to participants and their communities. 


\section{Chapter four: Survey findings}

\section{Introduction}

This chapter reports the findings from the initial survey of registered teachers and positional leaders across the ECE sector; the next chapter details the individual interviews and focus groups that were later conducted with centres recommended by sector leaders. Although there are commonalities in the findings across the two data sources, they are examined separately here and then analysed together, thematically, in the discussion chapter that follows.

The survey had an exceptional response, especially amongst positional leaders in the sector. It allows for a broad understanding of registered teachers' perceptions of leadership and professional practice as well as for comparisons between service types (kindergartens versus education and care centres) and roles (positional leaders versus teachers). Respondents were asked to answer Likert-style questions in each category by selecting the extent they agreed or disagreed with statements. These answers were then given a numerical value between 1 and 5 where 1 equated to 'strongly agree', 3 was 'neutral', and 5 was 'strongly disagree'. These numerical values allowed for a descriptive analysis. In addition, each section of the survey contained one text box where respondents could further articulate their experiences and opinions.

This chapter examines the data from the survey by beginning with broad trends before examining differences and similarities between groups. The quantitative data are examined primarily by using mean responses. In the final section on the quantitative data, where participants are broken into four groups based on their position within their organisation and the type of ECE service they work in, the data are reweighted to account for over and under-representation of specific groups within the participant sample.

Finally, the chapter ends with a general discussion of the qualitative data and how they are treated within the rest of the thesis. It breaks down the contribution of qualitative data by 
participant group and puts forward a justification for using these data together. It suggests two categories to which the data contribute:

1. Identifying barriers to practices within the workplace

2. Identifying good practice and strategies within the workplace

\section{Background and response rate of the survey}

The survey questionnaire replicated a survey conducted by Thornton and Wansbrough (2012), which in turn was based on a survey developed by Hipp and Huffman (2010); however, the current survey added a six-question section on Distributed Leadership for Professional Learning and removed a section pertaining to relational trust. The survey was conducted using the Qualtrics survey platform and advertised through direct email contact by the researcher, using the Ministry of Education's directory of ECE kindergartens and education and care services. Response to the survey was high (631 respondents) ${ }^{5}-$ I would like to thank the many teachers and positional leaders who took the time to answer it.

The responses were unevenly distributed amongst the registered teacher population, with an over-representation of positional leaders in both kindergartens and E\&C services. The response rates are shown in Table 4.1.

Table 4.1: Survey respondents by role and service type

\begin{tabular}{|l|l|l|l|}
\hline & $\begin{array}{l}\text { Positional } \\
\text { Leader }\end{array}$ & Teacher & Total \\
\hline Kindergarten & 125 & 74 & 199 \\
\hline $\begin{array}{l}\text { Education and } \\
\text { care (E\&C) }\end{array}$ & 353 & 79 & 432 \\
\hline Total & 478 & 153 & \\
\hline
\end{tabular}

The high number of positional leadership roles among survey respondents might be explained by the survey distribution method. The researcher contacted individual centres and kindergartens (see methods chapter for details) through organisational emails. It is

\footnotetext{
${ }^{5}$ This number cannot be compared against the total number of emails sent as the emails were sent to providers, and providers were asked to distribute the link to the survey amongst their teams. It is conceivable that, as an example, a single team might have provided six responses while another may not have responded at all.
} 
likely, in retrospect, that positional leaders received these emails on behalf of their organisations and either did not distribute them to their teams (as was requested in the email) or teachers did not take the opportunity to participate. This issue mirrors the data collected by Thornton and Wansbrough (2012) in their initial survey, though to a slightly greater degree (i.e. in this survey the proportion of positional leaders is slightly higher than in Thornton's and Wansborough's research). It is also notable that the skewed participation towards positional leaders was more prominent in EEC where $82 \%$ of respondents identified as positional leaders. This may be due to a number of reasons, however it is possible that teacher response rate in kindergartens was due to the higher proportion of trained teachers in this type of service (the survey stipulated that it was for trained teachers).

Despite this skew in responses, the overall numbers from each service type and each role was excellent. As a comparison, the survey by Thornton and Wansborough received a total of 214 responses; the current survey received almost three times that amount. This allows for comparison between the two surveys and also within the present survey: between categories, questions, and participant characteristics.

\section{Treatment of data}

Because of the skew in response rates towards some groups, the data were broken down in a variety of ways. First, response means were calculated for the entire sample, then by sector and position. These divisions allowed for easy comparisons (i.e. comparing the means for each question between positional leaders and teachers, or between kindergartens and centres). The next calculation separated the data into four groups to gauge differences in responses when position and place of work are combined. These data were calculated for the four groups (Kindergarten leaders, Kindergarten teachers, Centre leaders, Centre teachers) and then the means of each group were used to recalculate the overall responses. In other words, this last calculation attempted to provide a picture of responses across the sector that were not skewed by different response rates; each of the four groups was given equal weighting. From these data, a different picture of group responses emerged.

This section begins with general trends and then details differences within and between groups. For simplicity, the categories of the survey have been numbered and provided 
truncated names, as is shown in Table 4.2. Within each of these categories, the data drawn upon is quantitative unless otherwise stated. The full wording of questions within each category can be found in Appendix E. The term 'positively' is used to describe answers that strongly agree or agree with statements (for example, that agree with the statement 'Financial resources are made available to support professional development') whereas 'negatively' denotes the opposite.

Table 4.2: Categories of the survey

\begin{tabular}{|l|l|}
\hline Category & Truncated name \\
\hline 1 & Collective learning and practice \\
\hline 2 & Shared personal practice \\
\hline 3 & Shared, supportive leadership \\
\hline 4 & Supportive structural conditions \\
\hline 5 & Distributed leadership for professional learning \\
\hline
\end{tabular}

\section{General trends to the Likert-style questions}

Responses on the survey were skewed for all groups on all numerically assessed questions, towards positive answers, or answers that agreed with the statements. From qualitative comments on the surveys, it was evident that participants understood which answers were indicative of good practice and these were chosen to a far greater degree than negative answers. One respondent wrote, for example, "Whilst I would like to place 'strongly agree' for all these statements, the practicality is that this is not always possible due to time restraints etc. Otherwise I would have put 'strongly agree' for all" (EEC Positional Leader). This indicates that respondents understood answers as 'right' or 'wrong'. The desire to choose the 'right' answer is particularly notable on the questions that assess the structural conditions within the sector. Throughout the qualitative data, participants raise concerns over structural supports (primarily time and money) but even in this category of questions, respondents assessed the questions positively (mean answers to statements such as 'financial resources are made available to support professional development' corresponded most closely to 'agree').

Despite the skew towards positive answers, some variations between categories and individual questions are notable. The categories assessing distributed leadership for professional learning (5) and collective learning and practice (1) both rated positively, 
whereas supportive structural conditions (4) rated the most negatively across all questions. Shared personal practice (2) and shared supportive leadership (3) each had mixed results from question to question.

The table below (Table 4.3) codes responses to the five sections of questions as relatively positive and negative across the sector. Because the statements are all worded positively, scores that agree more with the statements are deemed 'positive' assessments of the workplace whereas scores that disagree more strongly with the statements are deemed 'negative' assessments of the workplace. The coding was determined by taking the average of numerical answers across all questions to form a baseline. Questions whose average answers are within one standard deviation (sd) of the overall average are considered 'average' and therefore not included in the chart, those outside of one standard deviation from the mean are considered either positive or negative depending on whether they agreed or disagreed with the statement. This calculation is meant only to indicate how positively all participants rated the question in relation to the other questions, and is not adjusted to reflect different groups.

Table 4.3: Proportion of survey questions rated positively and negatively by category

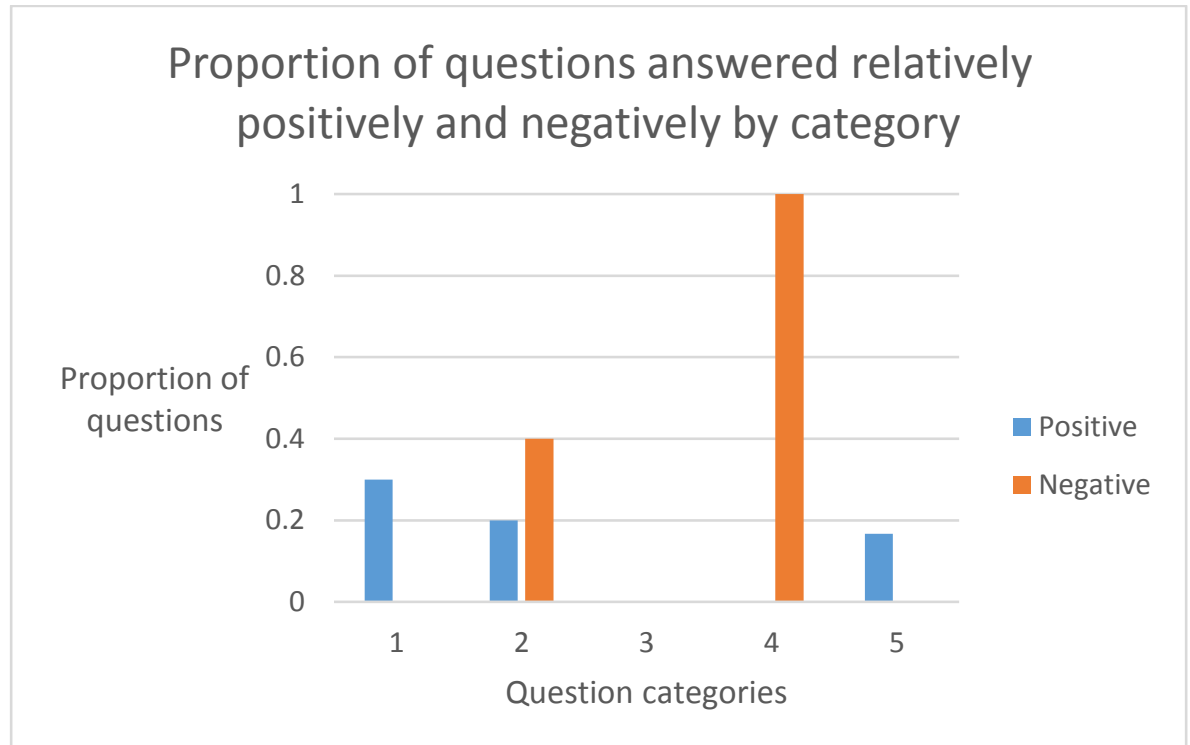


Within these categories, there was considerable variability between individual questions. Table 4.4, below, lists the questions that ranked most negatively and positively across the survey as a whole.

Table 4.4: Survey questions responded to most negatively and positively

\begin{tabular}{|c|c|c|}
\hline & Question (truncated) & Category \\
\hline \multirow{3}{*}{$\begin{array}{l}\text { Relatively } \\
\text { negative } \\
\text { responses }\end{array}$} & Opportunities exist for peer feedback & 2 \\
\hline & $\begin{array}{l}\text { Opportunities exist for mentoring and } \\
\text { coaching }\end{array}$ & 2 \\
\hline & $\begin{array}{l}\text { All questions relating to supportive structural } \\
\text { conditions }\end{array}$ & 5 \\
\hline \multirow{4}{*}{$\begin{array}{l}\text { Relatively } \\
\text { positive } \\
\text { responses }\end{array}$} & $\begin{array}{l}\text { Teachers plan and work together to find } \\
\text { solutions }\end{array}$ & 1 \\
\hline & $\begin{array}{l}\text { Teachers' dialogue reflects respect for diverse } \\
\text { ideas }\end{array}$ & 1 \\
\hline & $\begin{array}{l}\text { Teachers informally share suggestions to } \\
\text { improve children's learning }\end{array}$ & 2 \\
\hline & $\begin{array}{l}\text { I contribute to decisions about professional } \\
\text { learning in my workplace }\end{array}$ & 5 \\
\hline
\end{tabular}

\section{Comparison between groups}

\section{Differences between teachers and positional leaders}

On all questions that sought participants' views of practices, leaders indicated agreement with statements more than teachers. As the questions were all stated positively (e.g. 'the positional leader incorporates advice in decisions made') the data clearly show a more positive interpretation of leadership and professional learning at their workplaces than teachers. On all questions, the difference in mean scores between leader and teacher groups fell between zero and one. This reflects the overall skew towards positive responses on all questions for all groups. Table 4.5, below, shows the frequency of difference in means at intervals of one tenth of a whole number (0.1-0.9). 
Table 4.5: Frequency of difference of means between teachers and positional leaders

\begin{tabular}{|l|l|l|l|l|l|l|l|l|l|}
\hline $\begin{array}{l}\text { Difference } \\
\text { between teacher } \\
\text { and leader means }\end{array}$ & $\begin{array}{c}0.1- \\
02\end{array}$ & $\begin{array}{c}0.2- \\
0.3\end{array}$ & $\begin{array}{c}0.3- \\
0.4\end{array}$ & $\begin{array}{c}0.4- \\
0.5\end{array}$ & $\begin{array}{c}0.5- \\
0.6\end{array}$ & $\begin{array}{c}0.6- \\
0.7\end{array}$ & $\begin{array}{c}0.7 \\
0.8\end{array}$ & $\begin{array}{c}0.8- \\
0.9\end{array}$ & $\begin{array}{c}0.9- \\
1\end{array}$ \\
\hline $\begin{array}{l}\text { Number of } \\
\text { questions with } \\
\text { this difference }\end{array}$ & 2 & 6 & 7 & 4 & 8 & 5 & 0 & 1 & 0 \\
\hline
\end{tabular}

From these data, it is apparent that the differences in means between teachers and positional leaders fell most frequently between 0.3 and 0.6 . As such, differences from 0 to 0.3 range indicate relatively close agreement between positional leaders and teachers, from 0.2 to 0.6 indicate a more average level of disagreement, and from 0.6 through 0.8 indicate a relatively high level of disagreement. Again, this is strictly in relative terms, based on the overall narrow range of differences in means across groups.

The first of the question category, Collective Learning and Practice, had relative agreement across all questions. This section had the highest level of consistency across all groups of respondents.

The Shared Personal Practice category had higher difference of means (>0.6) between leaders and teachers on the statement 'Opportunities exist for teachers to provide feedback to peers related to strengthening teaching practices'. Leaders agreed with the statement more strongly than teachers.

The third category, Shared and Supportive Leadership, contained the most sections with high difference of means between teachers and leaders (three of eight questions had greater than 0.6 difference in mean), and also the question with the strongest disagreement. The statements with greatest difference are listed here with the strength of disagreement following in brackets:

- The positional leader incorporates advice in decisions made $(>0.6)$

- The positional leader is proactive and addresses areas where support is needed $(>0.6)$

- Leadership is promoted and nurtured among teachers $(>0.8)$ 
In Supportive Structural Conditions high differences of means between positional leaders and teachers occurred on two of the three statements: 'Time is provided to facilitate collaborative learning and shared practice' (difference between means $>0.6$ ) and 'Financial resources are made available to support professional development' $(>0.6)$.

The final category of statements, Distributed leadership for professional practice, contained just one statement with a high difference of means. 'I am given opportunities to lead professional learning within my team' had a difference of means greater than 0.6 between positional leaders and teachers.

Table 4.6: Areas of greatest disagreement between teachers and positional leaders, reweighted data by service type

\begin{tabular}{|l|l|l|l|}
\hline & $\begin{array}{l}\text { Kindergarten } \\
\text { difference }\end{array}$ & $\begin{array}{l}\text { EEC } \\
\text { difference }\end{array}$ & $\begin{array}{l}\text { Mean } \\
\text { Difference }\end{array}$ \\
\hline $\begin{array}{l}\text { Opportunities exist for teachers to provide } \\
\text { feedback to peers related to strengthening } \\
\text { teaching practices }\end{array}$ & 0.5 & 0.6 & 0.6 \\
\hline $\begin{array}{l}\text { The positional leader incorporates advice in } \\
\text { decisions made }\end{array}$ & 0.4 & 0.9 & 0.7 \\
\hline $\begin{array}{l}\text { The positional leader is proactive and addresses } \\
\text { areas where support is needed }\end{array}$ & 0.4 & 0.9 & 0.7 \\
\hline $\begin{array}{l}\text { Leadership is promoted and nurtured among } \\
\text { teachers }\end{array}$ & 0.6 & 1.0 & 0.8 \\
\hline $\begin{array}{l}\text { Time is provided to facilitate collaborative } \\
\text { learning and shared practice }\end{array}$ & 0.3 & 0.9 & 0.6 \\
\hline $\begin{array}{l}\text { Financial resources are made available to } \\
\text { support professional development }\end{array}$ & 0.4 & 0.9 & 0.6 \\
\hline $\begin{array}{l}\text { I am given opportunities to lead professional } \\
\text { learning within my team }\end{array}$ & 0.5 & 0.9 & 0.7 \\
\hline
\end{tabular}

From these data, four of the seven questions focus on issues of leadership and the perceived difference in agency between teachers and positional leaders. Importantly, this not only relates to the relative agency of the positions but also the extent to which positional leaders and teachers feel that teachers have agency within the services. Given the greatest difference between teachers and leaders within kindergartens and EEC is about the extent to which leadership is "promoted and nurtured among teachers," it is fair to note that positional leaders' self-perception about this aspect of their practice is markedly different from the teachers' experience. 
Two of the questions relate to structural supports, and here again it should be noted that while teachers and positional leaders work in the same services, teachers perceive limitations to money and time more acutely. Whether this is due to actual differences in the distribution of resources within centres, positional leaders feeling more responsible for resourcing decisions, or some other difference in experience is unclear.

Finally, the other question with a high level of disagreement relates to the peer feedback related to teaching and learning. This indicates a different understanding of the extent to which shared personal practices are encouraged or enabled in the services.

\section{Differences between kindergartens and early education and care centres}

Similarly, mean differences between kindergarten and EEC respondents also fell in a narrow range; the main difference between the groups was that the majority of kindergarten participants tended to respond more positively (agree more strongly) than EEC participants. The only exceptions to this trend were on the statements 'Financial resources are made available to support professional development' and 'Teachers are encouraged to share professional learning mainly after attending external professional development'. On these two statements, EEC participants agreed more strongly than their kindergarten counterparts.

The differences between provider types were minimal in all questions, generally less than 0.2 difference in means and never greater than 0.3 difference in means. This appearance of agreement, however, is slightly misleading, as the next section makes clear. The dominance of EEC Leaders within the EEC group ( $n=353$ positional leaders versus 79 teachers) resulted in a positively skewed overall mean within this provider group.

\section{Comparison when combining role and service type}

This section uses data that have been reweighted so that each of the four groups are represented equally when calculating differences in responses. This calculation was done so that the larger groups (particularly centre-based positional leaders) did not skew the overall difference between groups. Low mean scores again indicate agreement with questions (one being the strongest possible agreement) and vice versa (five being the highest). 
Table 4.7: Mean group score by category

\begin{tabular}{|l|l|l|l|l|}
\hline Category & $\begin{array}{l}\text { Kindergarten } \\
\text { Pos. Leaders }\end{array}$ & $\begin{array}{l}\text { Kindergarten } \\
\text { Teachers }\end{array}$ & $\begin{array}{l}\text { Centre-based } \\
\text { Pos. Leaders }\end{array}$ & $\begin{array}{l}\text { Centre-based } \\
\text { Teachers }\end{array}$ \\
\hline $\begin{array}{l}\text { Collective learning and } \\
\text { application }\end{array}$ & 1.31 & 1.57 & 1.53 & 1.81 \\
\hline Shared personal practice & 1.44 & 1.71 & 1.58 & 2.07 \\
\hline $\begin{array}{l}\text { Shared and supportive } \\
\text { leadership }\end{array}$ & 1.41 & 1.83 & 1.55 & 2.31 \\
\hline $\begin{array}{l}\text { Supportive structural } \\
\text { conditions }\end{array}$ & 1.97 & 2.28 & 1.92 & 2.78 \\
\hline $\begin{array}{l}\text { Distributed leadership } \\
\text { for professional learning }\end{array}$ & 1.39 & 1.71 & 1.49 & 2.11 \\
\hline
\end{tabular}

Table 4.7 indicates a number of interesting trends. First, in all cases, teachers in EEC disagreed with statements more than any other group across all question categories. Positional leaders in kindergartens agreed more than any other group to all questions except having financial resources available for professional development (question group 4, question 2). What becomes apparent from these then, is that the perception of practices, conditions and leadership were perceived to be best by kindergarten positional leaders and worst by EEC teachers.

Second, when corrected for weighting, the mean difference in answers between teachers and positional leaders is greater in EEC than kindergartens (the mean of EEC differences is .602 whereas for Kindergarten it is .316). Although convenience sampling was used, the high number of participants in the survey is notable, and this may indicate important differences in the perception of teachers and leaders depending on their service type.

Third, despite the differences within service types, there are still much greater gaps in perception between positional leaders and teachers than between service providers, even when the data are reweighted.

On top of these three trends, the reweighting of the data highlights more subtle differences in specific questions that each of the four groups differed from most relative to the others. 


\section{EEC Teachers}

In absolute ratings, EEC Teachers agreed most with the statement, "Professional development focuses on teaching and learning." They disagreed most with the statement, "Time is provided to facilitate collaborative learning and shared practice." Within the question categories, EEC Teachers, alongside both Kindergarten groups, agreed most with questions relating to Collective Learning and Practice.

In relation to the other role and service type groups, EEC Teachers had the highest mean disagreement of all groups; this carried across question groups as well as on the survey as a whole. The strongest differences between EEC teachers and their colleagues were on the questions:

- Leadership is promoted and nurtured among teachers.

- Time is provided to facilitate collaborative learning and shared practice.

- I am given opportunities to lead professional learning within my team.

In each of these questions, the EEC Teachers disagreed with the statements far more than other groups.

\section{EEC Positional Leaders}

In absolute ratings, EEC Positional leaders, like their teachers, disagreed most with the statement, "Time is provided to facilitate collaborative learning and shared practice." This group agreed most with the statement, "I contribute to decisions about professional learning in my workplace." On the level of question categories, EEC Positional Leaders agreed most strongly with the group of questions about Distributed Leadership for Professional Learning.

EEC Positional Leaders differed from the mean of all groups by a large amount on two questions:

- Leadership is promoted and nurtured among teachers.

- Financial resources are made available to support professional development.

Both of these questions were agreed with more than the overall mean. In the case of financial resources, EEC Positional Leaders were unique in the positivity of their response to 
the statement; here the difference in mean between EEC Leaders and Teachers was 0.91 this was extremely high within this dataset.

\section{Kindergarten Positional Leaders}

Kindergarten Positional Leaders agreed most strongly with the statement, "Teachers plan and work together to find solutions to meet the diverse needs of children and their families/ whānau." They disagreed most with the statement, "Financial resources are made available to support professional development."

In relation to the other groups, Kindergarten Positional Leaders differed most in their mean response to:

- Leadership is promoted and nurtured among teachers.

- Opportunities exist for teachers to provide feedback to peers related to strengthening teaching practices.

In both questions they agreed with the statement far more than the combined means of the other groups. For the second statement, there was very little variation in the means of the EEC Positional Leaders and Kindergarten Teachers: the Kindergarten Positional Leaders appear uniquely positive compared to the others.

\section{Kindergarten Teachers}

Kindergarten teachers also disagreed most with the statement, "Financial resources are made available to support professional development." They agreed most with the statement, "Teachers informally share ideas and suggestions for improving children's learning."

This group had the least amount of variation from the means of the other groups. The biggest reported difference was in their disagreement to the statement:

- Financial resources are made available to support professional development.

In sum, differences between the combined service type and position of participants showed the greatest difference in means between answers. In order to represent groups fairly, it is important to re-weight the data so that those who are over or under-represented do not skew the overall picture of the sector. In particular, EEC Teachers were proportionately 
underrepresented in the participant sample and this group had the least positive response to most questions in the survey. EEC positional leaders were overrepresented and this group tended to score statements very close to the mean of kindergarten teachers and positional leaders. As a result, the mean responses to questions appear less differentiated unless the data is reweighted by service type and position combined.

Table 4.8: Notable survey responses by service type and role

\begin{tabular}{|l|l|l|l|}
\hline & $\begin{array}{l}\text { Question responded to } \\
\text { most positively }\end{array}$ & $\begin{array}{l}\text { Question responded } \\
\text { to most negatively }\end{array}$ & $\begin{array}{l}\text { Question with } \\
\text { biggest difference in } \\
\text { response with other } \\
\text { groups }\end{array}$ \\
\hline $\begin{array}{l}\text { EEC Positional } \\
\text { Leaders }\end{array}$ & $\begin{array}{l}\text { I contribute to decisions } \\
\text { about professional } \\
\text { learning in my workplace }\end{array}$ & $\begin{array}{l}\text { Time is provided to } \\
\text { facilitate } \\
\text { collaborative } \\
\text { learning and shared } \\
\text { practice }\end{array}$ & $\begin{array}{l}\text { Financial resources } \\
\text { are made available } \\
\text { to support } \\
\text { professional } \\
\text { development }\end{array}$ \\
\hline EEC Teachers & $\begin{array}{l}\text { Professional } \\
\text { development focuses on } \\
\text { teaching and learning }\end{array}$ & $\begin{array}{l}\text { Time is provided to } \\
\text { facilitate } \\
\text { collaborative } \\
\text { learning and shared } \\
\text { practice }\end{array}$ & $\begin{array}{l}\text { Leadership is } \\
\text { promoted and } \\
\text { nurtured among } \\
\text { teachers }\end{array}$ \\
\hline $\begin{array}{l}\text { Kindergarten } \\
\text { Positional } \\
\text { Leaders }\end{array}$ & $\begin{array}{l}\text { Teachers plan and work } \\
\text { together to find } \\
\text { solutions to meet the } \\
\text { diverse needs of children } \\
\text { and their families/ } \\
\text { whānau }\end{array}$ & $\begin{array}{l}\text { Financial resources } \\
\text { are made available } \\
\text { to support } \\
\text { professional } \\
\text { development }\end{array}$ & $\begin{array}{l}\text { Opportunities exist } \\
\text { for teachers to } \\
\text { provide feedback to } \\
\text { peers related to } \\
\text { strengthening } \\
\text { teaching practices. }\end{array}$ \\
\hline $\begin{array}{l}\text { Kindergarten } \\
\text { Teachers }\end{array}$ & $\begin{array}{l}\text { Teachers informally } \\
\text { share ideas and } \\
\text { suggestions for } \\
\text { improving children's } \\
\text { learning }\end{array}$ & $\begin{array}{l}\text { Financial resources } \\
\text { are made available } \\
\text { to support } \\
\text { professional } \\
\text { development }\end{array}$ & $\begin{array}{l}\text { Financial resources } \\
\text { are made available } \\
\text { to support } \\
\text { professional } \\
\text { development }\end{array}$ \\
\hline
\end{tabular}

\section{Qualitative comments from the survey: barriers and good practices}

After each question section of the survey, participants were given the opportunity to add qualitative comments. This was to allow respondents to go into more depth in addressing the statements on the survey and also to potentially inform the focus groups and interviews that were later conducted with a much smaller number of participants. 
From the 631 participants of the survey, 60 made qualitative comments after some or all of the sections. In total, there were 123 qualitative comments made, though a small number of these were deemed overly ambiguous to code in any reliable way. Table 4.9 provides a breakdown of qualitative input based on service and role.

Table 4.9: Qualitative responses on the survey by role and service

\begin{tabular}{|l|l|l|l|}
\hline Group & $\begin{array}{l}\text { Total } \\
\text { Participants }\end{array}$ & $\begin{array}{l}\text { Participants } \\
\text { providing qualitative } \\
\text { comments }\end{array}$ & $\begin{array}{l}\text { \# of qualitative } \\
\text { comments }\end{array}$ \\
\hline $\begin{array}{l}\text { Kindergarten } \\
\text { Positional Leaders }\end{array}$ & 125 & 16 & 29 \\
\hline Kindergarten Teachers & 74 & 5 & 8 \\
\hline EEC Positional Leaders & 353 & 70 & 32 \\
\hline EEC Teachers & 79 & 7 & 16 \\
\hline
\end{tabular}

The comments sections on the survey tended to provide claims of good practice, barriers to achieving desired outcomes and implicit definitions of the terms used in the survey. Given the small proportion of participants who provided comments, the information gained cannot be taken as representational. However, some observations should be noted. In terms of barriers to good practice, there were multiple references to not having enough time and/or money to enact the practices which participants felt they should be doing. For example, respondents commented "lack of time hinders all" (EEC Leader), "time is provided but... there still isn't enough time!" (EEC Leader), "funding cuts have impacted majorly on time for collaboration and sharing ideas" (EEC Leader) and, "[professional learning] is becoming more difficult as [there is] pressure to increase contact time and reduce non contact- where we spend time together learning together" (Kindergarten Teacher).

However, despite time and financial resources being reported as the strongest barriers in the quantitative data, the qualitative data spoke more often about barriers occurring in personal teaching practices and personal inflexibility. For example:

some teachers... strive to work together as an effective team, but other teachers are dancing to their own tune, making the whole team quite dysfunctional (EEC Teacher) Throughout the qualitative comments, respondents identify people wanting power or holding onto power as a barrier. According to one respondent "bullying is a major issue" 
(EEC Leader) but, more often it is referred to less pejoratively. As one EEC Teacher explains, "success [in distributed leadership] depends on the Professional leadership being able to operate without the need to be in a position of control." Importantly, teachers and leaders felt the negative effects from two sides: from those in positions of power above them and from teachers in their workplaces:

Since becoming manager... I have brought in a collaborative way of working that gives more accountability and autonomy to teachers... Resistance has been difficult to manage when some in leadership positions want to stick with old practices due to feeling threatened by change. (EEC Leader)

Despite these comments about personal differences acting as barriers, teachers and positional leaders often referred positively to practices within their own workplaces. Interestingly, the positive comments also tended to be interpersonally focused. Some of these related to the participants' teams generally and other detailed areas in which workplaces were successful in enacting practices from the survey. For example, "I am very fortunate to have a team who are all very professional and teaching for the right reasons" (Kindergarten Leader). As one leader in EEC explained, the collective learning and application was working well in her current team, "but it's rare to be all on the same page" (EEC Leader).

From these findings I think it is important to note the predominance of issues related to interpersonal relationships and conflict in the qualitative findings. Although the comments are not necessarily representative of the sector as whole, for those who took the time and/or felt the need to comment further, they were often the focus of discussion. This may be because the structural issues that show up as greater concerns in the quantitative data are normalised and part of participants' daily, mundane work-life. In contrast, interpersonal relationships are immediate, unpredictable and consuming, especially in conflict.

It is also important to note that the vast majority of respondents answered positively about shared personal practice and collaborative learning. From this, it may be that interpersonal conflicts (e.g. with those who hoard power) are not the norm in the sector, yet again their frequency in the qualitative comments may indicate that they nevertheless present serious barriers to the participants who encountered them. 
References to both teachers and leaders indicate that power needs to be considered in terms of positional power, but also the power to sabotage collective practices through individual actions. These two types of power present challenges for both teachers and leaders trying to further collective professional learning and distributed leadership.

\section{Conclusion}

Findings from the survey showed a bias towards positive reporting, even on issues that received overwhelmingly negative qualitative comments. As a result, the data were examined in relative terms to find the areas that were agreed and disagreed with most by participants. All participant groups reported relatively high and consistent practices related to collective learning and application. All groups aside from EEC leaders felt that this was the strongest area of practice within their services. In contrast, EEC leaders were most positive about distributed leadership for professional learning in their practices. All groups felt most negatively about structural conditions - namely time allocated to collective professional learning and economic resources to enable professional learning.

The notable differences between groups occurs between positional leaders and teachers. Both teacher groups reported relatively negative views related to shared and supportive leadership practices in their centres. Within this category, the statement "leadership is supported and nurtured among teachers" had the most disagreement in the entire survey: teachers and positional leaders differed most in their evaluation of this statement. This difference in the experience of leadership is concerning given its importance within ECE and professional learning.

The qualitative data from the survey largely supports the data from the Likert-style questions. The structural conditions that services operate within were highlighted as barriers to achieving professional learning. However, the qualitative data also highlighted the importance that participants attached to interpersonal relationships. These were seen as enabling or thwarting professional learning and distributed leadership practices. Importantly, both teachers and positional leaders were experienced as blocking and enabling good practice. 


\section{Chapter five: Interview findings}

\section{Introduction}

This study set out to first gather a broad understanding of professional learning and distributed leadership within the New Zealand early childhood sector, and then to investigate conditions and practices that enable high performing teams. Initial information was gained through a widely distributed survey. The data gained from the survey, detailed in the previous chapter, provided insight into common practices and barriers for leadership and professional learning across the sector. The survey data allowed for comparison between the perceptions of positional leaders and teachers; the data also allowed limited comparison across service types within the sector and comparison when analysing role and service type together (e.g. kindergarten positional leaders versus EEC teachers). The survey results, however, did not allow for a deeper understanding of how leadership and professional learning results in various outcomes. As an example, the survey questioned participants' experiences of elements that are associated with distributed leadership, professional learning, structural conditions and so on, however, these data do not explain specific ways that leaders promote or inhibit these practices. Where the survey gives a broad overview of participants' perceptions of what is occurring in the sector, the focus groups and interviews in this chapter address how and why the practices are enacted. The interview data reported in this chapter are used to address the need for a deeper understanding of the contexts, practices and outcomes in ECE leadership in Aotearoa New Zealand.

The providers and the participants described below have all been given pseudonyms. In each case, interviews were first conducted with the positional leader of the service and then a separate interview was held with just the teaching team. The only exception to this was in Hall Street Early Education, where both the positional leader and the co-owner responsible for educational leadership chose to attend the meeting with the teachers, as discussed in the methodology chapter previously. 
Table 5.1: Contextual features of services interviewed

\begin{tabular}{|c|c|c|c|c|c|c|c|}
\hline Service name & Service type & $\begin{array}{l}\text { Positional } \\
\text { leader }\end{array}$ & $\begin{array}{l}\text { Number of } \\
\text { teachers }\end{array}$ & $\begin{array}{l}\text { Licensed for } \\
\text { number of } \\
\text { children }\end{array}$ & $\begin{array}{l}\text { Licensed for } \\
\text { age range }\end{array}$ & Location & $\begin{array}{l}\text { Decile rating } \\
\text { of nearest } \\
\text { school* }\end{array}$ \\
\hline $\begin{array}{l}\text { Fernlea } \\
\text { Kindergarten }\end{array}$ & Kindergarten & $\begin{array}{l}\text { Jane - } \\
\text { head teacher }\end{array}$ & 6 & 40 & $0-5$ & $\begin{array}{l}\text { Small town, } \\
\text { semi-rural }\end{array}$ & 1 \\
\hline $\begin{array}{l}\text { Hall Street } \\
\text { Early } \\
\text { Education } \\
\text { and Care }\end{array}$ & $\begin{array}{l}\text { Private early } \\
\text { childhood } \\
\text { centre }\end{array}$ & $\begin{array}{l}\text { Mel - } \\
\text { Head teacher }\end{array}$ & 10 & 30 & $0-5$ & City suburb & 9 \\
\hline $\begin{array}{l}\text { Mansfield } \\
\text { Early } \\
\text { Childhood } \\
\text { Centre }\end{array}$ & $\begin{array}{l}\text { Community- } \\
\text { based early } \\
\text { childhood } \\
\text { centre }\end{array}$ & $\begin{array}{l}\text { Helen - } \\
\text { Team leader }\end{array}$ & 6 & 30 & $2-5$ & City suburb & 4 \\
\hline
\end{tabular}

*Decile ratings are a New Zealand Ministry of Education system to rate the socio-economic level of the families which a school serves, 1 being low socio-economic and 10 being high socio-economic, based on various socio-economic indicators (Ministry of Education, 2016).

Each service and each role of participants has been given a code to make the referencing of quotations efficient throughout the findings and discussion chapters. Every quotation is referenced with a service and role, for example a teacher from Fernlea Kindergarten is referenced as (FLK, T).

Table 5.2: Codes used to reference interview participants' quotes

\begin{tabular}{|l|c|c|c|c|c|}
\hline & \multicolumn{3}{|c|}{ Service name } & \multicolumn{2}{c|}{ Role of participant } \\
\hline Full title: & Fernlea & Hall Street Early & Mansfield Early \\
& Kindergarten & Education and Care & Teacher & Positional \\
Centre & & leader \\
\hline Code: & FLK & HSE & MEC & T & PL \\
\hline
\end{tabular}

In the first part of this chapter, I give an overview of each of the services based on the interviews with the positional leaders and their teams. I focus on two aspects of each service to give a general picture of their operation:

- The context of the service, such as size, the community it services, the tenure of the team members, age of children who attend and its management structure; and,

- Features of the service that interviewees identified as being central to their approach to distributed leadership and professional learning. 
The second section of this chapter uses inductive coding to categorise and report the interview responses in relation to the research questions:

- How does distributed leadership contribute to teachers' professional learning in early childhood education settings?

- What is the positional leader's role in facilitating distributed leadership for professional learning?

In total, seven themes were identified in response to each of the research questions. They are presented in the second part of this chapter to lay the groundwork for the discussion chapter that follows.

As much as possible, I have reported the responses to the interviews in the language used by participants, though condensing the responses required some paraphrasing. Unsurprisingly, many of the participants used similar language to one another. This occurred even though the practices at the services varied. In the next chapter, the similarities and distinctions between the responses are teased out as I elaborate the themes identified through the interviews.

\section{Interview findings by service}

\section{Fernlea Kindergarten}

\section{Context}

Fernlea Kindergarten is situated in a socio-economically and culturally diverse town of 20 000. It is one of two kindergartens in the town associated with the regional kindergarten association; it is licensed for infants to five year old children. As with other kindergartens in its association, Fernlea has a head teacher who assumes the role of positional leader. The head teacher provides educational leadership and assumes some administrative duties; many formal management duties are supported by higher levels of management within the organisation. The team at Fernlea consists of six teachers and one head teacher, Jane. Five teachers have been at the kindergarten for between five and seven years, the sixth has been there for two years. Due to the infant group at this kindergarten, the ratio of teachers to 
children is higher than other kindergartens in the association and the head teacher has slightly increased non-contact time. The client demographic reflects the diverse socioeconomic and cultural communities of the town.

\section{Defining features of distributed leadership and professional learning in this service}

According to the Fernlea team, leadership at Fernlea is distributed throughout the team through the agreed structures of the workplace as well as in less formal, or more flexible, situations. Formally, teachers undertake a designated 'Kaitiaki' role, rotated so that everyone has regular opportunities to practice being responsible for oversight. The Kaitiaki role was developed and implemented by the current positional leader, and is a recognised leadership role within the kindergarten. The teacher in that role is responsible for oversight of the kindergarten when the head teacher is not present on the floor.

I have a Kaitiaki, so that's like a guardian, one of the permanent full-time teachers takes on that role, and they sort of oversee everything that's happening and people can go and pass on messages or they can make decisions about things that need to be made decisions if I'm off in a meeting or something like that, so that allows them to work through challenges... and it builds on their leadership skills as well. (FLK, PL)

The teachers explain that although this responsibility could be intimidating at the beginning, it has helped each of them grow leadership capability and to clarify for themselves their individual priorities and approaches to leadership. In response to interests and events, teachers also take on leadership of specific initiatives. This leadership includes facilitating the team's professional learning and planning, and liaising with the wider community. For the positional leader, fostering leadership is an important part of her role. In addition to establishing structures that enable leadership, such as the Kaitiaki, the head teacher mentors each member of the team individually to help them develop their leadership practice.

Fernlea is unique in this study in that it operates under an umbrella organisation, a kindergarten association. Distributed leadership and collaborative professional learning are specified through some of the systems and processes provided by the kindergarten association. The positional leader, Jane, and the teachers at Fernlea refer to these systems as supportive of leadership and professional learning. Appraisal is used to set personal 
professional goals and the prescribed kindergarten association appraisal process requires shared critical reflection on learning, including mentoring from the head teacher and team discussions to engage in critical dialogue about appraisal goals. The team also refer to the kindergarten's annual Strategic Teaching and Learning Plan goals which are written collaboratively by the head teacher, the teaching team and their senior teacher from the kindergarten association each year. The structure of these strategic goals requires shared responsibility and teacher leadership, and provides some direction to the team's professional learning and programme development throughout the year. One of the teachers described the way that the Strategic Teaching and Learning Plan encourages distributed leadership, explaining that every teacher has "areas of responsibility [where] we take on a leadership role of the two different goals that we've set; so we have allocated ourselves parts to play in that and facilitate to the group" (FLK, T). The development of a shared philosophy and vision is also guided by the kindergarten association. In sum, the umbrella organisation was, in this case, seen as integral to the kindergarten's development of distributed leadership and professional learning.

In her interview, the positional leader identified the need for mentoring and coaching to develop leadership capability. Jane described a number of elements necessary for fostering leadership with teachers: communication, building confidence, goal setting and supporting teachers to take on challenges. She described the complexity of adapting mentoring and coaching practices to meet the needs of individual teachers in the various stages of their learning journeys. According to Jane, the challenges of mentoring and coaching constituted an important part of the head teacher's role in developing leadership in teachers.

In addition to mentoring and coaching, Jane spoke of the structures she has developed that enable leadership distribution and professional learning throughout the teaching team.

These include using the teacher appraisal system to identify professional goals, interests and strengths; designated roles to provide opportunities for leadership practice and development; scheduled times for professional learning dialogue requiring shared responsibility; and the development of a shared vision and philosophy to be used as tools for re-gaining shared understanding at key professional learning moments.

The teachers at Fernlea lauded the value of distributed leadership. They described distributed leadership as responsive to situational needs. Jane's mentoring and coaching, 
according to the teaching team, supported their learning and leadership development. The teachers at Fernlea specified how Jane's practices support distributed leadership and professional learning. The teachers described her as a mentor, and outlined her mentoring and coaching strategies which they see as impacting on teacher development, including effective listening, asking questions to deepen thinking, and providing advice and resources. The team described her ability to understand individual teachers and support them in their leadership development as "a gift." Several teachers in this team have engaged in longterm professional development on leadership, continuing to set goals for their own leadership practice related to the professional development. Other teachers have set themselves leadership goals within the appraisal and teacher registration processes. Goal setting is one of the key elements of mentoring and coaching in this team, as described in both interviews.

The teachers articulated what they see as the benefits of distributed leadership, in relation to the teacher themselves, to the collective team, and to the children and community. Opportunities for leadership were described as professional learning opportunities. According to the teachers, the distributed leadership environment exposes them to a variety of other people's leadership approaches, knowledge and experience. The team expressed the benefits of this exposure not only for themselves, but also for children and parents in the community. They spoke, as examples, of the enriched learning programmes for children, and also of a parent who has started training to be a teacher after being encouraged to participate in the kindergarten. One of the teachers described the reach of the benefits of distributed leadership for their learning community:

I think multiple voices are heard, people's strengths and passions are nurtured, and the capability of all is grown, and I think that it also contributes to a climate of diversity and that aspect of asking questions and, you know, critically reflecting where it's not just coming from one person, yeah. So it grows a more vibrant learning community. (FLK, T)

Responsive opportunities for leadership were described by this team as being reactive to situations, events and interests that arise, such as emergent learning in the group of children, and teachers' areas of interest. The teachers explained that when leading a new initiative or plan for learning, they used a variety of approaches to leading the team's 
professional learning, such as sharing readings and resources, presenting workshops at staff meetings, and acting as the expert so that others could come to that teacher for advice and guidance in a particular area of knowledge. The teachers all agreed that articulating their thinking to others is a powerful learning experience for the presenter as well as the audience.

\section{Hall Street Early Education}

\section{Context}

Hall Street Early Education is a private early childhood centre, located in a city suburb with high school decile ratings. This full-day centre provides education and care for infants, toddlers and young children, and maintains high ratios of teachers to children compared with the regulated required ratios. The centre is licensed for 30 children aged $0-5$ years. It can be described as a full-service model for working parents, providing meals, bottles, and nappies. The owners started the centre eight years ago with a vision for high quality ECE, and continue to influence the direction of the centre through strategic planning and leadership of professional learning. The leadership team consists of the two owners, the head teacher, and the two designated education leaders - teachers who contribute significantly to leadership of the educational programme. The teaching team includes eight teachers with a wide variety of teaching experience.

\section{Defining features of distributed leadership and professional learning in this service}

The leadership structure of this centre involves multiple levels of leadership development, and teachers are encouraged to develop their leadership capability through the positional leader's distributed leadership approach. There are two Education Leader positions in which appointed teachers have increased responsibility for helping to lead the educational programme, and the head teacher leads the team onsite. The owners provide leadership of different aspects of the business and educational environment. The leadership structure of the centre also requires a collaborative approach; in the interview the teachers explained that having multiple people responsible for leadership of learning requires dialogue and the development of shared understandings. As a standard professional learning practice, the leadership team aims to send two or more teachers on external professional development 
events. The intention with this practice is to strengthen transfer of learning by having teachers share dialogue and share the leadership of bringing new learning back to the rest of the team. Non-contact time is arranged so that groups of two or more teachers can regularly engage in professional dialogue to collaborate and plan various aspects of leadership and learning in the programme. Thus the hierarchical leadership structure is complemented by practices that enable and encourage leadership across all of the teaching team.

Planned professional learning events are a distinctive feature of Hall Street. Professional learning for the team, professional learning for visiting early childhood teachers from other services, and educational workshops for parents and family are scheduled regularly throughout each calendar year. There is an expectation from the leadership team that every teacher will contribute to leading professional learning at these events over time. The owner attending the teachers' group interview shared her view that the Education Leaders have developed expertise as adult-educators through the development of these professional learning events, in researching and writing presentations, facilitating workshops, and mentoring other teachers to participate. In both the positional leader's interview and the teachers' group interview, there was a strong emphasis on the value of teachers articulating ideas about teaching. The process of developing and delivering a presentation - a practice all teachers participated in - was described as a professional learning experience for the teachers presenting.

The positional leader at Hall Street, Mel, was fairly new to being a head teacher, having been in this role for one year at the time of the interviews; this is a notable difference to the other two positional leaders in the study (one had been in her role for 11 years and the other, 13 years). Mel discussed systems and strategies for distributed leadership development including teacher leadership of professional learning events, and highlighted relationships as a foundation for distributed leadership and professional learning.

The positional leader explained that a key part of her role is fostering supportive relationships amongst the teachers as well between herself and the team. For Mel, this provides an environment of emotional well-being which enables teachers to develop confidence as leaders. She explained that strong relationships enable the team to better tackle difficulties collaboratively: “Together, we're just open for new challenges. We may be 
unsure at times but we know that together we can do it" (HSE, PL). Mel also described her approach of getting to know each teacher well so that she could encourage leadership on an individual basis. By knowing teachers well, she identified what teachers were interested in or challenged by so that she could offer learning resources such as readings and external professional development.

In addition to relationship development, Mel outlined several systems and strategies she used to develop teacher leadership. The appraisal system allowed her to see where each teacher could take up leadership and further professional learning. Using the appraisal system allowed Mel to make the most of arising interests and strengths in each teacher to encourage leadership of new initiatives and facilitation of professional learning for colleagues and parents. She proposed that her strengths-based perspective towards distributed leadership gave teachers the chance to be experts for their colleagues in areas which interested and motivated them.

In the team interview at Hall Street, teachers focused on similar ideas to the positional leader's interview. They highlighted emotional support from the head teacher and colleagues as being integral to their development of leadership and learning; they voiced their appreciation of the positional leader's emotional support, and regularly referred to the strength of their relationship with her as a supportive factor for distributed leadership and professional learning in the centre. As one teacher explained,

I'd say as well her role largely encompasses the wellbeing of the staff as well as the professional programme learning and that. But l'd say a lot of it is looking after us, making sure we're okay as well, yeah, and knowing how she can help us individually. (HSE, T)

The teachers also discussed collegiality as allowing leadership and learning to happen: "you can always feel support from the teachers,"; "the collegiality here is very special," and, "It's often about bringing your own ideas but it's also about supporting other people" (HSE, T). Conversely, possible difficulties described by the team included lack of support from colleagues and the challenge of gaining shared understanding amongst a large team of teachers before progress could be made together. These relationship-based issues reflected 
back the importance that this team placed on strong relationships as a foundation for leadership and learning.

The teachers and the positional leader also repeatedly described leadership of professional learning as a form of professional learning for the presenter. The many structured events at Hall Street encouraged this leadership and professional learning, both for the audience and for the facilitator. The teachers said that developing presentations was a powerful tool for their own professional learning, and that the challenging process of refining one's thoughts for a presentation necessarily crystallised their thinking and furthered the learning of the author/presenter. The teachers described feeling proud of their achievement and learning when they had shifted from initial fear of presenting to being pushed to give it a go and finally succeeding, and they appreciated the positional leader's encouragement and also the whole team's support in this endeavour.

\section{Mansfield Early Childhood Centre}

\section{Context}

Mansfield Early Childhood Centre is a community-based early childhood centre in a city suburb, licensed for 35 children from two to five years old. The centre has been operating for over twenty-five years, servicing a community of families with a wide range of incomes and diverse cultures. Mansfield is managed by a parent committee which is made up of current parents who volunteer to take part in the governance of the centre. The centre is led by the Team Leader, Helen, who has day-to-day leadership responsibility, and although she is technically managed and employed by the volunteer parent committee, it is worth noting that in this management structure there is no-one employed in a paid position above her. Helen has been the supervisor for eleven years and was a teacher at Mansfield for four years prior. The eight teachers have been at the centre between one and fifteen years.

\section{Defining features of distributed leadership and professional learning in this service}

Mansfield is unique in this study as a community centre run by a parent management committee. The positional leader explained that the centre and the team benefit from having a supportive parent management committee who value professional learning, as the committee approve the ratios and budget to allow professional dialogue to happen in 
informal and formal ways. This includes time for the positional leader to use on external professional networking projects, and for the teachers to attend external professional learning whenever it is deemed useful by the positional leader and the team. Both the positional leader's interview and the teachers' interview highlighted that the high teacherto-child ratio allows time each day for spontaneous reflective learning dialogue amongst teachers.

At Mansfield, Helen identified three features of her approach to professional learning and distributed leadership. The first of these was purposefully using informal and spontaneous professional dialogue to develop learning and leadership; the second was recognising the value of diversity in teacher leadership; and the third was establishing positive relationships as a foundation for distributed leadership and professional learning.

Informal and spontaneous professional dialogue is a defining feature of the way the positional leader at this centre described her approach to leadership and learning. She regularly mentioned the intuitive way the team communicates and works together. Through the interview, she developed the idea that knowing each other well supports teachers to lead. For example, when discussing the variety of ways leadership is distributed, Helen explained,

We've all worked together quite a long time so I guess the longevity of our team means that we've all... got to know each other really well, so sometimes there's I think there's probably a lot of unspoken things that just occur because we all know each other's strengths. (MEC, PL)

The 'strengths' that Helen refers to include, for her, the diversity that the teachers bring to the centre. In this case diversity includes cultural backgrounds, knowledge and experience that all contribute to different teaching and leadership approaches. She explained that she places high value on team diversity, and that she consciously tailors her leadership approach to different teachers' needs. She believes that each teacher benefits from a different kind of support to enact leadership and to contribute to professional learning, depending on variables such as personalities and confidence. She explained that everyone has the ability to lead and contribute in their own way when appreciated and supported, and that she looks for the different strengths and potential she can foster in each teacher in her team. 
She described the sharing of each person's unique strengths through leadership and collaboration as beneficial to the teaching team's professional growth and to the children's learning. This core value is evident beyond the leadership and learning of the teaching team; the positional leader explained that diversity is celebrated throughout the programme, and Helen is proud that the children at Mansfield explore diversity through conversation with teachers and purposefully chosen resources which celebrate the value of difference.

Helen explained that she intentionally leads her teaching team in a fun, relaxed and positive way. This is because she sees positive relationships and team culture as serious factors in fostering leadership and professional learning amongst her team: "I think by promoting really good open positive respectful and reciprocal relationships with your teaching team, ...then you should be able to enable leadership... where potential lies" (MEC, PL). The positional leader said that she aimed for an environment where teachers enjoy their work and each other's company and maintain a positive attitude even through challenges. She described showing the team a positive perspective on challenging situations, by purposefully re-presenting difficulties as opportunities for learning. Helen proposed that this positive relational environment fosters the kind of trust amongst the team which allows teachers to be constructively honest with one another as leaders and as learners: "It's an environment where I think everyone feels secure and safe enough to challenge ideas, ... and just have that understanding that there's no one right way of doing the things we're doing" (MEC, PL).

For the teachers at Mansfield, loyalty to the centre motivated them to take on leadership roles and continue to learn. Through the Mansfield interviews, the teachers conveyed reciprocal loyalty between the team leader and the teachers. The Mansfield team referred regularly to the culture of the centre, and used the phrase 'the Mansfield Way'. Their motivation was not only prompted by leader-teacher relationships, but also a sense of duty to the children and community.

The teachers highlighted positive relationships as important factors in allowing distributed leadership and professional learning to occur, mirroring the positional leader's views. The teachers explained that they felt their different strengths were valued by the head teacher and each other. This relational environment reportedly allowed them to contribute in 
meaningful ways to the life of the centre in spontaneous and planned ways. A sense of security in their professional relationships was posited by the teachers as allowing everyone to be honest and to engage in critical dialogue leading to professional learning, again mirroring the sentiments of the positional leader's interview.

The teachers appreciated being in an environment where different ideas are welcomed, trialled, and reflected in an approach similar to action learning. The positional leader reported that she wants everyone to feel encouraged to be honest, to discuss issues and share ideas, and the teachers reiterated that this professional learning climate is something they enjoy and aim to uphold:

I think Mansfield kind of has the culture, a distributed leadership culture, where any of us at any time feel comfortable enough to make suggestions ... I feel like it's just part of the culture that everyone kind of suggests things and comes up with ideas. (MEC, T)

They also highlighted informal daily professional dialogue as a useful tool for developing ideas collaboratively about the children's learning and the programme. They explained that this has an impact on their shared professional learning as they strive to find out more leading on from conversations about children's learning, and their discussions often result in teacher leadership when they share their new knowledge with the team. This team described their practice as a cycle of planning, acting, observing and reflecting.

\section{Interview findings and the research questions}

In this section, the six interviews are treated as a group and responses are related to the two research questions:

- How does distributed leadership contribute to teachers' professional learning in early childhood education settings?

- What is the positional leader's role in facilitating distributed leadership for professional learning?

Under each research question, interview responses are treated together and relevant emergent themes are described (see Table 5.3 and Table 5.4). 
Table 5.3: Interview findings related to research question 1.

\begin{tabular}{|c|c|c|c|c|c|c|c|}
\hline Question 1 & $\begin{array}{l}\text { Theme } \\
1\end{array}$ & $\begin{array}{l}\text { Theme } \\
2\end{array}$ & $\begin{array}{l}\text { Theme } \\
3\end{array}$ & Theme 4 & Theme 5 & Theme 6 & Theme 7 \\
\hline $\begin{array}{l}\text { How does } \\
\text { distributed } \\
\text { leadership } \\
\text { contribute to } \\
\text { teachers' } \\
\text { professional } \\
\text { learning in early } \\
\text { childhood } \\
\text { education settings? }\end{array}$ & $\begin{array}{l}\text { Teacher } \\
\text { inquiry } \\
\text { improves } \\
\text { teaching } \\
\text { practice }\end{array}$ & $\begin{array}{l}\text { Articulation } \\
\text { of thinking } \\
\text { results in } \\
\text { learning for } \\
\text { both the } \\
\text { presenter } \\
\text { and the } \\
\text { audience }\end{array}$ & $\begin{array}{l}\text { Diversity of } \\
\text { leadership, } \\
\text { knowledge, } \\
\text { and } \\
\text { experience } \\
\text { provides } \\
\text { rich } \\
\text { learning }\end{array}$ & $\begin{array}{l}\text { Engaging in } \\
\text { leadership } \\
\text { motivates } \\
\text { teachers }\end{array}$ & $\begin{array}{l}\text { Empowerment } \\
\text { of teacher } \\
\text { leaders fosters } \\
\text { professional } \\
\text { learning }\end{array}$ & $\begin{array}{l}\text { Professional } \\
\text { dialogue } \\
\text { amongst } \\
\text { teacher } \\
\text { leaders is } \\
\text { constructive }\end{array}$ & $\begin{array}{l}\text { Collaborative } \\
\text { learning } \\
\text { results in } \\
\text { transfer of } \\
\text { learning }\end{array}$ \\
\hline
\end{tabular}

Table 5.4: Interview findings related to research question 2.

\begin{tabular}{|l|l|l|l|l|l|l|l|}
\hline Question 2 & Theme & Theme & Theme & Theme 11 & Theme & Theme 13 & Theme \\
10 & 9 & Scaffolding & $\begin{array}{l}\text { Fostering } \\
\text { confidence }\end{array}$ & $\begin{array}{l}\text { Fostering well- } \\
\text { being and } \\
\text { relationships }\end{array}$ & $\begin{array}{l}\text { Developing } \\
\text { shared vision } \\
\text { and shared } \\
\text { understanding }\end{array}$ & $\begin{array}{l}\text { Developing and } \\
\text { implementing } \\
\text { systems and } \\
\text { roles }\end{array}$ & $\begin{array}{l}\text { Providing } \\
\text { resources } \\
\text { and } \\
\text { positional leader's } \\
\text { role in facilitating } \\
\text { distributed } \\
\text { leadership for } \\
\text { professional } \\
\text { learning? }\end{array}$
\end{tabular}

\section{Question 1: How does distributed leadership contribute to teachers' professional learning?}

\section{Theme 1: Teacher inquiry improves teaching practice}

Teachers and positional leaders in the three services described opportunities for distributed leadership involving or resulting in processes of inquiry, a process of problem solving and reflection in order to improve teaching practice. Fernlea's positional leader explained the process as, "allowing the teachers time to reflect and discuss [their teaching practice], and 
to put some of their strategies into place and then trial them out and then revisit them again" (FLK, PL).

A teacher from HSE made the connection to individual goal setting, explaining that inquiry can come from "people's personal goals too, you know if you're really interested in learning more about something to do with Reggio or something then you go out of your way to find out more information about that and share it with the team and then maybe with families," (HSE, T), proposing that a teacher's leadership of learning can filter out to the wider learning community.

The inquiry described by the three teams was both personal and embedded within the leaders' social surrounding. Alongside inquiry relating to personal goals, positional leaders and teacher leaders used inquiry in a process that relied on individual and team reflection. Overall, the process described mirrors action research (i.e. engaging a cycle of planning, implementation and reflection to improve the effectiveness of professional learning):

We actually reflect on how it went, what the impact was, what the change has been. Did the teachers get it or not get it and do we have to try again? Or what have they really taken and rolled with and how can we take that further? (HSE, T)

So between the leadership team... we always reflect where the team is currently at and then plan as to where we can grow better... So it is identifying areas of growth within the team and utilising those precious teacher learning days to improve practice. (HSE, PL)

Participants described inquiry learning as stemming from interests and goals, and also from issues and challenges. In the situations described by these teams, the inquiry process can come from distributed leadership and can also create opportunities for leadership of learning as well.

\section{Theme 2: Articulation of thinking results in learning for both the presenter and the} audience

A key aspect of leadership related to professional learning at these services was presenting professional learning and knowledge to others. Teachers and positional leaders at these 
services described the process of developing a presentation as having the side-effect of deepening and clarifying learning for the presenter. In this way, leading professional learning has a double benefit of learning for the presenter and the audience.

I think as teachers, that what we do, that's the biggest way of learning about something is to articulate it to your friends or to other people. (FLK, T) I actually find that process of writing [a presentation] actually helps me grow as a teacher and become a lot more articulate in being able to explain to others, to parents about why it is we do what we do. So I find that that writing bit is actually one of the biggest tools for deepening my own knowledge. (HSE, T)

One positional leader explained that presenting a workshop to parents or colleagues can be a valuable professional learning experience for the teacher presenting, because "it really grows your own thinking as a teacher, as you are required to summarize something that you know, or even question why [you] have been doing that" (HSE, PL). She goes on to say that this is, "another way where each teacher contributes to their [own] professional learning too, and how I encourage professional learning within the team," showing that it is part of her intentional leadership practice to offer these opportunities.

\section{Theme 3: Diversity of leadership, knowledge, and experience provides rich learning} Teachers and leaders described different ways that diversity is valued and has positive effects on professional learning. Distributed leadership allows for a diverse range of people to have influence, as opposed to a hierarchical approach where the main influence comes from a positional leader. Specifically, teachers and positional leaders placed positive value on experiencing a range of approaches to leadership in a distributed leadership environment:

If we think about all of the different leaders that we've known through time and maybe leaders in our schooling days, leaders in our community, no one of them is the same, like there's no one way to be the leader. So it's great for us to be in an environment where people do have different styles of doing it. (FLK, T) 
You sort of have to make sure that everyone knows... there's no one way to contribute and there's no one way to be a leader so you know.. there's so many different ways that you can do it and they're all as valuable as each other. (MEC, PL)

Further to leadership diversity, the culture and experience each team member brings was valued by these teams as contributing to a rich learning environment for both children and adults: "The benefits are you get multiple perspectives and diverse views and different opinions, and you get more ideas, more knowledge" (MEC, PL). Teachers and leaders used words such as "vibrant" and "rich" to describe the diversity of their learning communities, and made distinct links between team diversity and an increase in potential collaborative learning.

\section{Theme 4: Engaging in leadership motivates teachers}

Teachers' professional motivation and commitment were described as increasing through distributed leadership opportunities, including motivation for and commitment to ongoing professional learning. Teachers explained that they feel motivated and satisfied in their teaching when offered leadership opportunities.

So for me it definitely contributes to my sense of satisfaction in my role as a teacher to have opportunities to be a leader, to be both led and to be a leader... I think that it's motivating for teachers to have opportunities in a distributed leadership model, where teachers have opportunities to be empowered and to build their sense of belonging and to be part of a kind of family and a community. (FLK, T)

You're more involved, there's more commitment ... if you're all leading it and you're all involved in it, you're more likely to want it to succeed. (MEC, T)

Positional leaders saw the rewards of distributed leadership resulting in committed teachers:

I see that active involvement as a huge benefit because like I mentioned, if you've got them being actively involved and leading team discussions... then you've got them wanting to do it and you've got that motivation happening because they're empowered. (FLK, PL) 
To have motivated and committed teachers in the teaching team becomes a motivation for positional leaders to develop and maintain a distributed leadership environment.

\section{Theme 5: Empowerment of teacher leaders encourages professional learning}

According to both positional leaders and teachers, distributed leadership empowers teachers, and that empowerment results in improvement and articulation of practice. The Mansfield positional leader explained, "I think leadership gives you confidence and empowers you as a professional ... and I think you do need to have leadership qualities and skills so that you can properly, yeah, articulate how great we are," (MEC, PL), citing the need for teachers to feel able to advocate for the early childhood profession. She goes further in describing the benefits to the wider learning community:

On an individual level I think [distributed leadership] is empowering, and so I think you encourage teachers feeling good about themselves and their practice and their opinions and ideas, so I think it makes for better early childhood teachers, yeah, and which then trickles down into, you know, providing again a high quality environment for children to be learning in and for parents to be a part of. (MEC, PL)

Teachers in all three services described feeling empowerment and self-efficacy through engaging in leadership, and explained that this motivated them to engage in professional learning.

\section{Theme 6: Professional dialogue amongst teacher leaders is constructive}

Participants described professional dialogue as one of the most important arenas for professional learning, and propose that dialogue is enhanced in a team environment where teachers act as leaders. Professional dialogue can be scheduled in meeting times or spontaneous conversation during each day, and both kinds of dialogue are seen as highly valuable to professional learning by the participants.

I think conversation is absolutely crucial when it comes to professional learning 'cause that's when you can be, you know, asking for advice or hearing someone else's perspective or point of view, or just maybe, you know, hearing something and 
thinking about it in a different way. And so that's how I think professional learning comes... when your ideas are challenged or you think about things a different way, so having multiple opportunities for good conversation I think is crucial. (MEC, PL)

Distributed leadership in these teams was seen as resulting in professional, critical and honest discussion which in turn results in professional learning for teachers.

\section{Theme 7: Collaborative learning results in transfer of learning}

In each of these services, distributed leadership was regularly described as resulting in collaboration and co-construction. Teachers engaged in leadership take responsibility to collaborate with their teams throughout the development and implementation of initiatives. This is intended to ensure shared understanding amongst the team and to make the transfer of theory into practice more likely as a group. Teachers and positional leaders explain that teachers are expected to share any new knowledge and learning, and that groups of teachers work together to investigate ideas and develop aspects of the programme.

For me it's the opportunity to... share my knowledge with the team and then everybody getting on board and giving their two bits as well and creating a big learning environment where you're all participating. (FLK, T)

There's no one person that has the knowledge that means they're going to be the one that knows the answer at the end of the day 'cause I think it's more collaborative than that... I think we probably know as a team that we learn together and that we learn through the discussions that we have with each other... And the diversity of our team I think really helps to encourage and promote that sort of collaborative learning. (MEC,PL)

Participants made positive links between collaboration and transfer of learning into practice, inferring a connection between collaborative learning by teachers and children's learning in these services. 


\section{Question 2: What is the positional leader's role in facilitating distributed leadership for professional learning?}

\section{Theme 8: Mentoring and coaching}

Positional leaders at the focus services described a mentoring and coaching approach to developing leadership in teachers. The positional leaders described a sense of responsibility to mentor and coach:

My role is looking to support and be a mentor to those teachers that are wanting to take on those leadership roles and supporting their confidence through, sometimes they'll fly through on some things and sometimes they'll have a little bit of a knock back and you've just gotta support them through that. (FLK, PL)

I have seen her grow from a teacher in training to now into a teacher who actively takes on a leadership role within the team, where she is personally responsible... in leading the team in investigations and things like that, and I really do believe it is from I guess my mentorship and coaching... So I do get the sense of pride almost to see teachers grow in their own ways and seeing them be proud of themselves and wanting to grow and yeah, it makes me happy. (HSE, PL)

Further, positional leaders articulated mentoring and coaching strategies such as questioning and listening techniques:

Provocateur... I provoke thinking by asking good questions I think, and by modelling... a positive approach and attitude to learning and professional discussion and listening, and you know, taking on board other people's ideas and opinions. (MEC, $\mathrm{PL})$

Teachers reiterated that mentoring and coaching strategies are supportive factors in leadership development and professional learning. One of the Hall Street teachers said that an important aspect of the mentoring and coaching relationship was the positional leader "being in tune with your staff," and went on to say that it involves the positional leader getting "to know what [each teachers'] personal and professional goals are and then helping you strive towards them" (HSE,T). 
Mentoring and coaching are practices which were commonly understood by the participants in these three education services, the language of which was used in the interviews to frame some of the ways positional leaders support leadership development and professional learning.

\section{Theme 9: Scaffolding}

Teachers highlighted scaffolding as an effective strategy used by positional leaders to support leadership development and professional learning. Positional leaders offered a higher level of support when needed and gradually reduce involvement as the teachers increase their own knowledge and skills. Scaffolding by positional leaders was explained as being adaptable to teachers' varying levels of knowledge, skills and experience.

She senses somebody needed some support to do that, where she scaffolded people and really encouraged and supported people in that role so that everybody actually can grow their capabilities and their sense of achievement, and I think that that showed a great sense of atunement to looking at each person and nurturing those individual journeys for each of us. (FLK, T)

Teachers described their positional leaders giving them opportunities for leadership, "where you get some responsibility, you're given some responsibility or take on some responsibility," and they appreciate the support of being "nurtured a bit, you know until you kind of find your feet and get up and on with it" (MEC, T). Scaffolding is offered as a temporary leadership approach, where the leader is more active and then gradually less active in supporting the developing leader.

\section{Theme 10: Fostering confidence}

Positional leaders and teachers in this study proposed that fostering confidence was an important aspect of the positional leader's role in developing teacher leadership. Confidence was regularly referred to by both leaders and teachers at these services as key to developing leadership, and as a barrier to distributed leadership when confidence is low. 
Probably a main thing would be their beliefs in themselves, their self-esteem, their confidence in themselves to be actual leaders... Perhaps overcoming that notion of you know, "I need to be in a positional role to be identified as a leader." (HSE, PL)

And I think confidence motivates $m e, . .$. if I'm confident in something and we've got this opportunity for somebody to step up and I'm feeling confident about that then I might, whereas if I'm not feeling confident then I'm not motivated to step up and say, "Yeah I'Il take on that leadership role." (FLK, T)

Positional leaders described leadership practice which intentionally fosters confidence in their teachers:

I guess it's acknowledging and encouraging people who perhaps don't see leadership as something they can do or should do, so I think that's a challenge is to help provide you know, again, positive strategies for those members of the team to feel like they absolutely have something to contribute. (MEC, PL)

Further to the positional leader's role in fostering confidence, teachers also propose that fostering confidence in each other is part of distributed leadership; leadership development is the responsibility of the group rather than only the positional leader in these environments:

That's a part of distributed leadership is that, helping others to see the potential within themselves and yeah, see themselves as leaders... we've all got that potential and it's about, you know, leading yourself or helping others to you know, to see that in themselves. (MEC, T)

Although these are identified high performing teams in terms of distributed leadership and professional learning, it's interesting to note that confidence is spoken of as an issue in the present tense in these teams, and is described as an ongoing challenge for teachers wanting to engage in leadership.

\section{Theme 11: Providing resources and expertise}

Teachers and positional leaders talked about the positional leader's role in supporting teacher inquiry by finding academic articles and offering advice and guidance. This was 
described as a supportive strategy for leadership development; when teachers were attempting to lead an initiative for the first time, they sometimes relied on the positional leader to provide resources and expertise to overcome challenges.

Like if you've got an issue or something, she's always a pretty good, wiling person to communicate with. She's very responsive, and you know she's got great ideas and the feedback's the important, she can put you on the right track, offer you advice, feedback's good. (FLK, T)

Positional leaders were intentional about providing resources and expertise, for example by contributing research to add depth to team professional dialogue and learning:

So during those times when the team is together, if there's things that teachers are not too clear on, then I like to do a bit of research around that topic and then give them that information from there. (FLK, PL)

The positional leaders' practice of providing resources and expertise was purposeful, and clearly valued by teachers working in a distributed leadership environment, one teacher saying that the "time that we spend talking and learning from [the positional leaders] is priceless" (HSE, T).

\section{Theme12: Fostering well-being and relationships}

Positional leaders proposed that fostering well-being and relationships in teams was important to supporting the development of confidence, and then further, to supporting the development of leadership and learning.

I believe that to be an effective leader, I need to work on that connection with that relationship, as well as with the team, it all comes down to them trusting me that I actually care about them... they are not just a person working with me, that I actually care about who they are and what they are going through. (HSE, PL)

Relationships are absolutely the foundation of anything that's going to happen in a positive fashion so I think by promoting really good open, positive, respectful and reciprocal relationships with your teaching team and then you should be able to enable leadership, you know where it, where potential lies I think. (MEC, PL) 
In all six interviews, personal well-being and positive relationships featured as important factors in distributed leadership and collaborative professional learning, at times in a supportive sense and at other times conversely as a possible barrier when well-being and relationships are strained.

Both positional leaders and teachers referred to the particular role of the positional leader in fostering positive team relationships, describing the resulting relational environment as supportive of leadership development and professional learning.

\section{Theme 13: Developing shared vision and shared understanding}

Positional leaders in these teams facilitated the development of a shared vision and teaching philosophy, and used these as tools to gain shared understanding. Teachers and positional leaders saw value in developing a shared vision of where the team want to head together in teaching practice:

Each person has their own role but we have this shared vision, and if everybody's always working towards it then we're always leading our professional learning but we have some guidelines about sort of what we are wanting. (HSE, T)

These teams used such shared understanding to guide them through times of uncertainty or challenges:

That's where your team philosophy's quite important, you can sit down and nut that out and you all have that common vision, and when things may be a challenge you can go back and say, "Look, we've got our philosophy, this is what we've decided to do as a team, are you still seeing it the same way and if not what can we do?," or, "Yes, I'm still seeing it the same way, I just needed to be reminded about that." (FLK, $\mathrm{PL})$

Conversely, the need to gain shared understanding about best practice was also raised as one of the possible challenges of teaching and learning together as a team:

When people have got different opinions, that is a challenge, and working out the right way to listen and understand what someone else is saying and combining that with what you think or say, and you know when there's eight of you... it can take a 
while to negotiate all of those ... slightly different ways of thinking and understanding and opinions, so I guess that is a challenge. (MEC, PL)

Shared vision was an area which was highlighted by participants from each of the three services, and by both teachers and positional leaders, as an important factor for these teams to provide direction and cohesion in distributed leadership and professional learning.

\section{Theme 14: Developing and implementing systems and roles}

Positional leaders and teachers describe various systems and designated roles which encouraged and supported distributed leadership and professional learning. Appraisals were one common system which is mentioned in each of the centres as an effective system for leadership development and professional learning. One teacher at Mansfield described the link between appraisals and leadership:

I think it's also having... performance appraisals and things to help reflect on your practice and to get her advice on how you can challenge yourself and take on more of a leadership role, I think that's really helpful. (MEC, T)

The positional leader at Hall Street explained the intentionality of using appraisal as a vehicle for developing teachers' leadership:

It is through appraisals that I find out what their strengths are, what their passions are, and from there I guess I keep it in mind that this teacher is keen on this, so if an opportunity arises I will say to her, this is a chance for you to grow in that, or if presenting a workshop is something that they are aspiring for then the next seminar I will intentionally ask them to do that and prepare a presentation. (HSE, PL)

Teachers, engaged in leadership within these distributed leadership environments, also took responsibility for implementing and maintaining these systems for leadership development for themselves and each other:

We've got our appraisal, and they play probably a huge part in discussions and where you want to head as a teacher... So we're each knowledgeable, or try to be knowledgeable about each other's goals so we can support each other in each other's goals. (FLK, T) 
This is one example of how a distributed leadership environment results in teachers enacting some of the leadership practices of positional leaders.

A distinct set of systems and roles related to teacher leadership and learning were described by the positional leaders and teams at each of the three services, and the various ways in which the positional leader facilitated these systems and roles are detailed. One clear example is the Kaitiaki role at Fernlea, described in the Fernlea section above. Another unique example is Hall Street's Education Leader positions, teachers with added responsibility for leadership of the educational programme:

We've got two Education Leaders here and... those people are working at another level as adult educators in an exceptional way. I don't know that it happens in very many other centres and they, they too take the lead when we're presenting to our professional colleagues in our... seminar days. So if they're not presenting, they're coaching, quietly mentoring, cheering, laughing, all of those things to make those other things happen. (HSE, co-owner in teacher group interview)

Positional leaders took responsibility for designing, implementing and maintaining these systems and roles for the purpose of developing leadership and fostering ongoing professional learning within the workplace.

\section{Conclusion}

In sum, the data from the interviews in this study have given a broad view of leadership practices related to distributed leadership and professional learning. Themes have emerged detailing practices and outcomes related to the research questions, and a picture of effective leadership practice has begun to develop. In the following discussion chapter, further analysis of these themes will be undertaken in relation to the literature, and related to the survey data from the first part of the study. 


\section{Chapter six: Discussion}

\section{Introduction}

This study has examined the intersection between distributed leadership and professional learning in ECE contexts. A positive relationship between the two areas of practice has been established through the literature; data from the survey conducted for this project illuminates the extent to which ECE services practice distributed leadership and professional learning according to teachers and positional leaders throughout the sector. A set of interviews with high performing services was coded and categorised in the findings: it highlighted the perceived benefits of distributed leadership for professional learning as well as the key role of the positional leader in enabling both.

In this chapter the interview findings are analysed, and connections are made with the literature and the survey data where relevant. I use these to construct a framework of the beneficial effects of distributed leadership on professional learning and of effective leadership practices that enable both. The framework is meant to guide positional leaders in ECE in facilitating distributed leadership for professional learning.

\section{Working towards a framework of effective leadership practice}

This section analyses the interview findings in relation to literature and survey findings to develop a framework for effective leadership practice. The 14 themes which emerged from the interview findings are drawn together into six key ideas here. In the findings chapter, the themes were organised in response to the two research questions. In this discussion section, the six key ideas are built into a framework which brings the two research questions together to illustrate the learning benefits of distributed leadership for teachers and positional leadership practices which are effective (see Figure 6.1). 
Figure 6.1: Distributed leadership for professional learning framework

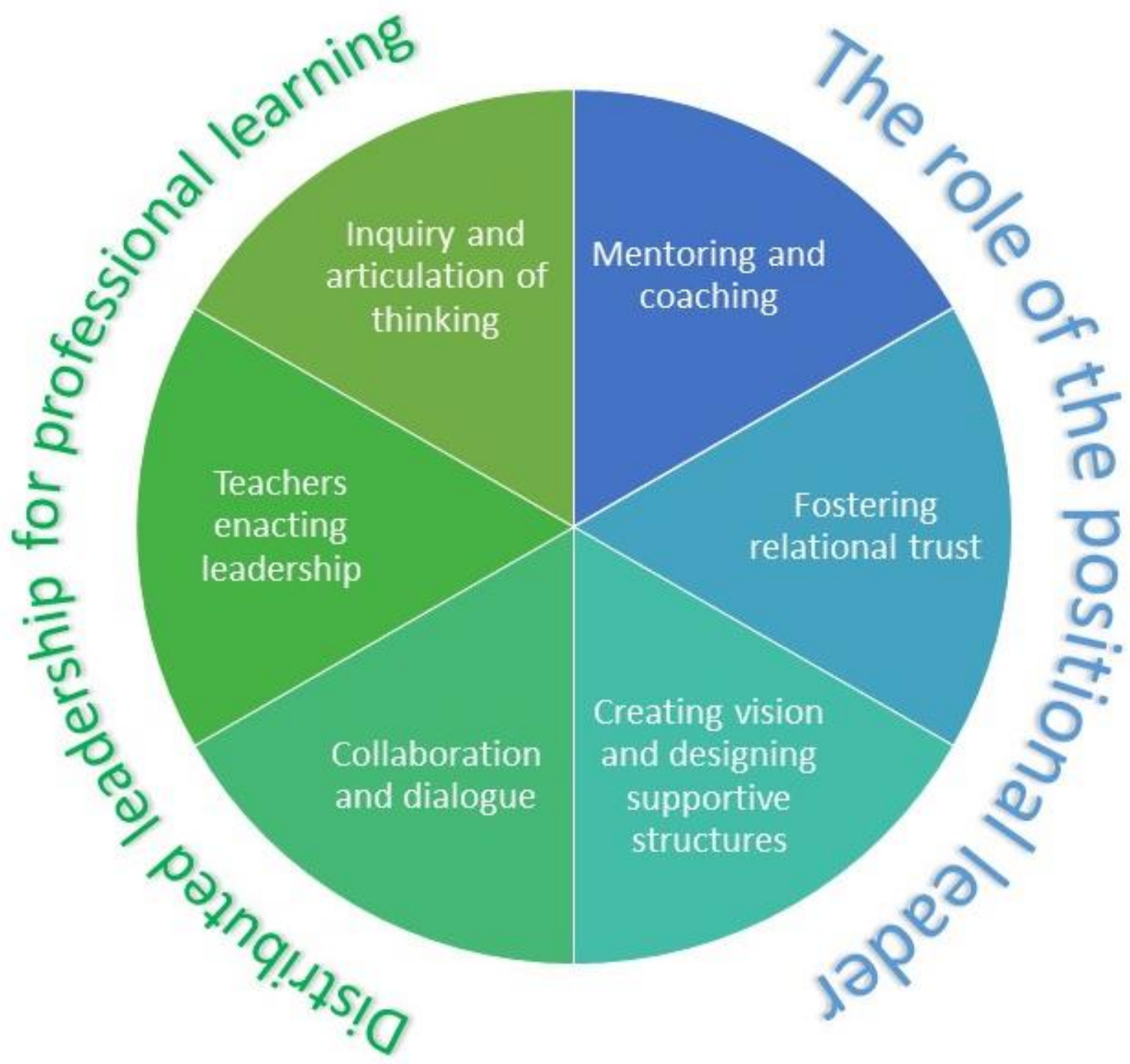

\section{Distributed leadership for professional learning}

This section addresses the first research question of the study, 'How does distributed leadership contribute to teachers' professional learning in early childhood education settings?'

Inquiry and articulation of ideas

The teams and positional leaders interviewed described a pathway where teachers engage in distributed leadership. The pathway involves teachers leading inquiry into practice and 
then articulating their ideas and, ultimately, changes in workplace practice as well. These teachers learn effectively when engaged in inquiry within their work context, and the professional learning is clarified and increased when they present their thinking to others. Two themes resulting from the interview findings contributed most strongly to this key idea: Teacher inquiry improves teaching practice; and Articulation of thinking results in learning for both the presenter and the audience. The survey findings are not referred to in this section due to lack of relevance.

From the interviews, it appears that distributed leadership fosters inquiry in two ways: by increasing teachers' confidence to raise questions; and by giving teachers opportunities to lead inquiry and innovation in areas of interest to them. In other words, two characteristics of professional learning communities, collective learning and application, and shared personal practice (Hord, 1997) occur within the culture of distributed leadership. In addition, distributed leadership encourages criticality, a feature of shared collective practice that can present difficulty (see Shared personal practice, in Chapter 2: Literature Review).

Teachers who see themselves as leaders take responsibility for leading inquiry, initiating projects and influencing change. Teachers are motivated to lead learning in areas of interest and prompted by real challenges as they come up. The resulting professional learning is engaging and meaningful to the team. One teacher interviewed described how effective professional learning is designed and implemented within the specific context the team is working in:

It's relevant, it's what we want to learn about instead of someone else coming in and harping on about stuff that's not relevant, and within our team if someone's leading it they also know that there's challenges, and so we can nut our way around it, instead of coming away from the PD somewhere else and going, "That was awesome but how's it going to work in my centre?" We make it work 'cause it's presented to us by people who know what our obstacles are. (HSE, T)

Teachers explained that they find professional learning engaging when it is led by one of the teaching team. The teacher who takes a leadership role in an inquiry can act as a resource, and the team are able to come back to that person over time as questions arise. This 
creates genuine ongoing reflective learning in a kind of action learning cycle, as practices are examined, new ways tried out and reflected upon, and further adjustments made.

These benefits of distributed leadership mirror claims about the benefits of professional learning communities as a whole (see Hord, 1997; Stoll, 2011; Webster-Wright, 2009). Interestingly here, though, it is both the teachers who assume leadership of a particular learning area as well as their colleagues who see improved engagement, outcomes and empowerment.

In the teams interviewed, the teacher taking the lead in an area of inquiry will often present some of the research and thinking to others, usually to their team members, and sometimes to parents or to professionals in the wider professional community. This aspect of leadership turns out to be a powerful learning experience for both the presenter and the audience. The most obvious learning here is that of the audience, who are receiving information and ideas in some kind of organised way as intended by the presenter. The learning for the presenter is more surprising and somewhat hidden from immediate view. The presenter is required to develop thinking, ideas and knowledge into a coherent format for presentation, and this turns out to be a reflective learning process in itself. The teachers interviewed highlighted this aspect of their professional learning as a benefit and necessary stage to concretise their learning.

This resonates with Poekert's (2012) claim that "teacher leadership leads to improved professional learning for colleagues and the teachers themselves" (p. 170). Similarly, Webster-Wright (2009) points to the centrality of "active" reflection (Boud, Keogh, and Walker, 1985, p. 7, as cited in Webster-Wright, 2009, p.722) within learning processes and, in a paraphrase of Kolb (1984), includes the "formulation of concepts" as part of this process. This "formulation of concepts" is precisely what teachers describe in their inquiry and preparation of professional learning, and this occurs in a necessarily concrete form.

The findings from this study suggest that inquiry and articulation complement one another, in that together they improve engagement and relevance and enable sustainable learning. Together they necessitate critical reflection and form a core outcome of distributed leadership within professional learning (Poekert, 2012). As such, they are a necessary part of a framework for professional learning within Aotearoa New Zealand in ECE. 


\section{Teachers enacting leadership}

This study suggests that distributed leadership empowers and motivates teachers to improve practice. According to interview participants, when teachers enact leadership, they become engaged in professional learning. Further, everyone benefits from the diversity of the team as each person is empowered to share their different strengths and interests. The positional leaders and teachers interviewed in this study place high value on distributed leadership in terms of their own empowerment and motivation and also in terms of experiencing the leadership enacted by their teacher colleagues.

This key idea relates most strongly to three themes from the interview findings: Diversity of leadership, knowledge, and experience provides rich learning; Engaging in leadership motivates teachers; and Empowerment of teacher leaders fosters professional learning. Each of these speaks to motivation and educational benefits of teacher leadership.

In order to participate in a distributed leadership environment, team members need to understand leadership as something that can be enacted by teachers and others. This requires a shift in thinking away from traditional models of leadership. As Lambert (2003, p. 4) has indicated, "how we define leadership frames how people will participate in it." The positional leaders interviewed said that one of the challenges to facilitating distributed leadership is helping teachers to change their perception of what leadership looks like. One positional leader explained that she approached this challenge by trying to, "unlock people's view and understanding of what leadership can be, what it can look like and... how it can be different for everyone" (MEC, PL). Where positional leaders talked about the difficulty of instilling this different perspective on leadership, teachers focused more on how much they enjoyed participating in a different kind of leadership, and how beneficial they felt it was to them to have leadership open to all. Teachers described resulting motivation, empowerment and engagement in professional learning, and gave examples of following their interests and feeling encouraged by their positional leader and their team. One teacher explained that her motivation to engage in leadership stemmed from "the opportunity to grow both personally and professionally when you take on different roles" (HSE, T). The teacher's descriptions mirror the claims put forward in literature on highlyfunctioning professional learning communities (Hord, 1997; Webster-Wright, 2009), 
however the teachers in this study attribute it specifically to the opportunity of leadership from within their respective teams.

The positional leader's role in this key idea is developed through the second half of the framework: mentoring and coaching; developing relational trust, and creating vision and design. The team also have a role in supporting each other's leadership; teachers interviewed talked about looking for ways to encourage team members to enact leadership, and being aware of each other's goals so that they could support one another's development. When teachers take responsibility for encouraging and developing each other's leadership, they are enacting leadership through this responsibility. This is a constructive cycle, with the potential to bring about positive change and meaningful development throughout a team.

In this light, the survey data can be read in in two ways. In order to engage in this part of the professional learning framework, teachers need opportunities to enact leadership, however, they also need to have a broader understanding of leadership - one that is based in practice rather than position. The teachers and positional leaders that I interviewed were identified as already having good distributed leadership and professional learning practices; it is possible that throughout the broader sector, positional leaders may also need to challenge and develop their concepts of leadership before distributed leadership can occur. This first level of understanding seems a necessary precursor to more specific and practical application within the learning community.

It is clear that the varied practices of leadership need to be recognised and teachers need to be empowered to assume these varied practices. In line with the literature, this will improve enthusiasm and morale (Clarkin-Phillips, 2009; Sheppard, Hurley \& Dibbon, 2010) and these factors in themselves can be considered incentives to improve practices (Spillane, Halverson \& Diamond, 2004). The role of the positional leader in constructing a context in which teacher leadership occurs will be addressed shortly, but it is also important to note that both teachers and positional leaders need to develop their understanding and skills in leadership. 


\section{Collaboration and dialogue}

Professional dialogue is an element of collaborative learning in ECE teams; teachers and positional leaders highlight collaboration and dialogue as essential to co-constructing new knowledge and sharing thinking in teaching teams. This key idea draws on two themes from the interview findings: Professional dialogue amongst teacher leaders is constructive; and Collaborative learning results in transfer of learning. This idea clearly links distributed leadership to professional learning in that distributed leadership results in collaboration and dialogue, and collaboration and dialogue improve teaching practice. When teachers collaborate on new learning, they are able to support one another in the process of trying out new practices, and can bring their various understandings together to create a stronger and more complex shared understanding than the understanding an individual teacher can likely develop alone. Both the professional learning literature and the ECE literature in Aotearoa New Zealand focus on collaboration as a key feature of effective practice (see, for example, Cherrington \& Thornton, 2013; Mitchell \& Cubey, 2003) even where distributed leadership is not mentioned as a model.

When teachers see themselves as leaders, they develop a culture of brave professional dialogue. This culture allows team members to raise issues and question practices and habits, opening up to inquiry into current and potential practices. As one teacher explained, "there's a little bit of debate, you kind of open each other's eyes to new perspectives and it's good... not necessarily having to agree with each other... it gives you room to think" (MEC, T). Participants described enjoying the dynamics of constructive professional dialogue. This space to think and formulate new ideas resonates with Rinaldi's (2006, p. 184) description of, "an idea of dialogue not as an exchange but as a process of transformation," where the ending is unknown and possibilities are open.

The survey data support the idea that collaboration and dialogue are important to ECE teams. The first section of the survey - 'Collective learning and application of learning' - had most positive response overall, and is also the section with the most agreement across all groups of participants. As noted in the survey discussion above, the vast majority of participants responded positively to a variety of statements about shared personal practice and collaborative learning. Three of the four statements responded to most positively in the entire survey were focused on professional dialogue and collaboration. These survey 
findings indicate that collaboration and dialogue is a current strength in ECE professional practice. As the interviews show, it is possible to utilise this powerful team practice to offer further opportunities for teachers to engage in leadership, and to promote further professional learning by practising leadership that intentionally focuses on collaboration and dialogue.

On the other hand, the survey data also revealed that opportunities "to provide feedback to peers related to strengthening teaching practices" were not rated as highly by teachers or positional leaders. The numerous negative comments about teachers and leaders holding onto power or holding on to old ways of doing things indicates that there is frustration when collaboration and shared practices are not enacted, or when others could not be trusted to put the educational goals of the team ahead of personal agendas. Colmer (2008, p.110) describes this occurring in her own attempts to develop a learning organisation, and she argues that mentorship is required for everyone who leads to see these challenges from a different perspective. It is interesting, in this regard, that opportunities for mentorship also rated poorly on the survey. The relative lack of opportunity for peer feedback may also speak to the difficulty in critically discussing individual practices rather than, say, general approaches to practice. Thornton and Wansbrough (2012) point out, for example, that the close working conditions in ECE may present a barrier to criticality. Once again, then, this is a necessary part of the framework that needs conscious development but that also requires other types of support from positional leaders. The section below, on developing relational trust, can be seen as tightly bound to collaboration and dialogue in this regard.

\section{The role of the positional leader}

This section addresses the second research question of the study, 'What is the positional leader's role in facilitating distributed leadership for professional learning?'

\section{Mentoring and coaching}

The literature review provided a brief overview of the wide ranging concept of 'Mentoring and coaching' - the interviews revealed the multiple ways that mentoring and coaching 
supported teachers and their professional learning. This category was a difficult part of the framework to construct because comments related to mentoring and coaching featured throughout all of the themes. However, four themes spoke to the concept most directly: Mentoring and coaching; Scaffolding; Fostering confidence; and Providing resources and expertise.

Leadership practices related to mentoring and coaching which were most raised in the interviews include facilitating goal setting, using questioning to provoke thinking, and providing adaptable levels of support depending on the teacher's stage in an area of learning. Clarkin-Phillips (2007) argues that mentoring and coaching support distributed leadership - my findings support this statement. Importantly, the role of mentor or coach is not strictly one of expertise, but also require the positional leader to be 'tuned in' to individual teachers' professional learning, as described by one positional leader interviewed:

If you've got those relationships with your teachers and you know who they are as teachers but also who they are as their own person, you can help and support and mentor them to be capable leaders in different aspects of their teaching careers. (FLK, PL)

Harrington (2015, p.181) describes this close understanding of the mentee as part of the beneficial learning experience for the mentor, a symbiotic relationship. In this way, mentors are truly members of learning communities as well as operating distinct forms of leadership.

The survey data brings up a concern about how mentoring and coaching is being practised and enabled in the wider ECE sector. A concerning disagreement between teachers and positional leaders arises in the statement, 'Opportunities exist for mentoring and coaching,' and also in the statement, 'leadership is promoted and nurtured among teachers.' As discussed earlier in this chapter, it is a concern worth addressing because those in the position to provide mentoring and coaching, and to nurture leadership in teachers, perceive this as already happening, whereas teachers who could benefit from mentoring and coaching do not perceive this as happening to same extent. Teachers are not experiencing mentoring and coaching as it is intended to be offered by their positional leaders. Positional leaders may not seek to improve this area of leadership practice when in fact it is in need of strengthening. 
In contrast to the survey data, interviews highlighted the explicit use of mentoring and coaching. This was recognised not only by the positional leaders but the teachers as well. And in addition to the improvements that individuals could then bring to professional learning, it is clear that mentorship and coaching made teachers feel valued and understood as individuals. Interestingly, this 'softer skill' in mentoring was implicitly acknowledged by leaders as they recognised that developing personal connections and personal understanding of others' learning journeys was also integral to leadership development. In this way, the positional leaders - regardless of any formal training in the area - had a great deal of understanding about mentoring and coaching.

Mentoring and coaching literature provides clear guidance on strategies and processes which have been proven through research to help individuals make progress towards meaningful goals (Brockbank \& McGill, 2007; Rowley, 2006; Thornton, 2015). This study suggests that such guidance may support positional leaders to facilitate the growth of distributed leadership and professional learning in ECE teaching teams.

\section{Developing relational trust}

Relationships and well-being are factors that came up time and again in the interview data, across all three teams and in positional leader and teacher interviews. Relationships are highlighted as affecting confidence, in terms of enacting leadership and also in terms of participating in and leading professional learning. These teams report experiencing high levels of relational trust, citing this as an important factor in their ability and willingness to participate in distributed leadership and professional learning. There is a clear expectation that it is part of the positional leader's responsibility (and talent) to nurture relational trust and personal well-being for the sake of teacher development.

This key idea, developing relational trust, is directly drawn from Theme 12 in the interview findings, Fostering well-being and relationships. It has important connections to several other themes, in particular those related to collaboration and confidence.

The focus in this key idea is the positional leader's role in developing relational trust. According to this study, ECE positional leaders have a responsibility to develop a positive and high functioning relational environment in the team in order for teachers to be able to 
engage in distributed leadership and professional learning, an idea which is supported in the literature (see Stamopoulos, 2012; Stoll, 2011; Thornton \& Cherrington, 2014). Teachers want to feel secure to bring up issues and to have robust professional dialogue, and they want to feel supported by the positional leader and also the team when pushing themselves to try out leadership in ways that are new for them.

Further to the positional leader's role, there is also an expectation of support from each other in the teams interviewed. In a distributed leadership environment there is often a blurred line between the leadership responsibility of the positional leader and the responsibility of every team member to enact leadership (Timperley, 2005), and that includes developing relational trust. One teacher described the benefits of the relational trust in her own team environment, explaining that:

If you're leading something and for some reason you don't feel okay with something... you always know that there's some other teacher that's going to step up for you and support you. (HSE, T)

Teachers appreciate the extra support of a whole team surrounding them, as opposed to relying on the support of one leader in a hierarchical model. Positional leaders benefit from knowing the team are helping work toward a climate of relational trust, and also benefit from being supported themselves as a member of the team.

Developing relational trust stands out from this study as one of the most important foundational factors in creating an environment of distributed leadership for professional learning. Interestingly, the section from the original survey on relational trust was excluded from the current survey in order to keep the research scope manageable (this will be further explained in the limitations section of the conclusion chapter). However, the importance of developing relational trust was so clear in both the survey qualitative comments and also the interview data, that it demanded a space in the resulting framework of effective leadership practice. This supports an emphasis in the literature on the importance of relational trust as a foundation for professional learning community and distributed leadership approaches (see, for example, Morrissey, 2000; Murphy et al, 2009; Stoll, 2011; Thornton \& Wansborough, 2012). 
Even though the survey did not include questions directly on relational trust, the qualitative comments featured on relationships with trust being an implicit factor that either enabled or thwarted effective professional learning and shared practice. It is clear from both parts of this research project, the survey and interview data, that positive and functional professional relationships must be addressed as the foundation for successful distributed leadership and professional learning. The positional leader has the power and the responsibility to focus on relational trust to support team development and ultimately to benefit children's learning in ECE.

\section{Creating vision and designing supportive structures}

The positional leader who aims to promote professional learning through a distributed leadership environment has an important role in oversight, keeping the 'big picture' in mind. The teams interviewed saw the positional leader's role in part as creating and sustaining shared vision and understanding, and designing systems and roles to develop and support distributed leadership and professional learning. These expansive tasks are ongoing, mirroring the philosophy of ongoing learning inherent in a professional learning community. These findings support previous research (e.g. Huffman \& Hipp, 2003; Robinson et al, 2009) but are expanded upon here, particularly in relation to creating vision about leadership and professional learning. Also, the interviews make clear that commitment to overseeing teacher's leadership and learning is not a one-time task. This key idea is mainly drawn from two themes from the interview findings: Developing shared vision and shared understanding; and Developing and implementing systems and roles.

The practices of developing shared vision and shared understanding have links to several of the other key ideas in this framework. Shared vision is mentioned in the Mentoring and coaching section as an aspect of the positional leader's role in coaching the team, and has relevance to mentoring and coaching individuals on goals that connect to the vision and goals of the service as a whole. The development of shared understanding is integral to the development of relational trust in a teaching team. Professional learning and inquiry is strengthened when the positional leader maintains group awareness of the team's shared vision, ensuring that the professional learning contributes toward aims for improvement. 
The interdependence of the elements of professional learning communities is implicit within much of the professional learning community literature, beginning with Hord (1997), but how these relate specifically to the positional leader is an area of research still in its infancy (Colmer et al., 2015; Marsh, 2015). In the interviews, the ongoing visionary role of the positional leader was illustrated by one teacher who used the metaphor of a river to represent the team's professional learning journey, explaining that the positional leader provides the structure to guide the river's direction as it flows (FLK, T). By looking at the influence of shared vision on the rest of the key ideas in the framework, this leadership practice can be seen as having far-reaching impact on distributed leadership for professional learning.

The interview findings have shown that shared vision also, importantly, includes communicating a vision about how professional learning operates and what leadership means within that context. Positional leaders reported this type of communication as laying the groundwork for professional learning. This is because this vision needed to occur prior to (and continue along with) the implementation of systems that facilitate shared professional practice. This aspect of the vision is crucial in developing the structures needed for sustained and engaged professional learning in that it precedes teacher empowerment and autonomy, especially for teachers with traditional understandings of leadership. The idea of a shared vision guiding leadership development supports Lambert's assertion that, "it is so important to use a shared vision as the guidepost for building leadership capacity" (2003, p. 19). In short, this study suggests that if positional leaders do not establish shared understanding of the ways that leadership operate and contribute to learning, the many benefits of having teachers who contribute to professional learning will not be realised.

The second part of the positional leader's oversight in this key idea is a responsibility for designing systems and roles. Well-designed organisational structure can create opportunities for teachers to lead, and can facilitate ongoing teacher development by providing the support needed. Distributed leadership and professional learning in the workplace require teachers to have time, space, opportunities and resources, as highlighted through the survey data, the interview data, and the literature (Colmer et al, 2014; Murphy et al, 2009; Stoll, 2011). A key example of this is evident in the Hall Street team where significant time and planning had gone into developing systems so that teachers could work 
on focused professional development within shared time. The creation of these systems enabled the service to manage the structural constraint of time where other EEC services complained that this was their biggest limitation to professional learning.

While positional leadership cannot improve all of the structural conditions facing EEC (for example, the positional leaders likely have limited influence on changes to funding) it can nevertheless provide a more enabling or disabling context for professional learning. Just as the positional leader can refocus individuals on the shared vision and goals of the team, they can also help shape an environment that facilitates this refocusing.

\section{Conclusion}

This chapter has brought diverse findings from all stages of the research together into a sixpart framework of effective leadership practice. The framework offers insight about effective leadership practices that contribute to creating a professional learning community where teachers engage in leadership and where professional learning is embedded and ongoing. 


\section{Chapter seven: Conclusion}

\section{Overview}

This final chapter summarises the research findings, and consideration is given to the implications for the ECE sector, including recommendations for policy and practice. Limitations of the research are outlined and recommendations for future research are made.

\section{Summary of research findings}

This research project aimed to examine perceptions and practices about distributed leadership and professional learning in ECE settings. The first phase of the research was intended to explore the perceptions of ECE teachers and positional leaders in the context of Aotearoa New Zealand, about current experiences and practices of professional learning communities and in particular leadership practices for distributed leadership and professional learning. The findings of the survey were generally positive regarding professional learning and leadership practices, but highlighted some areas of inconsistency and areas of concern worth further examination. The next phase of the research involved an in-depth qualitative study of three previously-identified high-quality ECE services, using individual interviews with positional leaders and focus group interviews with their teaching teams. The interview findings highlighted effective leadership practices which facilitate distributed leadership and professional learning, and the benefits of such practices for the development of ECE teachers. The findings were analysed and organised into a framework of effective leadership practice in order to answer the two research questions: How does distributed leadership contribute to teachers' professional learning in early childhood education settings? And, what is the positional leader's role in facilitating distributed leadership for professional learning?

Effective positional leaders and the teachers who work with them described strengths that develop as a direct result of sharing leadership roles for the purpose of professional learning. They also identified a broad range of practices that contribute to effective leadership. Although the services interviewed represented diverse communities and service types, and although some had very structured systems in place whereas others focused on 
flexibility, a number of common strengths and practices emerged. From these, it is clear that distributed leadership and professional learning were considered symbiotic and that positional leaders needed to develop certain leadership practices within their services in order to successfully enact both.

The important practices for leaders are: developing a shared pedagogical vision and a shared leadership/learning vision; structuring the service to enable distributed leadership and professional learning; mentoring and coaching; and developing relational trust. When these areas are considered in relation to the survey data, one can hypothesise that differences in perception between teachers and positional leaders across the sector may be due to dissimilar understandings about leadership, lack of skills or lack of understanding about how mentoring and coaching functions, lack of appropriate systems to support professional learning and distributed leadership, and lack of relational trust. The qualitative data from the survey - though a much smaller data set - supports all of these hypotheses.

The framework developed in the discussion chapter offers clear priorities in leadership development for professional learning alongside its benefits to professional learning for all teachers.

\section{Implications for the ECE sector in Aotearoa New Zealand}

The requirement for registered teachers in Aotearoa New Zealand to demonstrate their leadership practices provides obvious structural encouragement (or imperative) for the types of practices that enable professional learning and distributed leadership. The survey data paints a somewhat mixed picture about the extent to which these practices are occurring. The data is generally very positive, but when comparing groups, it is also clear that teachers do not feel that practices are as good as positional leaders do. Disparities between the groups are highlighted in perceptions about mentoring opportunities, supportive leadership practices, and teacher agency. These disparities map onto the framework developed in this thesis, suggesting that leadership practices across the sector would benefit from development specifically related to the leader practices that l've identified. 
The biggest challenge to leadership development in the sector remains the lack of a standard training programme for leaders. This issue has been raised repeatedly, both in governmental plans for the sector and by the institutions that monitor and support teaching and learning in ECE (Thornton et al., 2009; ERO, 2016). The Advisory Group on Early Learning, commissioned by the Ministry of Education, recommended a major professional development initiative for the ECE sector with a focus on leadership for learning over the next four years (Advisory Group on Early Learning, 2015). From 2019, the Education Council will become responsible for government funded professional learning; the Education Council has recently released a leadership development strategy for 2017 which proposes to include the ECE sector (Education Council, 2017). Whether funding becomes prioritised to include leadership development for ECE alongside the school sector remains to be seen. In the current situation, it is not surprising that without a standard leadership development programme, research projects that aim to improve leadership within the sector tend to use small scale trials that are limited in scope.

This research project breaks from that trend by drawing on the practices of highlyfunctioning services to understand the myriad ways that distributed leadership can be enacted as well as the role of the positional leader in nourishing distributed leadership and professional learning. The use of different service types - a community EEC service, a privately-owned EEC service and a kindergarten - demonstrates that distributed leadership and professional learning can be practised in a variety of ECE settings. Similarities between the teams and positional leaders interviewed also brought to light commonalities in the approaches of positional leaders despite their different contexts. Teachers, when given opportunities to enact leadership, lead and participate in inquiry and learn through articulation of thinking, and engage in collaboration and dialogue for improved professional learning outcomes. Effective positional leaders establish relational trust as a foundation for distributed leadership and professional learning, and utilise mentoring and coaching strategies to develop their team, while providing oversight and vision to teachers' development.

Based on the findings of this project, the researcher suggests the following recommendations for policy: 
- Fund a required programme of professional learning and development for ECE positional leaders, to increase effective pedagogical leadership practices across the sector;

- Increase ECE funding, to fund time for professional dialogue in ECE teams, and to stymie the recent cuts to non-contact time for teachers.

Following on from the results of this research, several recommendations for practice are suggested for positional leaders:

- Discuss reconceptualised notions of leadership with teaching teams, empowering teachers to participate in leadership;

- Learn and practice mentoring and coaching skills to facilitate teacher development;

- Create systems, time and space for teacher leadership so that the learning community can benefit from increased learning opportunities.

\section{Limitations of the research}

This research project aimed to give insight into current perceptions about distributed leadership and professional learning in the ECE sector in Aotearoa New Zealand, and to examine examples of effective leadership practice. However, as a small-scale qualitative project there are some clear limitations of the research:

- The survey sample, while reasonably large, was not designed to be proportionally representative of the sector. The self-selection method used resulted in uneven participation between various groups in the sector: teachers and positional leaders, and kindergarten and EEC employees.

- The three high-quality services chosen for interviews were selected in-part by geographical convenience, as the researcher did not have the resources to travel. Therefore, other possible exceptional leaders and teams around the country were excluded from selection. The selection was not broadly representative of practice in different areas of the country. 
- The fourth service, a Māori-immersion centre, had to withdraw from the project at the last minute due to an unpredictable event. The inclusion of a Māori perspective on leadership would have added relevance to the findings within the bicultural context of Aotearoa New Zealand.

\section{Recommendations for future research}

The findings of this research project have highlighted areas which may be of interest in future research. First, the unfortunate withdrawal of the Māori immersion centre from this project leaves a gap in understanding of how Māori perspectives on leadership interact with distributed leadership and professional learning; research could be undertaken to explore this so that practitioners in the sector may benefit from further bicultural understanding of leadership in ECE.

Second, differences in survey responses from teachers and positional leaders as well as from kindergartens and EEC services highlight that more research needs to be undertaken to understand more about these differences and why they are occurring.

Third, a programme for ECE leadership development could be designed using the framework in this project, with an accompanying research component to evaluate the effectiveness of such an approach.

\section{Final conclusion}

The symbiotic relationship between distributed leadership and professional learning for teachers has been explored through this research project. The ECE sector of Aotearoa New Zealand was surveyed to gain an overview of current perceptions, followed by an interviewbased study of three high quality services and their leadership and learning practices. The resulting framework of effective leadership practices is intended to provide guidance to those in positions of leadership in ECE, a group which has traditionally been left in the cold in terms of practical guidance and targeted professional learning. The researcher hopes that this study will contribute to a movement towards further support for these under-resourced professionals. 


\section{Reference list}

Advisory Group on Early Learning. (2015). Report of the advisory group on early learning. Wellington, New Zealand: Ministry of Education.

American Institute for Research (2017). Professional Learning Communities Assessment Revised. Retrieved from http://www.sedl.org/pubs/catalog/items/plc01.html

Atkin, J. (1996). From values and beliefs about learning to principles and practice. Paper presented at the Seminar Series No. 54, Incorporated Association of Registered Teachers of Victoria, Australia.

Aubrey, C., Godfrey, R., \& Harris, A. (2013). How do they manage? An investigation of early childhood leadership. Educational Management Administration \& Leadership, 41(1), 5-29.

Blaiklock, K. (2010). Te Whāriki, the New Zealand early childhood curriculum: Is it effective? International Journal of Early Years Education, 18(3), 201-212.

Brockbank, A., \& McGill, I. (2006). Facilitating reflective learning through mentoring and coaching. Philadelphia, PA: Kogan Page.

Brockbank, A., \& McGill, I. (2007). Facilitating reflective learning in higher education. Berkshire, United Kingdom: McGraw-Hill Education.

Campbell, G. (2013). Leadership practices supporting practitioner research. Journal of Educational Leadership, Policy and Practice, 28(1), 44.

Cherrington, S., \& Thornton, K. (2013). Continuing professional development in early childhood education in New Zealand. Early Years, 33(2), 119-132.

Clarkin-Phillips, J. (2007). Distributing the leadership: A case study of professional development. (MEd), The University of Waikato, Hamilton.

Clarkin-Phillips, J. (2009). Distributed leadership utilising everyone's strengths. Early Childhood Folio, 13, 22-27.

Clarkin-Phillips, J. (2011). Distributed leadership: Growing strong communities of practice in early childhood centres. Journal of Educational Leadership, Policy and Practice, 26(2), 14-25.

Clutterbuck, D. (2008). What's happening in coaching and mentoring? And what is the difference between them? Development and Learning in Organizations: An International Journal, 22(4), 8-10. 
Cohen, L., Manion, L., \& Morrison, K. (2013). Research methods in education. London, United Kingdom: Routledge.

Colmer, K. (2008). Leading a learning organisation: Australian early years centres as learning networks. European Early Childhood Education Research Journal, 16(1), 107-115.

Colmer, K., Waniganayake, M., \& Field, L. (2014). Leading professional learning in early childhood centres: Who are the educational leaders? Australasian Journal of Early Childhood, 39(4), 103.

Colmer, K., Waniganayake, M., \& Field, L. (2015). Implementing curriculum reform: insights into how Australian early childhood directors view professional development and learning. Professional Development in Education, 41(2), 203-221.

Cooper, M. (2014). 'Everyday teacher leadership': A reconceptualisation for early childhood education. Journal of Educational Leadership, Policy and Practice, 29(2), 84-96.

Cranston, J. (2009). Holding the reins of the professional learning community: Eight themes from research on principals' perceptions of professional learning communities. Canadian journal of educational administration and policy, 90(2), 1-22.

Day, D. V. (2001). Leadership development: A review in context. The Leadership Quarterly, 11(4), 581-613.

Dembkowski, S., Eldridge, F., Hunter, I., \& Whitmore, J. (2006). The Seven Steps of Effective Coaching. London, United Kingdom: Thorogood Publishing.

Dieronitou, I. (2014). Unveiling the restricted and extended possibilities of distributed leadership. Researchers World, 5(1), 37-43.

Education Council New Zealand. (2015). Practising Teacher Criteria. Retrieved from: https://educationcouncil.org.nz/content/practising-teacher-criteria

Education Council New Zealand. (2017). Leadership Strategy. Retrieved from: https://educationcouncil.org.nz/content/leadership-strategy

Education Review Office. (2016). Early Learning Curriculum: What's important and what works. New Zealand: Education Review Office.

Edwards, F. (2012). Learning communities for curriculum change: Key factors in an educational change process in New Zealand. Professional Development in Education, 38(1), 25-47.

Eraut, M. (2002). Conceptual Analysis and Research Questions: Do the Concepts of "Learning Community" and" Community of Practice" Provide Added Value? Paper presented at the Annual Meeting of the American Educational Research Association, New Orleans, Louisiana. 
Fletcher, S. J. (2012). Coaching: an overview. In S. Fletcher \& C. Mullen (Eds.) The SAGE handbook of mentoring and coaching in education (pp. 24-40). London, United Kingdom: Sage.

Fraenkel, J. R., Wallen, N. E., \& Hyun, H. H. (1993). How to design and evaluate research in education (Vol. 7). New York, NY: McGraw-Hill.

Fullan, M. (2005). Leadership \& sustainability: System thinkers in action. Thousand Oaks, CA: Corwin Press.

Harrington, C. (2015). Awakening beginning teachers' passion through mentoring. In C. Murphy \& K. Thornton (Eds.) Mentoring in Early Childhood Education: A Compilation of Thinking, Pedagogy and Practice (pp. 1-13). Wellington, New Zealand: NZCER Press.

Harris, A. (2013). Distributed school leadership: Developing tomorrow's leaders. New York, NY: Routledge.

Hatcher, R. (2005). The distribution of leadership and power in schools. British Journal of Sociology of Education, 26(2), 253-267.

Heikka, J. \& Waniganayake, M. (2011). Pedagogical leadership from a distributed perspective within the context of early childhood education. International Journal of Leadership in Education: Theory and Practice, 14(4), 499-512.

Hipp, K., Huffman, J., Pankake, A. \& Olivier, D. (2008). Sustaining professional learning communities: Case studies. Journal of Educational Change, 9(2), 173-195.

Hord, S. (1997). Professional learning communities: Communities of continuous inquiry and improvement. Austin, TX: Southwest Education Development Laboratory.

Hord, S. \& Sommers, W. (Eds.). (2008). Leading professional learning communities: Voices from research and practice. Thousand Oaks, CA: Corwin Press.

Huffman, J. \& Hipp, K. (2003). Reculturing schools as professional learning communities. Lanham, Maryland: Rowman \& Littlefield Education.

Huffman, J., \& Hipp, K. (2010). Diagnostic and Planning Tools. In K. Hipp \& J. Huffman (Eds.) Demystifying professional learning communities. School leadership at its best (pp. 4356). Plymouth, United Kingdom: Rowman \& Littlefield Education.

Johnson, B. \& Christensen, L. (2008). Educational research: Quantitative, qualitative, and mixed approaches. London, United Kingdom: Sage.

Lambert, L. (2003). Leadership capacity for lasting school improvement. Alexandria, VA: Association for Supervision and Curriculum Development. 
Leithwood, K., Mascall, B. \& Strauss, T. (Eds.). (2009). Distributed leadership according to the evidence. New York, NY: Routledge.

Ling, P. \& Ling, L. (2017). Introduction: Employing Paradigms in Education Research. In Methods and Paradigms in Education Research (pp. 1-18). Hershey, PA: IGI Global.

Ling, L. (2017). The Power of the Paradigm: Methods and Paradigms in Education Research. In L. Ling, \& P. Ling (Eds.), Methods and Paradigms in Education Research (pp. 19-41). Hershey, PA: IGI Global.

Marsh, S. (2015). A model for leadership that improves learning: new insights for schools and scholars. Leadership and Policy in Schools, 14(1), 67-103.

Merriam, S. (1998). Qualitative Research and Case Study Applications in Education. San Francisco, CA: Jossey-Bass.

Mertens, D. (2014). Research and evaluation in education and psychology: Integrating diversity with quantitative, qualitative, and mixed methods. London, United Kingdom: Sage.

Ministry of Education (1996). Te Whāriki: Early childhood curriculum. Wellington, New Zealand: Learning Media.

Ministry of Education (2002). Pathways to the future: Nga huarahi Arataki. A 10 year strategic plan for early childhood education. Wellington, New Zealand: Learning Media.

Ministry of Education. (2006). Ngā-arohaehae whai hua: Self-review guidelines for early childhood education. Wellington, New Zealand: Learning Media.

Ministry of Education. (2011). Leadership. Retrieved from http://www.educate.ece.govt.nz/learning/exploringPractice/EducationalLeadership/ LeadingProgrammes/Leadership.aspx

Ministry of Education. (2014). Leadership in Early Childhood Education for 5 out of 5 Children [brochure]. Wellington, New Zealand: Ministry of Education.

Ministry of Education. (2016). School Deciles. Retrieved from https://education.govt.nz/framework/main.php/running-aschool/resourcing/operational-funding/school-decile-ratings/?url=/school/runninga-school/resourcing/operational-funding/school-decile-ratings/

Mitchell, L. \& Cubey, P. (2003). Professional development in early childhood settings: Best evidence synthesis iteration (BES). Wellington, New Zealand: Ministry of Education.

Mitchell, J., Riley, P. \& Loughran, J. (2010). Leading professional learning in schools: emotion in action. Teacher Development, 14(4), 533-547. 
Morrissey, M. (2000). Professional learning communities: An ongoing exploration. Austin, Texas: Southwest Educational Development Laboratory.

Murphy, J., Smylie, M., Mayrowetz, D. \& Louis, K. S. (2009). The role of the principal in fostering the development of distributed leadership. School Leadership and Management, 29(2), 181-214.

Murphy, C. \& Thornton, K. (2015). Mentoring in early childhood education: A compilation of thinking, pedagogy and practice. Wellington, New Zealand: NZCER Press.

Nelson, T. H., Slavit, D., Perkins, M. \& Hathorn, T. (2008). A culture of collaborative inquiry: Learning to develop and support professional learning communities. Teachers College Record, 110(6), 1269-1303.

Newby, P. (2014). Research Methods for Education (2nd ed.). Florence: Taylor and Francis. Retrieved from http://ebookcentral.proquest.com/lib/vuw/detail.action?doclD=1734204

New Zealand Teachers' Council. (2009). Registered teacher criteria. Wellington, New Zealand: New Zealand Teachers' Council.

Ord, K., Mane, J., Smorti, S., Carroll-Lind, J., Robinson, L., Armstrong-Read, A., BrownCooper, P., Meredith, E., Rickard, D. \& Jalal, J. (2013). Developing pedagogical leadership in early childhood education. Wellington, New Zealand: Te Tari Puna Ora Aotearoa/New Zealand Childcare Association.

Palincsar, A. (1998). Social constructivist perspectives on teaching and learning. Annual Review of Psychology, 49(1), 345-375.

Poekert, P. E. (2012). Teacher leadership and professional development: Examining links between two concepts central to school improvement. Professional Development in Education, 38(2), 169-188.

Reynolds, B. \& Cardno, C. (2008). Leadership dilemmas in New Zealand early childhood education and care centres. Journal of Educational Leadership, Policy and Practice, 23(1), 18-29.

Rinaldi, C. (2006). In dialogue with Carlina Rinaldi: A discussion between Carlina Rinaldi, Gunilla Dahlberg and Peter Moss. In C. Rinaldi (Ed) In dialogue with Reggio Emilia: listening, researching and learning, (pp. 178-195). London, United Kingdom: Routledge.

Robinson, V., Hohepa, M., \& Lloyd, C. (2009). School Leadership and Student Outcomes: Identifying What Works and Why. Best Evidence Synthesis. Wellington, New Zealand: Ministry of Education. 
Rodd, J. (2013). Leadership in early childhood (4th ed.). Sydney, Australia: Allen \& Unwin.

Rowley, J. B. (2006). Becoming a high-performance mentor: a guide to reflection and action. Thousand Oaks, CA: Corwin Press.

Scotland, J. (2012). Exploring the philosophical underpinnings of research: Relating ontology and epistemology to the methodology and methods of the scientific, interpretive, and critical research paradigms. English Language Teaching, 5(9), 9-16.

Sheppard, B., Hurley, N. \& Dibbon, D. (2010). Distributed Leadership, Teacher Morale, and Teacher Enthusiasm: Unraveling the Leadership Pathways to School Success. Paper presented at American Educational Research 202 Association. Denver, Colorado. May 2010. Retrieved from http://eric.ed.gov/PDFS/ED509954.pdf

Spillane, J. P., Halverson, R. \& Diamond, J. B. (2004). Towards a theory of leadership practice: A distributed perspective. Journal of curriculum studies, 36(1), 3-34.

Stamopoulos, E. (2012). Reframing early childhood leadership. Australasian Journal of Early Childhood, 37(2), 42-48

Stoll, L., Bolam, R., McMahon, A., Wallace, M. \& Thomas, S. (2006). Professional learning communities: A review of the literature. Journal of Educational Change, 7(4), 221258.

Stoll, L. (2011). Leading professional learning communities. In J. Robertson \& H. Timperley (Eds.), Leadership and learning (pp. 103-117). London, United Kingdom: Sage.

Thornton, K. (2010). 'School Leadership and Student Outcomes': The Best Evidence Synthesis Iteration: Relevance for Early Childhood Education and Implications for Leadership Practice. Journal of Educational Leadership, Policy and Practice, 25(1), 3141.

Thornton, K. (2014). Mentors as educational leaders and change agents. International Journal of Mentoring and Coaching in Education, 3(1), 18-31.

Thornton, K. (2015). The impact of mentoring on leadership capacity and professional learning. In C. Murphy \& K. Thornton (Eds.) Mentoring in Early Childhood Education: A Compilation of Thinking, Pedagogy and Practice (pp. 1-13). Wellington, New Zealand: NZCER Press.

Thornton, K. \& Cherrington, S. (2014). Leadership in professional learning communities. Australasian Journal of Early Childhood, 39(3), 94-102.

Thornton, K. \& Wansbrough, D. (2012). Professional learning communities in early childhood education. Journal of Educational Leadership, Policy and Practice, 27(2), 51. 
Thornton, K., Wansbrough, D., Clarkin-Phillips, J., Aitken, H., \& Tamati, A. (2009).

Conceptualising leadership in early childhood education in Aotearoa New Zealand.

Wellington, New Zealand: New Zealanad Teachers Council.

Timperley, H. S. (2005). Distributed leadership: Developing theory from practice. Journal of Curriculum Studies, 37(4), 395-420.

Timperley, H., Wilson, A., Barrar, H. \& Fung, I. (2008). Teacher professional learning and development: best evidence synthesis iteration (BES). Wellington, New Zealand: Ministry of Education.

Torrance, D. (2015). Professional learning for distributed leadership: primary head teachers' perspectives. Professional Development in Education, 41(3), 487-507.

Torres, M. N. \& Mercado, M. (2004). Living the Praxis of Teacher Education through Teacher Research. Scholar-Practitioner Quarterly, 2(2), 59-73.

Vescio, V., Ross, D. \& Adams, A. (2008). A review of research on the impact of professional learning communities on teaching practice and student learning. Teaching and Teacher Education, 24(1), 80-91.

Watson, B. \& Williams, B. (2011). Leveraging the benefits of professional learning. Special issue: Professional Learning, 50, 22-32.

Webster-Wright, A. (2009). Reframing professional development through understanding authentic professional learning. Review of Educational Research, 79(2), 702-739.

Weisz-Koves, T. (2011). Developing teacher leadership in early childhood education in Aotearoa through a potential-based approach. Journal of Educational Leadership, Policy and Practice, 26(2), 35. 


\section{Appendices}

Index
A: Interview questions
B: Survey email
C: Information sheets for interview participants
D: Consent forms for interview participants
E: Survey questions 


\section{Appendix A: Interview questions}

Interview questions for positional leaders

Distributed leadership:

1. What do you intentionally do to encourage leadership in your teachers? What are your most successful strategies?

2. What challenges or barriers have you experienced in distributing leadership?

3. What drawbacks do you see, if any, to developing teacher leadership?

4. What motivates you to develop your teachers' leadership? What do you see as the benefits?

\section{Professional learning:}

1. What systems do you use to allocate time and space to professional learning in your team?

2. How are decisions made regarding what is learnt, and how it is learnt, in your team?

3. What challenges or barriers have you experienced in trying to promote professional learning?

4. What motivates you to promote professional learning in your team? What do you see as the benefits?

5. What supports you when you are promoting professional learning?

Distributed leadership for professional learning:

1. What leadership role do you take in your team's professional learning?

2. In what ways are teachers involved in leading professional learning in your team?

3. What challenges or barriers have you experienced in distributing leadership for professional learning?

4. What do you see as the benefits of teachers leading professional learning?

5. What do you intentionally do to encourage your teachers to lead professional learning? What are your most successful strategies?

Is there anything else you would like to comment on or add?

\section{Focus group interview questions for teachers}

Distributed leadership:

1. What opportunities do you have to enact leadership in your team? 
2. What motivates you to step up for leadership as a teacher?

3. What challenges or barriers have you experienced in enacting leadership?

4. What do you think are the best ways your positional leader can support and foster distributed leadership?

\section{Professional learning:}

1. What systems are used to allocate time and space to professional learning in your team?

2. How are decisions made regarding what is learnt, and how it is learnt, in your team?

3. What challenges or barriers have you experienced in trying to engage in professional learning?

4. What motivates you to engage in professional learning? What do you see as the benefits?

Distributed leadership for professional learning:

1. What leadership role does your positional leader take in your team's professional learning?

2. In what ways are teachers involved in leading professional learning in your team?

3. What challenges or barriers have you experienced in stepping up to lead professional learning?

4. What do you see as the benefits of teachers leading professional learning?

5. What do you think are the best ways your positional leader can support and foster teachers' leadership of professional learning?

Is there anything else you would like to comment on or add? 


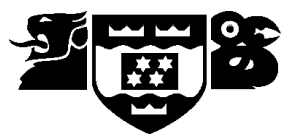

FACULTY OF EDUCATION

\section{Calling all qualified ECE teachers and leaders!}

Kia ora! My name is Rachel Denee and I'm undertaking a Master's degree in educational leadership at Victoria University of Wellington. I am interested in finding out more about the relationship between distributed leadership and professional learning in early childhood education in New Zealand.

You are invited to participate in an anonymous survey that explores teachers and leaders' experiences of distributed leadership and professional learning in early childhood teaching teams. The survey will only take about 5 minutes to complete. It's part of a wider research study exploring distributed leadership practices that foster professional learning. Results of this survey will be included in publications and presentations and will contribute to a greater understanding of effective early childhood leadership and professional learning practices.

It will be much appreciated if you can encourage your whole teaching team to complete the survey (:)

\section{Please complete by Friday $30^{\text {th }}$ October.}

By completing this survey you are consenting to participate in the research. Participation in this survey is optional and your responses will not be able to be identified. Please click on the link below to begin this short survey:

\section{https://vuw.qualtrics.com/ife/preview/SV cGDvclRAowd3hL7}

Many thanks,

Rachel Denee. 


\title{
Appendix C: Information sheets for interview participants \\ VICTORIA UNIVERSITY OF WELLINGTON \\ Te Whare Wananga o te Upoko o te Ika a Maui
}

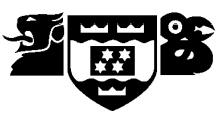

FACULTY OF EDUCATION

\author{
Research project: Distributed Leadership for Professional Learning \\ Information Sheet for individual interview participants \\ Researcher: Rachel Denee
}

The aim of this research project is to examine the relationship between distributed leadership practices and teachers' professional learning in early childhood education services in New Zealand.

As part of the research I am seeking the participation of qualified early childhood educators and leaders in services identified as high quality, in order to examine best practice. Your service has been recommended and identified as being of high quality. This project requires team participation; therefore it is necessary for the positional leader and at least two teachers to be willing to participate in order for a service to be included in the research, and ideally the whole team will participate. Please have a team discussion to establish whether or not there are enough team members willing to participate in this project.

Participation will involve one individual interview for those in positions of leadership, and one focus group interview for teachers. Individual interviews will take approximately 45 minutes. Scheduling will be negotiable and every effort will be made to find a time and location convenient to you.

Your participation is voluntary and you are under no obligation to agree to be a part of this project. You will be offered a Summary of Research once it is completed.

If you agree to participate, please print off the consent form, fill it in, scan it and email it back to me at deneerach@myvuw.ac.nz. I will then be in touch to schedule an interview time.

This project has gained approval from the Victoria University of Wellington Human Ethics Committee (HEC). Should any participants feel the need to withdraw from the project, they may do so without question at any time before the focus group interviews are carried out. Responses collected will form the basis of my research project and will be put into a written report in a manner that ensures you are not identifiable. All material collected will be kept confidential. No other person besides me and my supervisor, Dr Kate Thornton, will see the transcripts of interviews. The thesis will be submitted for marking to the School of Educational Policy and deposited in the University Library. It is intended that one or more articles will be submitted for publication in scholarly journals. Surveys and transcripts will be destroyed five years after the end of the project. If you have any ethics queries, you may contact the HEC Convener: AProf Susan Corbett, email susan.corbett@vuw.ac.nz, telephone +64-4-4635480.

If you have any questions or would like to receive further information about the project or the informed consent requirement, you are welcome to contact me by email: deneerach@myvuw.ac.nz; or my supervisor, Dr. Kate Thornton on +64-4-463 9776, by email: kate.thornton@vuw.ac.nz, at the School of Educational Policy and Implementation, at Victoria University of Wellington, PO Box 600, Wellington.

Many thanks,

Rachel Denee. 
VICTORIA UNIVERSITY OF WELLINGTON

Te Whare Wananga o te Upoko o te Ika a Maui

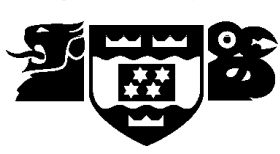

FACULTY OF EDUCATION

\author{
Research project: Distributed Leadership for Professional Learning \\ Information Sheet for focus group interview participants \\ Researcher: Rachel Denee
}

The aim of this research project is to examine the relationship between distributed leadership practices and teachers' professional learning in early childhood education services in New Zealand.

As part of the research I am seeking the participation of qualified early childhood educators and leaders in services identified as high quality, in order to examine best practice. Your service has been recommended and identified as being of high quality. This project requires team participation; therefore it is necessary for the positional leader and at least two teachers to be willing to participate in order for a service to be included in the research, and ideally the whole team will participate. Please have a team discussion to establish whether or not there are enough team members willing to participate in this project.

Participation will involve one individual interview for those in positions of leadership, and one focus group interview for teachers. Focus group interviews will take approximately one hour, and will include teachers from two or more services at a time. Scheduling will be negotiable and every effort will be made to find a time and location convenient to as many focus group participants as possible. The location will most likely be at one of the teams' centre of employment, on a week night after work.

Focus group interviews will involve teachers from two or more early childhood services. Including teachers from multiple services is intended to foster a more dynamic discussion, helping participants to develop and articulate their ideas. There is a set of ground rules which must be followed to ensure an ethical process. By participating in the focus groups, individuals agree to the following:

- Confidentiality will be maintained. This means that participants will not share what is said during the focus group interview with anyone outside of the focus group.

- Each participant must have an opportunity to contribute. The researcher/facilitator will help to manage this.

- For the purposes of this interview, all perspectives are valid and relevant, and are to be treated with respect. 
- The focus group interview will be audio-recorded for transcribing; this ensures an accurate record. Any person transcribing the recordings will be required to sign a confidentiality agreement.

Your participation is voluntary and you are under no obligation to agree to be a part of this project. You will be offered a Summary of Research once it is completed.

If you agree to participate, please print off the consent form, fill it in, scan it and email it back to me at deneerach@myvuw.ac.nz. I will then be in touch to schedule an interview time.

This project has gained approval from the Victoria University of Wellington Human Ethics Committee (HEC). Should any participants feel the need to withdraw from the project, they may do so without question at any time before the focus group interviews are carried out. Responses collected will form the basis of my research project and will be put into a written report in a manner that ensures you are not identifiable. All material collected will be kept confidential. No other person besides me and my supervisor, Dr Kate Thornton, will see the transcripts of interviews. The thesis will be submitted for marking to the School of Educational Policy and deposited in the University Library. It is intended that one or more articles will be submitted for publication in scholarly journals. Surveys and transcripts will be destroyed five years after the end of the project. If you have any ethics queries, you may contact the HEC Convener: AProf Susan Corbett, email susan.corbett@vuw.ac.nz, telephone +64-4-463 5480.

If you have any questions or would like to receive further information about the project or the informed consent requirement, you are welcome to contact me by email: deneerach@myvuw.ac.nz; or my supervisor, Dr. Kate Thornton on +64-4-463 9776, by email: kate.thornton@vuw.ac.nz, at the School of Educational Policy and Implementation, at Victoria University of Wellington, PO Box 600, Wellington.

Many thanks, Rachel Denee. 


\section{Appendix D: Consent forms for interview participants \\ VICTORIA UNIVERSITY OF WELLINGTON \\ Te Whare Wananga o te Upoko o te Ika a Maui}

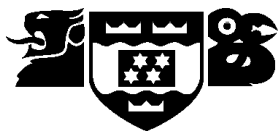

\section{FACULTY OF EDUCATION}

\section{Consent form for Professional Leaders}

\section{Research project: Distributed Leadership for Professional Learning}

Please tick, sign and date this form if you agree to participate

$\square \quad$ I have been given and have understood an explanation relating to the nature and purpose of this research project. I have had the opportunity to ask questions about it.

$\square$ I give permission for Rachel Denee to interview me about my leadership role.

$\square$ I understand that I will be given a chance to review my contribution, in the form of a summary of interview.

$\square$ I understand the material will not be attributed to me and that I will not be identified in any way.

$\square \quad$ I understand that this data will be kept secure and only the researcher will have access to that data. I also understand that all the data collected will be destroyed five years after the conclusion of the project.

$\square \quad$ I would like to be sent a Summary of Research.

I agree to participate in this research.

Name

Signature

Date 


\section{VICTORIA UNIVERSITY OF WELLINGTON \\ Te Whare Wananga o te Upoko o te Ika a Maui}

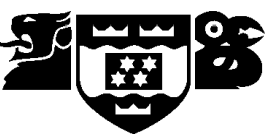

FACULTY OF EDUCATION

\section{Consent form for Teachers}

\section{Research project: Distributed Leadership for Professional Learning}

Please tick, sign and date this form if you agree to participate

$\square \quad$ I have been given and have understood an explanation relating to the nature and purpose of this research project. I have had the opportunity to ask questions about it.

$\square \quad$ I give permission for Rachel Denee to interview me in a focus group about my leadership and learning.

$\square \quad$ I understand that I will be given a chance to review my contribution, in the form of a summary of interview.

$\square \quad$ I understand the material will not be attributed to me and that I will not be identified in any way.

$\square \quad$ I understand that this data will be kept secure and only the researcher will have access to that data. I also understand that all the data collected will be destroyed five years after the conclusion of the project.

$\square \quad$ I would like to be sent a Summary of Research.

I agree to participate in this research.

Name

Signature

Date 


\section{Appendix E: Survey questions}

\section{Survey}

Please note: The term 'positional leader' is used throughout this survey to indicate the person with overall team leadership responsibility, often known as Supervisor, Head Teacher, or Centre Manager.

\section{Service type:}

What type of service do you work in?

Kindergarten $\circ \quad$ Education and care $\circ$

\section{Leadership position:}

Are you in a professional leadership position?

Yes $0 \quad$ No 0

Collective learning and application:

Please select the degree of agreement or disagreement with each of the following statements with regard to collective learning and application in your service.

\begin{tabular}{|c|c|c|c|c|c|}
\hline & & Strongly agree & Agree & Disagree & Strongly disagree \\
\hline & $\begin{array}{l}\text { Teachers work together to } \\
\text { seek knowledge, skills and } \\
\text { strategies and apply this new } \\
\text { learning to their work. }\end{array}$ & & & & \\
\hline 2. & $\begin{array}{l}\text { Collegial relationships exist } \\
\text { amongst staff members that } \\
\text { reflect commitment to service } \\
\text { improvement. }\end{array}$ & & & & \\
\hline 3. & $\begin{array}{l}\text { Teachers plan and work } \\
\text { together to find solutions to } \\
\text { meet the diverse needs of } \\
\text { children and their families/ } \\
\text { whannau. }\end{array}$ & & & & \\
\hline 4. & $\begin{array}{l}\text { Teachers engage in regular } \\
\text { dialogue that reflects a } \\
\text { respect for diverse ideas and } \\
\text { that leads to continued } \\
\text { inquiry. }\end{array}$ & & & & \\
\hline 5. & $\begin{array}{l}\text { Professional development } \\
\text { focuses on teaching and } \\
\text { learning. }\end{array}$ & & & & \\
\hline 6. & $\begin{array}{l}\text { Teachers work alongside } \\
\text { parents/whānau to learn } \\
\text { together and apply new } \\
\text { knowledge to solve problems. }\end{array}$ & & & & \\
\hline & $\begin{array}{l}\text { Dialogue between teachers } \\
\text { focuses on strengthening } \\
\text { teaching and learning. }\end{array}$ & & & & \\
\hline
\end{tabular}

Comments on collective learning and application: 


\section{Shared personal practice:}

Please select the degree of agreement or disagreement with each of the following statements with regard to shared personal practice in your service.

\begin{tabular}{|l|l|l|l|l|}
\hline & Strongly agree & Agree & Disagree & Strongly disagree \\
\hline $\begin{array}{l}\text { Opportunities exist for teachers to } \\
\text { provide feedback to peers related } \\
\text { to strengthening teaching } \\
\text { practices. }\end{array}$ & & & & \\
\hline $\begin{array}{l}\text { Teachers informally share ideas } \\
\text { and suggestions for improving } \\
\text { children's learning. }\end{array}$ & & & & \\
\hline $\begin{array}{l}\text { Teachers collaboratively review } \\
\text { children's learning to share and } \\
\text { plan to progress the learning. }\end{array}$ & & & & \\
\hline $\begin{array}{l}\text { Opportunities exist for coaching } \\
\text { and mentoring. }\end{array}$ & & & & \\
\hline $\begin{array}{l}\text { Individuals and teams have the } \\
\text { opportunity to apply learning and } \\
\text { share the results of their practices. }\end{array}$ & & & & \\
\hline $\begin{array}{l}\text { Teachers feel comfortable to } \\
\text { disagree with one another and } \\
\text { challenge each other's views. }\end{array}$ & & & & \\
\hline
\end{tabular}

Comments on shared personal practice:

Shared and supportive leadership:

Please select the degree of agreement or disagreement with each of the following statements with regard to shared and supportive leadership in your service.

\begin{tabular}{|l|l|l|l|l|}
\hline & Strongly agree & Agree & Disagree & Strongly disagree \\
\hline $\begin{array}{l}\text { Teachers are consistently involved } \\
\text { in discussions about issues } \\
\text { affecting the service and } \\
\text { suggestions are incorporated into } \\
\text { decisions made by the positional } \\
\text { leader. }\end{array}$ & & & & \\
\hline $\begin{array}{l}\text { The positional leader } \\
\text { incorporates advice in } \\
\text { decisions made. }\end{array}$ & & & & \\
\hline $\begin{array}{l}\text { Teachers have access to key } \\
\text { information that enables } \\
\text { them to work effectively. }\end{array}$ & & & & \\
\hline $\begin{array}{l}\text { The positional leader is } \\
\text { proactive and addresses areas } \\
\text { where support is needed. }\end{array}$ & & & & \\
\hline $\begin{array}{l}\text { Opportunities are provided } \\
\text { for teachers to initiate } \\
\text { change. }\end{array}$ & & & & \\
\hline $\begin{array}{l}\text { Leadership is promoted and } \\
\text { nurtured among teachers. }\end{array}$ & & & & \\
\hline $\begin{array}{l}\text { Teachers use multiple sources } \\
\text { of data to make decisions } \\
\text { about teaching and learning. }\end{array}$ & & & & \\
\hline $\begin{array}{l}\text { Decisions concerning teaching } \\
\text { and learning are made } \\
\text { collaboratively with the team. }\end{array}$ & & & & \\
\hline
\end{tabular}


Comments on shared and supportive leadership:

\section{Supportive structural conditions:}

Please select the degree of agreement or disagreement with each of the following statements with regard to supportive structural conditions in your service.

\begin{tabular}{|l|l|l|l|l|}
\hline & Strongly agree & Agree & Disagree & Strongly disagree \\
\hline $\begin{array}{l}\text { Time is provided to facilitate } \\
\text { collaborative learning and shared } \\
\text { practice. }\end{array}$ & & & & \\
\hline $\begin{array}{l}\text { Financial resources are made } \\
\text { available to support professional } \\
\text { development. }\end{array}$ & & & & \\
\hline $\begin{array}{l}\text { Communication systems promote a } \\
\text { flow of information among staff } \\
\text { members and the wider service } \\
\text { community. }\end{array}$ & & & & \\
\hline
\end{tabular}

\section{Comments on supportive structural conditions:}

\section{Distributed leadership for professional learning:}

Please select the degree of agreement or disagreement with each of the following statements with regard to distributed leadership for professional learning in your service.

\begin{tabular}{|l|l|l|l|l|}
\hline & Strongly agree & Agree & Disagree & Strongly disagree \\
\hline $\begin{array}{l}\text { I contribute to decisions about } \\
\text { professional learning in my } \\
\text { workplace. }\end{array}$ & & & & \\
\hline $\begin{array}{l}\text { Teachers are encouraged to share } \\
\text { professional learning in our team } \\
\text { mainly after attending external } \\
\text { professional development. }\end{array}$ & & & & \\
\hline $\begin{array}{l}\text { I am given opportunities to lead } \\
\text { professional learning with my } \\
\text { team. }\end{array}$ & & & & \\
\hline $\begin{array}{l}\text { When teachers in my workplace } \\
\text { lead professional learning, it } \\
\text { positively impacts on our teaching } \\
\text { practice. }\end{array}$ & & & & \\
\hline $\begin{array}{l}\text { In my workplace, professional } \\
\text { learning experiences are connected } \\
\text { and develop our knowledge over } \\
\text { time. }\end{array}$ & & & & \\
\hline $\begin{array}{l}\text { Our teaching team understands } \\
\text { how professional learning topics } \\
\text { contribute to goals about teaching } \\
\text { practice. }\end{array}$ & & & & \\
\hline
\end{tabular}

Comments on distributed leadership for professional learning: 